
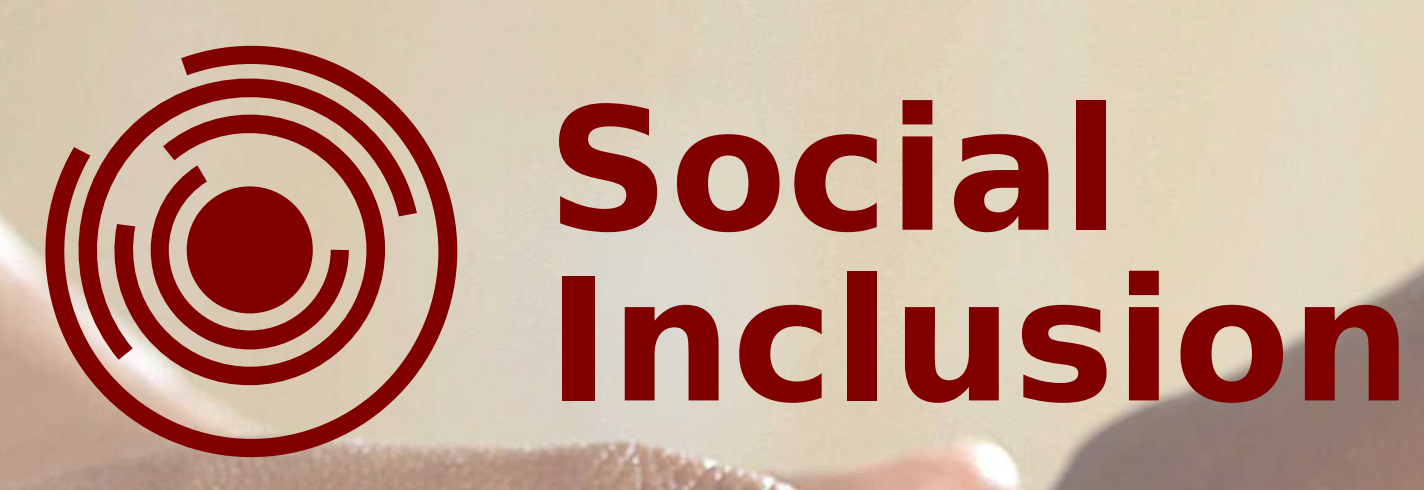

Volume 1 (2013) | Issue 1 Basel, Switzerland

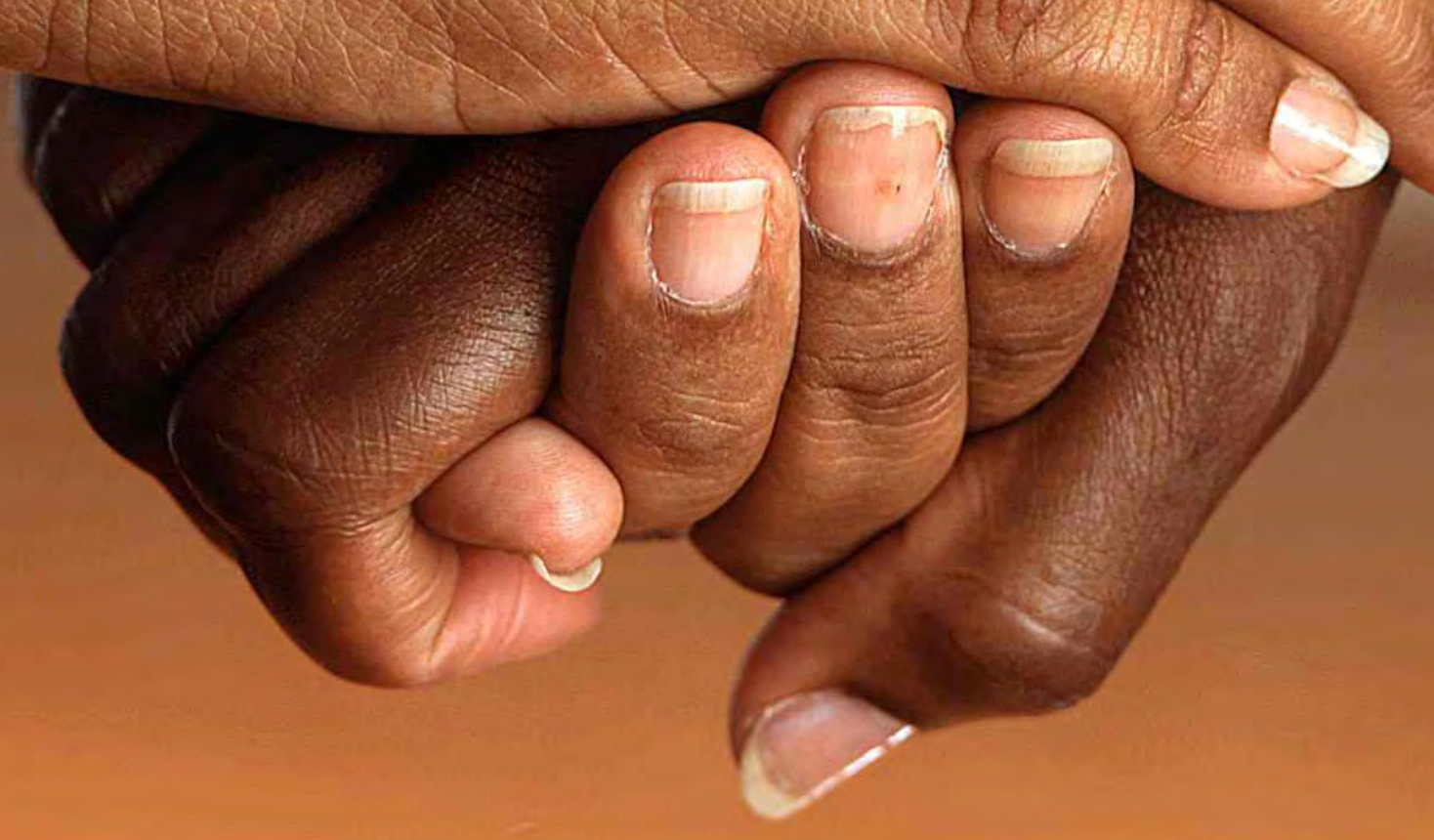

librello \&s 
Social Inclusion 2013 | Volume 1 | Issue 1

Social Inclusion is an international, open access, academic, interdisciplinary journal, published by Librello.

\section{Cover image}

A close-up of clasped hands belonging to two

African-American females

Photographer: Rhoda Baer 


\section{About Social Inclusion}

Social Inclusion is a quarterly peer-reviewed journal, which provides academics and policymakers with a forum to discuss and promote a more socially inclusive society. The journal encourages researchers to publish their results on topics concerning social and cultural cohesiveness, marginalized social groups, social stratification, minority-majority interaction, cultural diversity, national identity, and core-periphery relations, while making significant contributions to the understanding and enhancement of social inclusion worldwide.

Social Inclusion aims at being an interdisciplinary journal, covering a broad range of topics, such as immigration, poverty, education, minorities, disability, discrimination, and inequality, with a special focus on studies which discuss solutions, strategies and models for social inclusion.

Social Inclusion invites contributions from a broad range of disciplinary backgrounds and specializations, inter alia sociology, political science, international relations, history, cultural studies, geography, media studies, educational studies, communication science, and language studies. We welcome conceptual analysis, historical perspectives, and investigations based on empirical findings, while accepting regular research articles, review articles, commentaries, and reviews.

\section{(1) Social $\begin{aligned} & \text { Snclusion } \\ & \text { Inclusion }\end{aligned}$}

http://librelloph.com/socialinclusion 


\section{Editorial Team}

\section{Editor-in-Chief}

Ulf Hedetoft - University of Copenhagen, Denmark

\section{Managing Editor}

António Vieira - Librello, Switzerland

\section{Editorial Board}

Jo Aldridge - Loughborough University, UK Gary Bouma - Monash University, Australia Katrine Fangen - University of Oslo, Norway Fethi Mansouri - Deakin University, Australia

\section{Editorial Board}

Aleksandra Ålund - Linköping University, Sweden

Andrew Azzopardi - University of Malta, Malta

Olof Bäckman - Stockholm University, Sweden

Simone Baglioni - Glasgow Caledonian University, UK

Tehmina Basit - Staffordshire University, UK

Christophe Bertoss - French Institute of International Relations, France

Giovanna Campani - University of Florence, Italy

Maria Amparo Cruz-Saco - Connecticut College, USA

Fred Dallmayr - University of Notre Dame, USA

Merike Darmody - The Economic and Social Research Institute, Ireland / Trinity College, Ireland Thomas Faist - Bielefeld University, Germany

Dan Goodley - University of Sheffield, UK

Evelyn Forget - University of Manitoba, Canada

Tone Fløtten - Fafo Institute for Labour and Welfare Research, Norway

Shaun Grech - Manchester Metropolitan University, UK

Peter Herrmann - University of Eastern Finland, Finland / EURISPES, Italy

Jennifer Jackson-Preece - London School of Economics and Political Science, UK

Richard James - University of Melbourne, Australia

Kerry Kennedy - Hong Kong Institute of Education, Hong Kong

Sue Kilpatrick - University of Tasmania, Australia

Piet Kommers - University of Twente, The Netherlands

Dagmar Kutsar - University of Tartu, Estonia

Simon Langlois - University Laval, Canada

Ian Law - University of Leeds, UK

Yaojun Li - Manchester University, UK

Robert Lingard - University of Queensland, Australia

Tove Malloy - Flensburg University, Germany / University of Southern Denmark, Denmark

Roy McConkey - University of Ulster, UK

Martin Mills - University of Queensland, Australia

Paul Morris - Victoria University of Wellington, New Zealand

Joane Nagel - University of Kansas, USA

Peder Pedersen - Aarhus University, Denmark

Abby Peterson - University of Gothenburg, Sweden

Mark Priestley - University of Leeds, UK

Annick Prieur - Aalborg University, Denmark

Stefano Sacchi - University of Milan, Italy / Collegio Carlo Alberto, Italy

Carl-Ulrik Schierup - Linköping University, Sweden

Roger Slee - Victoria Institute, Australia

Anwar Tlili - King's College London, UK

Lynn Todman - Adler School of Professional Psychology, USA

Sally Tomlinson - University of Oxford, UK

Fiona Verity - Flinders University, Australia 
Steve Vertovec - Max Planck Institute for the Study of Religious and Ethnic Diversity, Germany Lisa Waddington - Maastricht University, The Netherlands

Gail Whiteford - Macquarie University, Australia

Fiona Williams - Leeds University, UK

Terry Wotherspoon - University of Saskatchewan, Canada

Nira Yuval-Davis - University of East London, UK 


\section{Table of Contents}

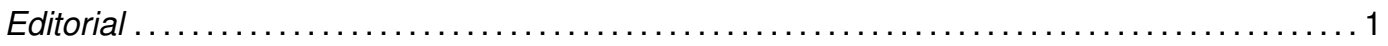

Social Inclusion: Inaugural Editorial

Ulf R. Hedetoft

Faculty of Humanities, University of Copenhagen, Denmark

Research Article

Identifying the Barriers to Women's Agency in Domestic Violence: The Tensions between

Women's Personal Experiences and Systemic Responses

Jo Aldridge

Department of Social Sciences, Loughborough University, UK

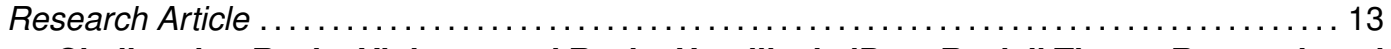

Challenging Racist Violence and Racist Hostility in 'Post-Racial' Times: Research and Action in Leeds, UK, 2006-2012

Ian Law ${ }^{1,2, *}$, Jenny Simms ${ }^{3}$ and Ala Sirriyeh ${ }^{4}$

${ }^{1}$ School of Sociology and Social Policy, University of Leeds, UK

${ }^{2}$ Centre for Ethnicity and Racism Studies, University of Leeds, Leeds, UK

${ }^{3}$ Independent Researcher

${ }^{4}$ School of Social and International Studies, University of Bradford, UK

* Corresponding author

Research Article. .

The "Idle No More" Movement: Paradoxes of First Nations Inclusion in the Canadian Context

Terry Wotherspoon* and John Hansen

Department of Sociology, University of Saskatchewan, Canada

* Corresponding author

Review 37

Disability and Health: A Research Agenda

Hasheem Mannan ${ }^{1,2, *}$, and Malcolm MacLachlan ${ }^{2,3}$

${ }^{1}$ Nossal Institute for Global Health, University of Melbourne, Victoria, Australia

${ }^{2}$ Centre for Global Health \& School of Psychology, Trinity College Dublin, Ireland

${ }^{3}$ Centre for Rehabilitation Studies, Stellenbosch University, South Africa

* Corresponding author

Research Article 46

Social Capital and Stratification of Young People

Alireza Behtoui ${ }^{1,2}$

${ }^{1}$ Institute for Migration, Ethnicity and Society (REMESO), Department of Social and Welfare Studies, Linköping University, Sweden

2 Department of Social Anthropology, Stockholm University, Sweden

Research Article

Social Class and Social Capital in China and Britain: A Comparative Study

Yaojun Li

Institute for Social Change, School of Social Sciences, Manchester University, UK

Research Article

A Neo-Rawlsian Approach to Residential Integration

Kevin J. Brown

Department of Business, Economics, and Political Science, Asbury University, USA 


\section{Social I nclusion: I naugural Editorial}

Ulf R. Hedetoft

Faculty of Humanities, University of Copenhagen, Njalsgade 80, 2300 Copenhagen S., Denmark;

E-Mail: hedetoft@hum.ku.dk; Tel.: +45 35328053; Fax: +45 35328052

Submitted: 25 February 2013 | Accepted: 25 February 2013 | Published: 26 February 2013

Social inclusion is a concept that we all applaud. Normatively we tend to agree that it is a goal societies should pursue-and it is indeed a social and cultural value that most, if not quite all, societies profess to be based on. Social inclusiveness, cultural cohesion, communal values, a shared identity, mutual recognition, respectful dialogue, peaceful interaction, policies of integration: these are positively charged notions, aims indeed worth subscribing to.

Sadly, this is not a description of a factual state of affairs. Realities are starkly different, relegating the notions just outlined to a realm of relatively starryeyed idealism. In the practical world, in the societies 'out there', things are very different. Beyond all the different interpretations of what social inclusion means and how it is to be achieved (not a trivial matter, giving rise, as it does, to heated debates and disagreements-see e.g. [1-3]), social inclusion encounters powerful opposition-cohesiveness battling division, communities experiencing multiple forms of fragmentation, individualism often trumping collective solidarity, integration facing counteracting tendencies of marginalization, people being forcefully displaced from their homes, and migrant flows challenging historically cherished national or ethnic identities. The normative ideals may well be those of inclusiveness, tolerance, and recognition, but, more and more, social, ethnic, and cultural units around the world-nation-states, local communities, urban conurbations, families-are cracking at the seams, under pressure from a confluence of centrifugal and crosscutting forces representing complex cultural diversities, glaring inequalities, minority-majority conflicts, esca- lating marginalization, racial or sexual discrimination, and open manifestations of hostility and violence (for an overview of the field, see e.g. $[4,5])$.

Some would argue that this depressing list of antinomies is really no more than a characterization of the world as it has 'always' been, and up to a certain point they would be right: we have seen and heard all this before. However, there are indications both that the gap between ideal and reality is widening and that the challenges against social inclusion are multiplying. This is, somewhat paradoxically, due in part to the political attention (nationally and internationally) that key notions like social inclusiveness, diversity management, cultural integration of ethnic minorities, and recognition of differences have attracted over the last decades: the more these values have been promoted and spearheaded by political and community leaders, the more failures (and they are legion) to deliver convincing, sustainable and workable models for the social and democratic accommodation of differences have tended to produce sentiments of powerlessness, frustration, and anomie among members of the social (often national) fabric threatened by fragmentation [6]. In turn, this has led to new kinds of contestation at the political level, new forms of nationalist demagoguery, political discourses advocating cultural revanchism, the construction of new walls against the world, or a return to 'things as they used to be' $[7,8]$.

However, though this is all true, by pointing to the incompatibility between political rhetoric and social achievement we have identified neither the root causes nor the gravity of the dilemma facing social inclusion. In that regard, it is necessary to point to (at (c) 2013 by the authors; licensee Librello, Switzerland. This open access article was published under a Creative Commons Attribution License (http://creativecommons.org/licenses/by/3.0/).

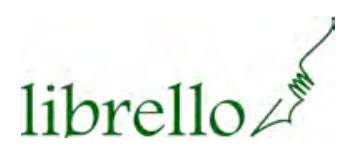


least) three factors that both individually and in combination weigh heavily into the equation: the current and persistent economic crisis; the impending implosion of the welfare state; global shifts and the changing world order. It is impossible to deal in depth with these comprehensive issues in this brief editorial, so a few observations and tentative conclusions will have to suffice.

The crisis, by its very nature, tends to highlight and deepen social divisions, due to scarcer resources, less available jobs, and a diminished disposition for social solidarity. Increased marginalization, in-group/outgroup differentiation, and opposition to incoming migrants and refugees are reactions to be expected and can indeed be recorded $[9,10]$. An important question is whether the crisis is temporary or more permanent, a blip on the economic radar or more structural in nature. We might hope for the former, but indications are that the crisis is more protracted, endemic and structurally transformative than was first imagined; if so, social inclusion will prove to be a daunting task for many years to come.

This connects to the weakened capacities of the welfare state $[11,12]$. Although the crisis has clearly not supported the maintenance of a strong, redistributive, and egalitarian welfare state overseeing and guarding social cohesion, it should be acknowledged that even without the crisis, the welfare state (which

\section{References}

1. Askonas PF, Stewart A, editors. Social Inclusion: Possibilities and Tensions. London, UK: Macmillan; 2000.

2. Commonwealth of Australia. Social Inclusion: The Origins, Meaning, Definition and Implications of the Concept Social Inclusion/Exclusion. Revised edition. Canberra, Australia: Commonwealth of Australia; January 2009.

3. Parekh B. Rethinking Multiculturalism: Cultural Diversity and Political Theory. Basingstoke, UK: Macmillan; 2000.

4. Global Commission on International Migration (GCIM). Migration in an Interconnected World: New Directions for Action. Report of the Global Commission on International Migration. Geneva, Switzerland: GCIM; 2005. Available from: http://www.gcim.org (accessed on 22 February 2013).

5. Gold SJ, Nawyn SJ, editors. The Routledge International Handbook of Migration Studies. Abingdon, UK and New York, USA: Routledge; 2013.

6. Silj A, editor. European Multiculturalism Revisited. London, UK: Zed Books; 2010.

7. Guelke A, editor. The Challenge of EthnoNationalism: Case Studies in Identity Politics. Basingstoke, UK: Palgrave Macmillan; 2010.

8. Mudde C. Populist Radical Right Parties in Europe. Cambridge, UK: Cambridge University Press; 2007.

9. Razin A, Wahba J. Capturing Differences between exists in many guises, and in some regions of the world not at all) is facing serious difficulties, partly due to additional economic pressures (mainly deriving from soaring costs of social benefits, education, and health care), partly the erosion of national sovereignties, and partly the liberalization and transnationalization of economic flows, which erode the taxation basis of states [13]. This in turn implicates the third factor, generic global shift and flows, involving both a multipolar restructuring of global politics and massive demographic cross-border mobility-developments which challenge receiving societies (already weakened due to crisis effects and overtaxed welfare systems) to devise intelligent instruments and models for coping with novel and ever fluctuating diversity [14-16].

On this background, it is clear that there is a crying need for a scholarly outlet of the highest academic quality that will allow researchers from a variety of disciplines to swiftly and openly publish the results of their investigations into issues concerning social inclusion. As noted in the 'Focus and Scope' text, we invite contributions of a conceptual, historical, and empirical nature alike, and will give special priority to studies that offer academically motivated reflections on and proposals for solutions, strategies, and models for achieving social inclusion, whilst taking account of the intractability of the problems it presents and the multiple actors, interests, and attachments involved.

Free and Controlled Immigration: Country Bilateral Data. Immigration and the Welfare State: New Evidence from the EU. 2011. Available from: http://www.voxeu. org/article/immigration-and-welfare-state-new-evidenc e-eu (accessed on 22 February 2013).

10. Vertovec S, Wessendorf $S$, editors. The Multiculturalism Backlash. London, UK: Routledge; 2010.

11. Razin A, Sadka A, Suwankiri B. Migration and the Welfare State. Cambridge, MA, USA: MIT Press; 2011.

12. Stanicek B. The Impact of the Financial Crisis on Employment and the Social Inclusion of Young People. What Should Be Done? Foundation Robert Schumann Policy Paper, European Issues, no. 220, 28 November 2011.

13. Kymlicka W, Banting K. Immigration, Multiculturalism and the Welfare State. Ethics \& International Affairs. 2006;20(3):281-304.

14. von Amersfoort H. Citizenship, Ethnicity and Mainstream Society: The European Welfare States Navigating between Exclusion and Inclusion. In: Barrett MD, Flood C, Eade J, editors. Nationalism, Ethnicity, Citizenship: Multidisciplinary Perspectives. Newcastle upon Tyne, UK: Cambridge Scholars; 2011, pp. 77-100.

15. Hedetoft U. Multiculturalism: Symptom, Cause or Solution? In: Taras R, editor. Challenging Multiculturalism. European Models of Diversity. Edinburgh, UK: Edinburgh University Press; 2013, pp. 319-333.

16. Vertovec S. Super-Diversity and Its Implications. Ethnic and Racial Studies. 2007;30(6):1024-1054. 


\title{
I dentifying the Barriers to Women's Agency in Domestic Violence: The Tensions between Women's Personal Experiences and Systemic Responses
}

\author{
Jo Aldridge \\ Department of Social Sciences, Loughborough University, Loughborough, Leicestershire, LE11 3TU, UK; \\ E-Mail: j.aldridge@lboro.ac.uk; Tel.: +44 1509223670; Fax: +44 1509223944
}

Submitted: 21 February 2013 | In revised form: 21 March 2013 | Accepted: 27 March 2013 |

Published: 9 April 2013

\begin{abstract}
Despite advances in knowledge and understanding about the impacts of domestic violence on women's lives, global research on violence against women shows there is a need for research that not only places women centre stage in research praxis, but also that involves them more collaboratively in genuine dialogue about their experiences, including their agentic stances. This is especially the case for marginalised and socially excluded women victims of domestic violence, such as those who are not known or do not present to services and who survive abusive relationships alone or with little outside support. Evidence from two studies reported here-secondary analysis of women with severe and enduring mental health problems and a collaborative narrative project with unsupported women victims of domestic violencesuggest that women's capacity for agency are compromised by a number of critical factors, and that these are also reflected in the tensions between micro-macro analyses and understanding of the impact of domestic violence on women. This article considers the barriers to women's agency from the women's perspective and in the context of broader, systemic dynamics, including the denial or obscuring of abuse by governments and states and the consequences of stringent fiscal retrenchment that put women at increased risk of domestic violence.
\end{abstract}

Keywords: agency; domestic violence; gender inequality; resilience

\section{Introduction}

While research suggests that many women exercise a degree of agency and resistance to domestic violence when it occurs [1], it is also recognised that specific aspects of women's agency in unsupported domestic violence contexts are largely missing. Thus, any attempts to make generalisations for broader populations of abused and victimised women based on this evidence, or to use it in domestic violence preventive work, are somewhat compromised. Extensive research with women victims of domestic 
violence over many years has shown that its consequences for women are often both profound and far-reaching, including physical illnesses and conditions, and mental health problems that can occur both as a result of the initial and ongoing trauma of each violent episode and also as a consequence of more long term emotional problems [2,3]. These effects can also result in what Larkin [4] describes as unique or innate vulnerabilities among some women, thus reducing their capacity for developing agency and for resisting the impacts of social exclusion and marginalisation.

The harms caused by domestic violence, the perpetuation of women's vulnerability as victims and the barriers to agency or resilience are also compounded by broader, systemic factors such as ineffective or inappropriate support services and interventions, as well as political and ideological influences (see [3]). Romito [2] argues, for example, that the obfuscation of male violence against women more broadly in society and the silencing effects of violence for women victims occur as a result of governmental or state 'tactics' or 'strategies' for hiding male violence that, she states, are evident in countries across the world. Such devices present as 'ways of seeing, conceptualising and naming reality' and manifest themselves as both common sense perspectives and as ideology, specifically, 'when they centre on the interests of those in power and may be 'institutionalised' in various ways, such as laws, scientific or pseudoscientific theories and the work practices of legal and social services' ([2], p. 43). Currently, there is also growing concern that the prevailing economic crisis will have disproportionate consequences for women, thus enhancing their susceptibility to the impacts of social exclusion, personal harm and further or more serious violence and abuse [5], and thus reducing their capacity for agency.

Global population-based surveys reveal the prevalence of domestic violence worldwide. The WHO Multi-country study on women's health and domestic violence against women [6], for example, shows that '15-71\% of women experience physical and/or sexual violence by an intimate partner at some point in their lives'. In the UK alone, one incidence of domestic violence is reported to the police by a woman every minute [7] and domestic violence accounts for one quarter of all recorded violent crime $[8,9]$. While the latest national statistics from the UK on domestic violence seem to suggest a reduction in the number of domestic violence incidents experienced by women between 1993 and 2010 [10], consideration of both the methods of data collection and the ways in which these data are interpreted suggest that the opposite may in fact be the case. Indeed, it is claimed in the Home Office guidance report itself ([11], p. 2):

Domestic violence figures that relate to incidents reported in face-to-face British Crime Survey interviews should be treated with caution.
Prevalence rates for domestic violence derived from the self-completion module are around five times higher for adults than those obtained from face-toface interviews.

Furthermore, even though there are now wide numbers of population-based prevalence surveys of domestic violence, it is often not clear whether or not these data are collected from women who have received domestic violence support. It is also claimed that what is missing from global and national research studies and evidence on domestic violence and its impact on women are the voices and perspectives of non help-seeking women. As Ellsberg and Heise ([12], p. 33) argue, most research on domestic violence is conducted among women who are already in receipt of domestic violence services and the number of women who do not seek help or disclose domestic abuse 'greatly outnumber those who do seek help'.

\section{I dentifying and Recruiting Women Victims of Domestic Violence for Research Purposes}

In many respects, in both research and practice terms we often only know about women victims of domestic violence because we know of them, that is, from information about where and how they obtain help and support. Such women are often identified and recruited to research studies through support agencies, networks, mediators and women's advocates etc., and it is more difficult to identify and recruit unsupported women victims for research purposes without such benefaction or through collaboration. Simmons and colleagues [13] argue, however, that, 'most women in abusive/controlling relationships simply do not utilize formal helping structures (e.g., shelters, domestic violence support groups, hot lines)' ([13], p. 1299). Similarly, it is also acknowledged that, because of the difficulties of identifying and gaining access to them, we know less about the experiences and needs of multiply vulnerable, marginalised groups more broadly, for example, those in remote communities, those who live beyond the limits of the law and stigmatised groups. The result is we understand little about those missed in comparison with those 'captured' in and by research ([14], p. 11). Thus, identifying and recruiting marginalised, multiply vulnerable people in research, and in practice, remains a dilemma for researchers and professionals working with vulnerable populations generally. It is commonly understood that identification and recruitment strategies must, in these cases, rely on informal word-of-mouth practices -in research terms this often means relying on nonprobability sampling, such as convenience or snowball sampling. Indeed, some have argued that peer identification and recruitment is often more successful among marginalised populations than any more formal strategies used by researchers themselves $[15,16]$. 
Researchers that look to recruit multiply vulnerable, marginalised individuals also often rely on gaining access to participants at specific locations or in more visible communities, including street-based locations, emergency treatment centres and so on (see $[14,16,17])$. However, in many cases, the nature, extent and impacts of domestic violence on women mean that the abuse may not have been disclosed outside the immediate domestic sphere or the abusive relationship itself and thus is not manifest in any visible or known 'community'. Furthermore, abused women may also engage in self-denying behaviour, as one of the effects of the violence itself and may also be afraid to disclose abuse for fear of putting themselves and their children at further risk. We also know that even when they are forced to present to services, for emergency medical treatment, for example, women often attempt to conceal the abuse even when it has resulted in physical injuries to themselves or they are never asked about it by those health professionals responsible for their treatment [18]. Thus, even tried and tested methods of identifying and recruiting other vulnerable, excluded populations for research purposes are often neither appropriate nor achievable for populations such as victimised and abused women. In essence then, what is needed when attempting to recruit and work with multiply vulnerable, unsupported women victims of domestic violence (in order to address real gaps in knowledge) is for researchers to strike the right balance between devising appropriate and sensitive ways of successfully identifying and working with these women, and also in ways that ensure their safety and rights are at the forefront of research design and praxis. In short, as Penrod and colleagues [19] argue, researchers must endeavour to, 'balance the acquisition of knowledge with the rights of participants' ([19], p. 101). In terms of recruitment procedures, convenience sampling would seem to be the most appropriate and effective means of identifying and gaining access to unsupported women victims of domestic violence, and often word of mouth approaches can work best here. In her study of women who experience domestic violence in Calcutta, for example, Sen [20] used word of mouth techniques -cold-calling in slums, contact with activists and even her friends and family in Calcutta-in order to identify and access her sample of largely hidden victimised women.

Similarly, Rodriquez and colleagues' [21] study of Spanish speaking Latino families in a rural community in the US found personal contacts to be the most useful method of identification and recruitment, even after multiple strategies for recruitment had been used: 'The research team learned that word of mouth and the use of existing community resources were the most powerful recruitment strategies' ([21], p. 87). In identifying unsupported victims of domestic violence, such word of mouth techniques are often critical, although in many respects these do not result in high numbers of women participants. However, this does not mean that the rigour or credibility of the research is inevitably surrendered for the sake of access, but that this must be balanced against the necessity of 'conducting studies in populations where inherent barriers exist relative to key issues such as recruitment, attrition, sampling size...' ([22], p. 1; my emphasis).

Gaining access to unsupported women victims of domestic violence was a key objective in the Write It Project-a participatory narrative study in the UK that used intensive sampling techniques with non helpseeking women participants. This study came about as a result of secondary analysis of data from a UKwide mental health study, which looked at the experiences and needs of women with serious mental health problems and who were being cared for by their children (see [23]). Thus, in terms of the evidence generated from both of these studies, the stories or narratives of the women themselves were obtained both purposefully and serendipitously from unsupported women victims of domestic violence.

\subsection{Analysis of Mental Health Data}

Secondary analysis of the interview data from the mental health study showed that one of the key factors in the onset of mental illness among many of the women participants was domestic violence, which the women revealed during the course of the interviews about the cause or causes, from their perspective, of their health problems. Although the focus of the project itself was on the women's needs as mental health patients and as parents, their mental health problems occurred and persisted, they believed, as a result of their domestic violence experiences, even though these were not considerations in the aetiology and treatment of their mental health problems by the mental health professionals involved in their care.

Twenty-three out of the 35 mothers interviewed for the study disclosed abuse and talked, without being asked, about their experiences of domestic violence. These women also said that they believed their mental health problems had been triggered by past sexual, physical and/or emotional abuse from their former partners. To give just two examples from the mental health study, one of the women, Susan, who was being treated for chronic depression (as well as Crohn's Disease), revealed that the severity of her former partner's abuse had been such that she had had a Court Order put in place to prevent the man from coming to the home or having any contact with their children (two daughters who were providing informal care for Susan). Susan believed that her illnesses were made worse by the ongoing stress of worrying about whether her former partner would break the Court Order-which he had done on 
numerous occasions-and come into the house. Another of the women, Pat, described the symptoms of her obsessive compulsive disorder (OCD), which manifested themselves in constantly checking that the windows and doors in her house were locked; she attributed this behaviour to her former partner's violence towards her and their children: 'He had my children at knifepoint...and I think maybe with my doors and things he used to come...even after he left, he used to come and kick all the windows and everything in so maybe that is where I get my OCD from' ([23], p. 40).

The secondary analysis data from this study suggested the need to look more closely at the needs of unsupported women victims of domestic violence using methods that might help to draw out women's individual stories in more detail. Furthermore, in recognising the need for research studies that draw on more in-depth, participatory accounts, the objective was to not to recruit large numbers of women to further studies, but to obtain a richness of data through small numbers of participants, allowing unsupported women victims of domestic violence to tell their stories in their own time using (written) narrative approaches; these were based on 'real dialogue rather than one-way communication', and a more creative or imaginative approach ([1], p. 729).

\subsection{The Write It Study}

The Write It narrative study used informal, word of mouth techniques to identify and recruit women to the project, which was publicised online (through a dedicated website), at conferences, through networks of professionals, academics, activists and student bodies; the intention was to recruit unsupported women through informal processes via these networks and individuals. These types of intensive approaches are, as Crosby and colleagues [22] argue, limited in their statistical influence to test hypotheses and effects, but their value lies more in 'addressing gaps in empirical literature and evidence as these gaps may be valuable for informing public health policy and practice' ([22], p. 3). Furthermore, much narrative research is premised not on quantity but on quality of data from smaller sample sizes that 'results in unique and rich data that cannot be obtained from experiments, questionnaires or observations' ([22], p. $3)$. The intention of the Write It study was therefore to use in-depth narrative data from unsupported women victims of domestic violence to consider issues of personal agency in these unsupported contexts, and thus contribute new evidence and insights to an established body of knowledge about the impacts of domestic violence and women's needs.

In methods terms, intensive qualitative approaches such as narrative, life story or autobiographical techniques provide ways of illuminating lived experience through highly personalised and subjective narrative explication; they provide in-depth insights as opposed to the breadth of data offered in extensive or what are also referred to as nomotheic approaches (see [24]). With respect to narrative research methods specifically, Lieblich et al. [25] state most narrative studies that are based on life story methods, for example, 'are conducted with smaller groups of individuals [although] the quantity of data gathered... is large' ([25], p. 9) (and this is reflected in their own narrative study of just two case studies). The participatory written narrative project with unsupported women victims of domestic violence also adopted similar techniques to the intensive case study approach where the researcher focuses 'on only one specific instance of the phenomenon to be studied... each instance is studied in its own specific context, and in greater detail than in extensive research' ([26], p. 2; [27]). Thus, three cases were studied in-depth, while other participants continued to volunteer their written accounts of domestic violence also via the dedicated website.

More recently, there has been a shift in narrative research (and theory) that has moved away from the 'grand narratives' of the past ('of human intention and progress' ([28], p. 10)), to small-scale narratives, which embrace individualised 'meaning making' and subjectivity ([28], p. 4). With respect to research on domestic violence, this shift is congruent with the call for more evidence from unsupported women victims using intensive or participatory approaches [12], which will inevitably draw on much smaller populations of women (not least because they are more difficult to reach, as discussed). In the context of a micro-macro analysis or understanding of domestic violence, intensive, small-scale narratives can at least serve to illuminate the tensions between these dual (and seemingly opposing) dynamics.

The women who volunteered for the Write It study were unsupported survivors of domestic violence; that is, they had survived abusive relationships on their own either without seeking support at all or failing to get appropriate or effective help when they had looked for it. Drawing on three retrospective survivor accounts specifically, and in depth, presented useful opportunities to identify and examine issues relating to personal agency, but also meant that safety issues were not as critical as they would have been had the women still been involved in abusive relationships while participating in the study.

\section{Barriers to Women's Agency in Domestic Violence Settings}

Evidence from both the Write It project [29] and secondary analysis of data from the mental health study suggest that women's capacity for agency (and for developing resilience) is compromised by a number of critical factors. These factors relate to the women's own personal perceptions of the barriers to 
agency in domestic violence contexts-the lack of attention to the impacts of domestic violence on women's mental health; the lack of focus on perpetrator accountability; and the lack of appropriate recognition and support from family and friends and wider communities-and that also occur as a consequence of macro, systemic dynamics; specifically, the lack of emphasis on broader social, political and economic understandings of domestic violence, and the consequences of stringent fiscal retrenchment that put women at increased risk of domestic abuse.

While Wilcox [1] has argued that women's capacity to resist violence is often under-estimated and, in her own research on domestic violence, found that women 'maintained agentic stances, actively pursuing safety for themselves and for their children' ([1], p. 738), there is often a notable difference between women's ability to resist violence as it occurs through self-protective strategies, and their ability to adopt agentic stances and use these to survive abusive relationships. Evidence from both the Write It project and the mental health study showed that the women's resistance to violence and abuse when it occurred often seemed to them to be necessary acts of selfdefence and self-preservation and that they were forced simply to react to violent episodes as they arose. Writing about her experiences of abuse retrospectively, Carla said that she maintained 'a naive belief that one day the violence and other abuse would end', and only managed to escape the relationship through the support of a friend 'who had grown up with a very abusive father and he was the only person who recognised the signs in my relationship and told me that it wasn't normal and that I did deserve a better life'.

For unsupported women victims of domestic violence, finding the strength to endure and overcome abusive episodes in their relationships, and choosing to leave them, too often lies in chance occurrences such as these or specific moments of self-realisation. For Carla, such a moment occurred when she saw her partner's violence towards her mirrored in the way he treated the new puppy they had bought together. Writing about this episode in the form of a letter to her former abusive partner, Carla wrote:

Towards the last 6 months of our marriage, I found the courage to start standing up to you. One of the main reasons, was we got a puppy, I saw how you treated a defenceless animal and it made me so angry. I'm certain that you were jealous of my attention being directed at her, you'd beat her with a brush handle if she made a mess, and you split her nose open once.

Williamson [30] argues that it is these moments of self-realisation or recognition of abuse that often lead to the triggers for women's resistance to violence, even when this takes 'the form of internalizing blame for allowing someone to abuse you' ([30], p. 1418). Given the right kinds of support at the right times, such moments of self-realisation also present vital opportunities to aid women in their agentic stances as well as their survival strategies. Indeed, from a therapeutic perspective, getting women to recognize violence for what it is and naming it are seen to be critical first steps in their recovery from the effects of domestic violence (see [3]). Nevertheless, it is also recognized that women rarely 'take action on their own behalf' ([31], p. 220) and require interventionsthrough formal health and social care support services, as well as, where appropriate, the informal support of family and friends-in order to recognize the abuse for what it is, understand that it is wrong and to decide to put an end to self-blame behaviour and thinking ([31], p. 220).

However, the chances and likelihood of women being able to access these necessary sources of support both currently and in the future are considerably reduced in the context of the global economic crisis and the erosion of welfare state provision in countries worldwide; and this is regardless of whether women recognize abuse and take action when it occurs. In the UK, there are genuine concerns that the introduction of Universal Credit, for example, will have disproportionate impacts on women victims of domestic violence and their children and, coupled with the cuts to domestic violence services, 'may result in some survivors either returning to the violent relationship or prevent them from leaving' at all ([32], p. 2). Furthermore, recent global research based on women's stories, as well as articles and case studies from unions and NGOs, conducted by the Trades Union Congress ([5], introduction), shows 'just how deeply the global economic crisis has affected women all over the world' resulting in unemployment, lack of job security and, 'the increased risk of sexual and domestic abuse'.

\section{The Impact of Domestic Violence on Women's Mental Health}

While there is evidence that many women recover their mental health once they leave abusive relationships, it is also clear that others suffer more long-term effects (see for example [31,33]). Secondary analysis of data from the mental health project revealed long-term mental health problems among the women participants. What was also notable from these data was that, for the women themselves, the real reason-as they saw it-for the onset of their mental health problems was not being addressed in any therapeutic sense because their experiences of domestic violence had not been considered as an aetiological factor in their diagnoses. And yet the connection between domestic violence and mental illness among women who are its victims is well documented in global research on male 
violence (see [34-36]). Indeed, Taft ([31], p. 1) states:

Research has shown the prevalence and patterns of mental health disorders precipitated and/or aggravated by intimate partner abuse. This pattern has been found not only in cases of domestic violence in Australia but also globally, that the greater the frequency and severity of the abuse, the greater the harm to the female victim's mental health.

Furthermore, reviews of interventions and support services for women victims of domestic violence have revealed an absence of integrated approaches, as well as inconsistencies in psychotherapeutic services for these women even when domestic violence is seen as a precipitating factor in women's mental health problems [3]. Additionally, psychotherapeutic treatments for victims of trauma, for example, those with Post Traumatic Stress Disorder (PTSD), have, until more recently, tended to focus on victims of conflict or rape and not women who have experienced domestic violence [37]. Although Hughes and Jones [38] note that research in the US has shown that women victims of domestic violence often meet PTSD criteria, standardized PTSD assessment by trained professionals is needed as well as 'greater public health involvement for prevention, identification, and medical treatment of domestic violence and PTSD' ([38], p. 5). Lundy and Grossman [39] argue that mental health services practitioners tend not to identify women victims of domestic violence among their patients or recognise their experiences of abuse either as a precipitating or enduring factor in their mental illness, in the main because women often do not disclose abuse or they only want help with managing the symptoms.

It has been argued that where mental health problems occur as a consequence of domestic violence, and particularly when domestic violence occurs in early age and when the violence is severe and enduring [38], these need to be understood and treatment needs to be given in the context of genuine psychological trauma. However, a strict emphasis on the medical model as a response to domestic violence victimisation, rather than a more social ecological approach, may also serve to pathologise the problem [40] and indeed the woman herself, and thus further victimise her. Importantly, such an approach may also serve to shift the focus away from the culpability of the perpetrator. This effect has been noted elsewhere; in Humphries' and Thiara's [33] research on domestic violence and women's mental health, for example, they found that 'psychiatrists saw no role for themselves (or in fact for other professionals) in relation to trauma, counselling or depression linked to the controlling tactics and violence of the perpetrator' ([33], p. 216).

\section{Perpetrator Accountability}

For the women involved in both the mental health and narrative studies, this lack of genuine focus on the culpability of the perpetrators of domestic violence served to deny women choice or agency in their relationships as well as contributed further to their feelings of hopelessness, fear of not being believed and the 'unreality' of their situation. Furthermore, these outcomes only served to foster or prolong the women's feelings of anxiety, thus contributing to their existing mental health worries. The lack of attention to the role and responsibility of the perpetrators of domestic abuse not only by the women's family and friends, but also by professionals whose job it was to support and protect them, is reflected in this extract from Susan's account from the Write It study:

I didn't feel safe in the house or out of it, I knew that he had been spending time in my neighbour's homes and gardens and not only was this unnerving, but also, I felt betrayed by those who I had been on good terms with. I received a text at one point from my youngest brother's partner stating that she hoped that I was OK but that she didn't want to become involved-I was devastated! Not involved???? They were my family...Overall I felt badly served by both the housing department, as I perceived that they had forced me back into the family home when I left, and with the police who had not fulfilled their duty to protect me.

Indeed, evidence from both studies showed that the attitude and reactions of others who were in a position to help the women were either unsupportive or in fact served to deter them from further helpseeking action, and thus re-victimised them. This also served to extend the parameters of their 'unreality' [30] of living with an abusive partner from within the confines of the domestic sphere to the external, equally 'unreal' world 'out there' that was both mirroring and confirming the women's sense and experiences of injustice and disbelief. To give a further example from the Write It study of how women's personal experiences of the 'unreality' of domestic violence are reinforced externally, in broader (legal) contexts, when Rosie's partner eventually left her after years of abuse, she sought the advice of a solicitor. Describing this episode in her narrative account, Rosie wrote:

It took me ages to summon the courage even to go to the door of her [her solicitor's] building. When I finally met her she was really awful. I couldn't believe it. In my mind she was behaving just like he had done. I briefly told her what had been happening to me and when I'd finished all she said was she hoped I wasn't expecting any financial compensation for what he'd done to me as, he 
would "really have to have almost killed you for that to happen". I never went back. His solicitor also seemed to be working not only in his favour, but also behaving in the same way, sending awful threatening letters and that...it was horrible. I don't think they should be allowed to behave in that way.

Rosie's experiences here reflect broader concerns about the obfuscation of abuse-the shift away from attention on the perpetrator to the troubled (or even troublesome) woman victim. It is certainly the case that in comparison to the extent of research, policy and practice interventions for women victim-survivors of domestic violence, less attention has focused on perpetrator accountability and prevention. And yet, as Katz [41] has argued, the way to protect women and the true 'heart of the problem' lies in understanding the mentality and behaviour of male abusers. While this problem has been highlighted in a number of research studies and in reviews of domestic violence literature and evidence, in practice, programmes that work with the male perpetrators of domestic violence demonstrate limited or inconsistent success in maintaining perpetrator engagement with these programmes or in changing attitudes.

In the main, perpetrator programmes aimed at addressing and preventing domestic violence demonstrate inconsistent outcomes for a number of reasons: referral processes to available programmes are inadequate; perpetrator programmes fail to secure continuity of engagement with male abusers; men take an instrumental approach to perpetrator programmes (for example, they only engage because they want to be able to have contact with their children and avoid care proceedings); successful engagement with perpetrator programmes and group therapy relies on male readiness to change [42-44]. Arguably, such outcomes are only compounded by the unwillingness of others-the kinship and friendships networks and groups of both perpetrators and women victims; legal, health, education professionals-to take active stances against domestic violence when it occurs and against male abusers themselves.

Drawing on evidence from his own research and years of counselling practice in the US with male abusers, Bancroft [45] has argued that attention needs to focus on how men think about women and relationships, in order to get them to change in their behaviours; too often, he states, the focus is on protecting women without properly addressing men's behaviour, except through the criminal courts. The ways in which male violence is hidden or deniedculturally, politically, socially-also helps to sustain male violence against women and means that men can continue to abuse unchecked. Bancroft, for example, notes the ways in which abusive men readily garner support for their behaviour both informally and formally through family, friends, professional and legal sources because of the lack of understanding about male violence against women or their willingness to condemn the behaviour of perpetrators. In parallel with Rosie's experiences cited above, Bancroft found that members of the legal profession often 'go out of their way to discredit and demean women who report abuse' and that such tactics 'can closely parallel those of abusers, and the result is re-victimisation of the woman' ([45], p. 378). He calls for legal standards for lawyers or solicitors who represent accused abusers in order to properly protect women victims.

\section{Support from Kinship/ Friendship Networks and Wider Communities}

It is also clear that women's ability to adopt agentic stances and survive domestic violence, while dependent on their capacity for resistance and selfprotection as and when violence occurs, also require intensive levels of support at these critical junctures. Humphries and Thiara [33] state that effective interventions at such times rely on '[a] nonstigmatising service that responds with sensitivity to women's abuse experience' ([33], p. 222). Evidence from the two studies discussed here suggests that effective interventions should also involve family and friendship communities and networks not only in supporting the victim herself during these times, but also in recognising the culpability of the perpetrator and taking an active stand against him. As Rosie wrote in her narrative for the Write It project:

In an ideal world, what I wanted was for someone to go and talk to my family and his family and tell them with some kind of authority that it was wrong, that he was wrong for abusing me, but that would never have happened. As long as this was just happening to me and the focus wasn't on him and what he did, then nothing was ever going to change.

In order to ensure the safety of women and their children, this type of net widening approach would require sensitive negotiations between health and social care professionals and women victims of abuse themselves, as well as with their kinship and friendship networks and communities. Evidence from counselling practice with male abusers suggests that these types of approaches are often the most helpful for women victims of domestic abuse, particularly in addressing the violent and abusive behaviour of perpetrators themselves. Bancroft [45] argues, for example, that 'nothing would work faster to end the abuse of women than having the friends and family of abusive men stop enabling them' ([45], p. 378); and he makes a number of recommendations for the ways in which kinship and friendship networks can help to support women victims of domestic violence in proactive ways ([45], pp. 376-378). Similarly, research by Anderson and colleagues [46] found that both social and spiritual support are critical factors in 
helping women victims of domestic violence develop resilience and resistance. However, it is also the case that women often have little control over how supportive other people and organisations will be when they disclose abuse and, too often, this relies on an arbitrary set of fortunate (or unfortunate) circumstances and conditions. In Anderson and colleagues' study, for example, some women participants found spiritual and religious leaders and communities to be supportive while others did not.

Although community-based responses to domestic violence are not always positive, some studies of domestic violence survivors have shown that they can be helpful when individuals and groups (such as neighbours, women friends, teachers) demonstrate greater understanding about domestic violence and its impacts on women (see [1], p. 731). In such cases Wilcox argues that community-based responses should be seen as an additional strategy in approaches to domestic violence work. Evidence from both the mental health and narrative studies would support this proposal, alongside strategies that help to generate greater understanding about domestic violence, its long-term consequences for women's mental health and about perpetrator accountability. Informal alliances made up of the family and friends of abused women need to be identified and involved in joint approaches to domestic violence that help women victims resist and escape abuse, and take active stances against it. It would perhaps be most helpful if the family, friends and supporters of these women were recognised in health and social care contexts, for example, as important contributors to their care, support and survival in the same way informal carers (of ill, disabled or older relatives) are recognised in health and social care policy and practice.

Currently, it is recognised that there is a 'paucity of evidence-based prevention approaches' to domestic violence globally due to the separate development of both research and advocacy as well as because of the 'complex array of factors that increase the likelihood of such violence occurring in the first place' ([6], p. $3)$. These factors, once again, relate to broader social, political and economic concerns such as gender and economic inequality and, for example, ideas about 'normative' masculinity. In the UK, a recent domestic violence prevention campaign drew attention to domestic violence in intimate teen relationships. However, without a congruent focus on issues such as gender and economic inequality, the impact and influence of patriarchy, masculine identities (i.e. some of the reasons underpinning women's ongoing domestic violence victimisation) then such programmes will, arguably, have little long-term effect. Plans by the UK government to address domestic and other forms of violence against women and girls do not currently include strategies to address broader understanding and perspectives on domestic violence as a form of gender and economic inequality, for example [47].

\section{Conclusion}

There is considerable scope for unsupported women survivors of domestic violence to contribute new evidence about their strategies for agency and survival, especially in studies that use more participatory or collaborative approaches [1]. We need to know more about these aspects of domestic violence and women's 'agentic' stances [1] from women themselves in order to improve the helpseeking opportunities of other unsupported women victims of domestic violence. This is particularly important at such times of global economic crisis when, 'there is real anxiety about the impact of the economic crisis on women's safety and support...' ([5], p. 5).

Furthermore, as Haaken [48] proposes, one of the effects of these and other types of global emergencies is, 'that the focus narrows to immediate survival, with diminished capacity for perspective-taking' ([48], p. 168). It is crucial to ensure that one of the additional consequences for women of the economic crisis is not their further marginalisation or reluctance to seek help through the lack of a broader perspective on domestic violence. This is also particularly pertinent because the mechanisms for identifying unsupported women victims of domestic violence, recruiting them to research studies and encouraging them to disclose abuse in order for them to make crucial transitions from victim to survivor, are fraught with almost selfperpetuating dilemmas and challenges that are caught up in the intersection between micro and macro worlds, between women's own experiences as the victims of domestic violence and the influence of much broader social, political and fiscal dynamics. Thus, women's experiences of abuse and the stories they have to tell are always and inevitably influenced by these wider concerns and tensions: the forever toing and fro-ing between action and counteraction, between myth and counter-myth, between evidence and ideology, that serve so well the crises circumstances that are seen by some as essential conditions for the preservation of capitalism and patriarchy (see [48]).

A key message to emerge from both the narrative and mental health studies described here was that these and other kinds of barriers many women face in developing agency and resilience are manifold and are often too overwhelming for them to attempt to seek help or to choose to leave abusive relationships on their own. However, many women who experience and survive abusive relationships unsupported may demonstrate considerable resilience, as well as survival expertise, even though these skills may not be obvious to the women themselves. It is the role of researchers, as well as health and social care and 
other professionals, to identify and assay this expertise-through close collaborations with unsupported women victims of domestic violencebased not just on a handful of cases, but on larger samples of women in order to understand the mechanisms for women's survival and recovery in the longer term. This should ensure that the experiences

\section{References and Notes}

1. Wilcox P. Communities, care and domestic violence. Critical Social Policy. 2006;26(4):722-747.

2. Romito P. A deafening silence: Hidden violence against women and children. Bristol, UK: The Policy Press; 2008.

3. Seeley J, Plunkett C. Women and domestic violence: Standards for counselling practice. St. Kilda, Australia: The Salvation Army Crisis Services; 2002.

4. Larkin M. Vulnerable groups in health and social care. London, UK: Sage; 2009.

5. Trades Union Council (TUC). Bearing the brunt, leading the response: Women and the global economic crisis. London, UK: TUC; 2011. Available from: www.tuc.org.uk/extras/TUC_Global-women.pdf (accessed on 17 January 2013).

6. World Health Organisation; London School of Hygiene and Tropical Medicine. Preventing intimate partner and sexual violence against women: Taking action and generating evidence. Geneva, Switzerland: WHO; 2010.

7. Stanko E. The day to count: A snapshot of the impact of domestic violence in the UK. Criminal J ustice; 2000,1:2.

8. Dodd T, Nicholas S, Povey D, Walker A. Crime in England and Wales 2003/2004. London, UK: Home Office; 2004. Available from: http://www.homeoffice. gov.uk/rds/pdfs04/hosb1004.pdf (accessed on 17 January 2013).

9. Home Office. Ending violence against women and girls in the UK. 2004. Available from: http://www.homeoffice.gov.uk/crime/violence-againstwomen-girls/domestic-violence (accessed on 14 February 2013).

10. Chaplin R, Flatley J, Smith K, editors. Crime in England and Wales 2010/11. London, UK: Home Office; 2011. Available from: http://www.homeoffice. gov.uk/publications/science-research-statistics/researc h-statistics/crime-research/hosb1011/hosb1011?view =Binary (accessed on 21 March 2013).

11. Home Office. User guide to Home Office statistics. London, UK: Home Office; 2011. Available from: http://www.homeoffice.gov.uk/publications/scie nce-research-statistics/research-statistics/crime-resea rch/user-guide-crime-statistics/user-guide-crime-statis tics? view=Binary (accessed on 21 March 2013.

12. Ellsberg $M$, Heise $L$. Researching violence against women: A practical guide for researchers and activists. Geneva, Switzerland: World Health Organisation; 2005. of women victims of domestic violence, and the individual and collective stories that they tell, continue to inform and underpin formal responses to domestic violence work, and also help to confirm that domestic violence, 'does not have to be the centrepiece of [their] identity' ([46], p. 1279).

13. Simmons CA, Farrar M, Frazer K, Thompson MJ. From the voices of women: Facilitating survivor access to IPV services. Violence against Women. 2011;17(10): 1226-1243.

14. Abdul-Quader AS, Heckathorn DD, Sabin K, Saidel T. Implementation and analysis of respondentdriven sampling: Lessons learned from the field. Journal of Urban Health: Bulletin of the New York Academy of Medicine. 2006;83(7):12-15.

15. Gile KJ, Handcock MS. Respondent-driven sampling: An assessment of current methodology. Sociological Methodology. 2010;40(1):285-327.

16. Platt $L$, Wall $M$, Rhodes $T$, et al. Methods to recruit hard-to-reach rroups: Comparing two chain referral sampling methods of recruiting injecting drug users across nine states in Russia and Estonia. Journal of Urban Health: Bulletin of the New York Academy of Medicine. 2006;83(7): 139-153.

17. Joanou JP. The Bad and the Ugly: Ethical concerns in participatory photographic methods with children living and working on the streets of Lima, Peru. Visual Studies. 2009;24(3):214-223.

18. Hegarty KL, Taft AJ. Overcoming the barriers to disclosure and inquiry of partner abuse for women attending general practice. Australian and New Zealand Journal of Public Health. 2001;25(5):433437.

19. Penrod J. A discussion of chain referral as a method of sampling hard-to-reach populations. J ournal of Transcultural Nursing. 2003; 14(2): 100-107.

20.Sen P. Enhancing women's choices in responding to domestic violence in Calcutta: A comparison of employment and education. The European Journal of Development Research. 1999;11(2):65-86.

21. Rodriguez MD, Rodriguez J, Davis $M$. Recruitment of first-generation Latinos in a rural community: The essential nature of personal contact. Family Process. 2006;45(1):87-106.

22. Crosby RA, Salazar LF, DiClemente RJ, Lang DL. Balancing rigor against the inherent limitations of investigating hard-to-Reach populations. Health Education Research. 2010;25(1):1-5.

23. Aldridge J, Becker $\mathrm{S}$. Children caring for parents with mental illness: Perspectives of young carers, parents and professionals. Bristol, UK: The Policy Press; 2003.

24. Franz CR, Robey D. An investigation of user led system design: Rational and political perspectives. Communications of the ACM. 1984;27(12):1202-1217.

25. Lieblich A, Tuval-Mashiach R, Zilber T. Narrative 
research: Reading, analysis and interpretation. London, UK: Sage; 1998.

26. Swanborn P. Case study research: What, why and how? London, UK: Sage; 2010.

27. Plummer K. Documents of Life 2: An invitation to a critical humanism. London, UK: Sage; 2001.

28. Goodson IR. Developing narrative theory. London, UK: Routledge; 2013.

29. The Write It Project recruited small numbers of unsupported women victims and survivors of domestic violence and used participatory narrative techniques that enabled the women to write about their experiences in their own ways, focusing specifically on personal agency and resilience strategies. The study used intensive participatory methods that meant the women maintained control over their stories and how these were recounted and presented. Three women wrote extensively and intensively about their experiences of domestic violence for the project and these accounts will be reproduced in full and unedited in the final report.

30. Williamson $E$. Living in the world of the domestic violence perpetrator: Negotiating the unreality of coercive control. Violence against Women. 2010; 16(12): 1412-1423.

31. Taft A. Promoting women's mental health: The challenges of intimate/domestic violence against women. Australian Domestic and Family Violence Clearing House. 2003; Issues Paper 8:1-24.

32. Women's Aid. Universal Credit and Related Regulations-Response from Women's Aid. J uly 2012.

33. Humphries C, Thiara R. Mental health and domestic violence: "I call it symptoms of abuse". British J ournal of Social Work. 2003;33(2):209-226.

34. Golding J M. Intimate partner violence as a risk factor for mental disorders: A meta-analysis. Journal of Family Violence. 1999; 14(2):99-132.

35. Campbell JC. Health consequences of intimate partner violence. The Lancet. 2002;359(13):13311336.

36. Astbury J, Cabral M. Women's mental health: An evidence based review. Geneva, Switzerland: Mental Health Determinants and Populations, Department of Mental Health and Substance Dependence, World Health Organisation; 2000. Available from: http://www5.who.int/mental_health/download.cfm? id=0000000067 (accessed on 18 February 2003).

37. Jones $L$, Hughes $M$, Unterstaller $U$. PostTraumatic Stress Disorder (PTSD) in victims of domestic violence: A review of the research. Trauma, Violence and Abuse. 2001;2(2):99-119.

38. Hughes $\mathrm{MJ}$, Jones L. Women, Domestic Violence and Posttraumatic Stress Disorder (PTSD). San Diego, CA, USA: Department of Health and Human Services; 2000.

39. Lundy M, Grossman S. Clinical research and practice with battered women: What We know, what we need to know. Trauma, Violence and Abuse. 2001;2(2): 120-141.

40. Romito ([2], p. 69) refers to this as the 'psychologising' of domestic violence, which consists of, 'interpreting a problem in individualistic and psychological rather than political or economic and social terms.'

41. Katz J. In: Bancroft L. 'Why does he do that?' Inside the minds of angry and controlling men. New York, NY, USA: The Penguin Group; 2002, first page.

42. Stanley N, Miller P, Richardson FH, Thomson G. A stop-start response: Social services' interventions with children and families notified following domestic violence incidents. British Journal of Social Work. 2001;41(2):296-313.

43. Stanley N, Graham-Kevan N, Borthwick R. Fathers and domestic violence: Building motivation for change through perpetrator programmes. Child Abuse Review. 2012;21(4):264-274.

44. Zalmanowitz SJ, Babins-Wagner R, Rodger S, Corbett BA, Leschied A. The association of readiness to change and motivational interviewing with treatment outcomes in males involved in domestic violence group therapy. Journal of Interpersonal Violence. 15 October 2012; doi:10.1177/0886260512 459381.

45. Bancroft L. 'Why does he do that?' Inside the minds of angry and controlling men. New York, NY, USA: The Penguin Group; 2002.

46. Anderson KM, Renner LM, Danis FS. Recovery: Resilience and growth in the aftermath of domestic violence. Violence against Women. 2012;18(11): 1279-1299.

47. Her Majesty's Government, UK. A call to end violence against women and girls: Action Plan 2013. Available from: http://www.homeoffice.gov.uk/publications/ crime/call-end-violence-women-girls/vawg-actionplan-2013? view=Binary (accessed on 14 March 2013).

48. Haaken J. Hard knocks: Domestic violence and the psychology of storytelling. London, UK: Routledge; 2010. 


\title{
Challenging Racist Violence and Racist Hostility in 'Post-Racial' Times: Research and Action in Leeds, UK, 2006- 2012
}

\author{
Ian Law ${ }^{1,2, *}$, Jenny Simms ${ }^{3}$ and Ala Sirriyeh ${ }^{4}$ \\ ${ }^{1}$ School of Sociology and Social Policy, University of Leeds, Leeds, LS2 9JT, UK; E-Mail: i.g.law@leeds.ac.uk \\ ${ }^{2}$ Centre for Ethnicity and Racism Studies, University of Leeds, Leeds, LS2 9JT, UK \\ ${ }^{3}$ Independent Researcher; E-Mail: jennysimms44@hotmail.com \\ ${ }^{4}$ School of Social and International Studies, University of Bradford, West Yorkshire, BD7 1DP, UK; \\ E-Mail: a.sirriyeh@bradford.ac.uk \\ * Corresponding Author
}

Submitted: 13 February 2013 | In revised form: 18 March 2013 | Accepted: 10 April 2013 |

Published: 22 April 2013

\begin{abstract}
Despite increasing understanding of, information about and official commitment to challenge these patterns, racist hostility and violence continue to have an enduring presence in urban and rural life in the UK. This indicates the paradoxical nature of this racial crisis and challenges for antiracism as a political project. This paper charts how these issues play out at the local level through an examination of a five year process from problem identification through to research, response, action and aftermath from 2006 to 2012 in the city of Leeds, UK, with a focus on two predominantly white working class social housing estates in the city. We explore how embedded tensions and antagonisms can begin to be challenged, while examining how the contemporary climate of austerity and cuts in services, together with prevailing post-racial thinking, make the likelihood of such concerted action in the UK increasingly remote.
\end{abstract}

Keywords: antiracism; housing; racist harassment

\section{I ntroduction}

Racist hostility and violence continue to be a significant and enduring dimension of both urban and rural life both in the UK and Europe despite increasing understanding of, information about and official commitment to challenge these trends. This indicates both challenges for antiracism as a political project and the paradoxical nature of this racial crisis. In this paper we chart how these issues play out at the local level through revisiting a study conducted in 20062007 in two predominantly white working-class social housing estates in the city of Leeds, UK. Leeds is a large city in the north of England with a population of

(c) 2013 by the authors; licensee Librello, Switzerland. This open access article was published under a Creative Commons Attribution License (http://creativecommons.org/licenses/by/3.0/). 
751,500 at the 2011 Census. The paper begins by outlining the background and context in which this study was commissioned and the methodology we used. The paper then discusses the study findings through exploring victims' experiences of racist hostility, explanations for the hostility and violence and, finally, the responses to this hostility. In the final section we draw on the aftermath of the report's presentation to local stakeholders and a recent return research visit in 2011-2012 to the original study site, during which we interviewed staff members from key local agencies to review impact and responses since the original study took place.

This paper positions evidence of declining action and commitment in the context of the 'post-racial' [1]. In this era, commitment and action by public agencies is declining as there is a denial and silencing of the significance of race and racism in the lived experiences of minorities and these issues are displaced from the political agenda [2]. A recent research report which examined the response of public authorities' commitment and action to eliminate targeted harassment and violence in the UK has confirmed that decreasing numbers of authorities are taking action, working on prevention, supporting victims and working with perpetrators [3].

\section{The Leeds Study}

The research study conducted in 2006-2007 arose from concerns expressed by local area housing management staff about increasing racial harassment. A number of recent serious cases and race hate in parts of this area of Leeds had also been identified as a key concern in a city wide report on hate crime in November 2006. This report concluded that,

'Empirical evidence has clearly identified that on certain estates on specific streets there effectively exist 'no-go areas' for black and minority ethnic families due to the level of intimidation and harassment families have received' ([4], p. 5).

One hundred sixteen racist incidents were recorded by Leeds City Council, and a similar high number were recorded by the Police and Leeds Racial Harassment Project in 2005/06 in the local area [5]. These incidents included firebombing, racist graffiti, racist abuse, property and vehicle damage, smashed windows, throwing bricks, assault, setting fires, threats and intimidation, and repeated racist victimisation by groups of local young people. This was recognised by the Council as an increasing trend of both organised and spontaneous racist victimisation of black, Asian and minority ethnic (BAME) families. Understanding the drivers of local hostility and antagonism in the area, and understanding the problems which newcomers, and in particular BAME households, experienced on the estate was seen as a key objective.
This area is dominated by social housing (mainly council owned) where unemployment and benefit dependency have increased since the loss of manufacturing jobs in the 1970s and 1980s. A sustained programme of intensive neighbourhood management had also been in operation in this locality which had highlighted wider problems of racist hostility and racist victimisation. The historical and continued formation of predominantly white council estates in this area, due to a specific range of processes, had recently been subject to change due to an increase in lettings to BAME tenants. This was facilitated by the introduction of more 'customer-focused' housing lettings systems and lettings to refugees. Historical patterns of housing allocation, racial discrimination, segregation of 'problem' families and self-segregation/avoidance choices by both BAME and white households led to the production of an area which was almost exclusively white. The impact of housing renewal and allocation policy involved initial re-housing of predominantly white households from slum clearance into the area when it was built [6]. Long-standing reticence to offer housing to black and minority ethnic households in areas outside the main areas of black and minority ethnic settlement in the city, combined with the 'dumping' of white households with multiple problems in the area produced a context which reinforced ethnic and racial divisions in housing choices $[7,8]$. Long-standing perceptions and experiences of high levels of racial hostility in this area and other parts of Leeds had been a significant constraint on the housing choices of many BAME households [9].

The introduction of choice-based lettings (CBL) systems together with improving agency responses to racist violence had in recent years begun to improve opportunities for housing choice. CBL allows housing applicants to view details on, choose between, and apply (or 'bid') for currently available-to-let properties. This contrasts with traditional housing allocation systems where applicants are normally faced with only a choice of whether to accept or reject a property deemed 'suitable' by a social landlord. In this way, $\mathrm{CBL}$ aims to transform the letting of social housing from a producer-driven function to a consumer-led service. Originating in the Netherlands, the application of CBL in Britain was given substantial impetus by the English Housing Green Paper of 2000 [10]. This backed CBL as empowering housing applicants by enabling them to play a direct role in selecting their future home.

Government targets aimed to extend $\mathrm{CBL}$ to all local authorities in England by 2010, following the introduction of such schemes in 27 local authority areas during 2001-2003. An evaluation of the impact of these programmes found that in Leeds, perhaps even more than in towns like Bolton and Bradford, minority ethnic social renters were spatially concentrated in 2001, with 52\% living in three of the council's 29 housing management administrative 
areas [11]. The reduction of ethnic concentration of BAME lettings was a direct consequence of the introduction of CBL in Leeds, with the proportion of these lettings in 'areas of concentration' falling from $47 \%$ pre-CBL to only $27 \%$ post-CBL. Similarly lettings to BAME households in areas of low black and ethnic minority concentration, including this area, had doubled overall. Other factors which may have played a role in this process of 'de-segregation' included the Immigration and Asylum Act 1999 from which a dispersal programme was established whereby people claiming asylum were dispersed to live in allocated housing in regions outside London and the South East of England [12].

In some cases this process of 'de-segregation' has involved offering and letting properties to households who are immediately at high risk of racist violence, as our study found. In response, amendments to CBL were made to give back some additional scope for managerial action including risk assessment procedures. This meant housing staff making a judgement about whether it was safe for a black or minority ethnic family to move into a particular property. It was clear that many such families were prepared to face such risks because of the insecurity and poor quality of their previous housing circumstances. Increasing ethnic diversity of households is certain to continue despite the risk of violence due to pressing housing needs, reduction in racial discrimination by housing institutions and greater opportunity for household choice. In this dynamic context, effective and fair management of the needs and concerns of all households is needed.

Leeds City Council first adopted a Racial Harassment Policy in 1986. Evidence from the early years of that policy showed a sporadic pattern of racist violence being reported across most inner and outer estates and areas, which could not be easily explained in terms of competition, territorialism or activities of extreme right groups. Twenty years later, levels of reported incidents of race hate in Leeds were between 4,000 and 5,000 across the city and indicated the durability, geographical spread and significance of such violence. Reported incidents had hugely increased during this period which confirmed significant improvements in public reporting, staff awareness and agency recording practices. However, reported incidents were acknowledged to be a fraction of the total number, with real levels of race hate incidents likely to be upwards of 10,000 per year. Factors which strengthen the bonds between families, including changing economic opportunities and isolation from social networks outside the local area, can strengthen mobilisation to respond to external threats and dangers. Strong communities may often be highly exclusionary. A key to understanding how this process works was to examine local norms, values and sanctions to conform operating across a range of networks including families, friends/peer groups and other informal forms of association.

Our research examined perceptions expressed by victims of racist hostility, other residents and staff from key agencies in the two housing estates in Leeds. Interviews and focus groups were completed with 103 research participants. In the first phase of data collection (late December 2006 to J anuary 2007) we interviewed 20 'key informants', comprising voluntary and public sector workers with responsibility for the area. Through this initial work we aimed to build up an informed picture of both the history and context of racial tension in the area and agency perspectives. This was in order to situate the incidence of racial harassment and victimisation through accessing 'expert narratives'. This data is representative of the perspectives of people working to tackle and explain racism within the community. In addition a further seven key informants were interviewed at later stages of the project.

From January to March 2007 we conducted fieldwork with 11 people who, along with other members of their families, had been identified as victims of racial harassment on the estate. These interviews did not always take place on the estate as several people had moved away from the estate and been re-housed. At the time of writing our 2007 report, five families had moved out of the area and were living elsewhere, two of these in temporary accommodation. Three were still living in the area, but had applied to move, and three were living in the area and planning to stay.

Between March and June 2007 we undertook semistructured interviews and focus groups with 65 residents on the estates. The majority of interviews took place in resident's homes, although two chose to be interviewed at a local housing office. This interview based approach was complemented by the writing of extensive field-notes. These documented meetings, contacts and conversations in the field. In total 45 residents were interviewed, together with four focus groups with 20 young people who were residents on the estate.

A local election took place within the period we were carrying out the research. The British National Party (BNP) was actively and visibly campaigning in the area. Commenting on this often gave us a route into tackling the subject of racism. As such, the research can be situated within a particular temporal context, within which the politics of race had some prominence and salience for some people. It was notable that many people did not hold racist views, contested racism or were unaware of the problem. There was a complexity and micro-geography of who appeared to be concerned about race and why. It must also be noted that participants often brought up the topic themselves in relation to housing allocation policy and repairs. We found it productive to find how people themselves introduced the topic offering them prompts around areas that we learned, were 'catalysts' 
for such a discussion such as the local election, housing, newcomers' experiences, dominant families on the estate and crime and anti-social behaviour.

In 2011-2012 we conducted semi-structured interviews with six key informants from agencies working in these estates to assess the impact of the 2007 study and review responses to racist hostility in the area since the original study had taken place, including changing circumstances. These perspectives are discussed in the section on responses later on. First, we explore the 2007 study findings on victims experiences of racist hostility and explanations for the hostility.

\section{Victims' Experiences of Racist Hostility}

Evidence from victims identified the immediate and escalating levels of racist violence they experienced. The routine 'everyday' nature of this hostility and violence included: verbal abuse, graffiti, eggs thrown at houses, cars burnt out, physical assaults on children and adults, and petrol bombing. Most respondents experienced repeat or continuous racist harassment while living on the estates, often with similar patterns of escalation until they were forced to move away. Harassment often began with verbal abuse and actions such as eggs being thrown and escalated to more severe forms of violence and harassment. Families commented on the routine and everyday nature of harassment and, in this context, they felt it was too difficult to report all the 'incidents'.

Few respondents felt able to continue living in the area after these experiences and many compromised on the quality of their accommodation when relocating to safer housing. Four of the five families who were no longer living in the area had been relocated in emergency circumstances due to violent attacks on their property in combination with other incidents. One of these families had to be escorted from the property by the Police to ensure their safety when a large group of people had gathered outside their house. As a result, victims often felt isolated in these communities and constantly under siege.

Oh I would say it is like a jail. It is like you are living in jail (Black African female resident).

People [in the local area] are very united. They are racist. They come as a group because the youths they come together in an area...even the elders there support the youths (Black African female resident).

A variety of strategies were deployed in response to these experiences including avoidance and changes to daily routines, negotiation, trying to 'keep neighbours onside' and late reporting of cases [13]. The impact on families included deterioration in physical and mental health, markedly so for children. Significant difficulties were experienced in obtaining re-housing following racist harassment. Victims described widespread hostility in this area combining overt aggressive racism, particularly from children and young people, with more covert everyday racist talk from older people. Although there was also recognition of some positive interactions with some neighbours and other residents. They identified a serious lack of awareness and exposure to cultural diversity in the local community. They were also intimidated due to BNP activities in the area. Victims expressed some positive comments about the support from individuals from agencies including Housing, Police, Victim Support and Leeds Racial Harassment Project (now Stop Hate UK), but were critical of the ability of agencies to respond effectively given the scale of widespread racist hostility and the weakness of enforcement processes. There was room for significant improvement in many aspects of work with victims including information and advice, casework support, re-housing, enforcement and prevention.

\section{Understanding Racist Hostility}

The drivers of racist hostility were found to include resentment of BAME families' ability to access social housing, jealousy of lifestyle and possessions, and perceptions of unfair preferential treatment $[14,15]$. Competition-based racist hostility in relation to housing and employment was strongly voiced [16]. This was compounded by everyday racist talk/hearsay, related misinformation, and the denial of racist intent. One centrally important contextual factor was community self-policing: power and mobilisation of local family and community networks to enforce hostility, drive families out and maintain an atmosphere of fear and intimidation. There was an instrumental promotion of racist hostility where it was seen to be useful to achieve family, community or criminal goals. Several tensions in the area were linked to very narrow and specific social and geographic boundaries of trust and safety, and racisms on this estate were linked to fear of the 'other' and fierce allegiance to those who are close to oneself.

Poverty, abandonment and disempowerment were often articulated through racist hostility. Mistrust of authority and feelings of disengagement had led to community self-regulation practices that were exclusionary and defensive. Narratives of neglect and lack of care were strongly expressed together with some strong sense of community pride and affection for the area. Hostility to public agencies, and an embattled sense of political and social abandonment and isolation with local values of 'toughing it out' and 'looking after your own' were frequently expressed. Therefore, for many households in these areas racist hostility met a test of practical adequacy and sensemaking and fitted with core norms and values.

Racism in this locality took a number of forms, was 
expressed in a variety of ways and also intersected with a multiplicity of other bitter resentments and emotions related to class, poverty and gendered identities. It was often hard for both residents and researchers to separate issues of racism from other common practices of resentment, exclusion and suspicion within estate life. People on the estate were not always explicitly racist in terms of skin colour, but drew upon spectra of belonging and entitlement that factored in class, family, affiliation, heritage and levels of contribution to estate life. Race difference was often used as a channel for rage, anger and disaffection, as an expressive tool, but not always the sole motivation. This helped to account for the high level of denial, distancing and justification expressed in relation to racism. Some of the more severe racist incidents on the estate were precipitated or triggered by noise nuisance, alcohol, adjunctive traffic incidents/accidents and unsociable hours.

Black African families were highly visible key targets of racist hostility. Catch-all terms such as 'Kosovan' and 'asylum-seeker' were also used in labelling households as problematic and for targeting hostilities. People with southern English accents, people in paid employment and Eastern Europeans had also been targets of harassment. An important aspect of our research was consultation with local politicians. In a 2012 interview with us, the local Labour MP, Rt. Hon Hilary Benn MP for Leeds Central confirmed the complications of the locality.

It is very hard to believe until you experience it, the culture of the two estates is that they felt detached from the prosperity of the city and this, in turn, bred resentment. We had such problems; the two estates were separated by a stretch of grass and so insular were the attitudes of some on the estate that those from the other estate were regarded as foreigners never mind those from 5000 miles away [17].

Lastly, the significant role of the BNP was examined showing how their message of representation of the excluded working classes tied in with local understandings and denials of racism, while undeniably racialising pre-existing resentments [18]. This was again confirmed by the local MP:

Sometimes the Labour Party, nationally, finds it hard to talk about race and immigration so when I am on the doorstep, talking to constituents, I often hear "You don't want to hear this" or "You don't want to talk about this". Well, we are done for if people think we don't want to talk about it [17].

Racist values were being passed on across generations, both within families on the estate and through other informal contact between children, young people and adults. Large groups of young people congregating in one area were often labelled as 'gangs' and subsequently many accounts of racist hostility were linked to their presence. However, interventions aimed primarily at young people did not address the role of parents and other adults who were involved in inciting racist behaviour and the wider community was often complicit in its inaction and protection of perpetrators. It emerged from our focus groups with young people that they were aware from school teachers, the Police and youth workers that expressing racist views was deemed inappropriate or wrong. However, further exploration of the issues with the young people led to an understanding that some young people did hold essentially racist views, often based on fear, jealousy and perceived unfair preferential treatment.

It's because the Council won't let any of the white people move in to houses because they're giving them to all the foreigners. My aunt waited three years for a house and they gave it to a pair of Kosovans (White young male, age 16).

This finding is also reflected in recent research in the West Midlands [16] which argues that white working class racialised opinions should be seen in the context of people feeling the effects of neighbourhood loss, political disconnection and competition for scarce resources.

\section{Responding to Racist Hostility}

The need for an improvement in agency responses was recognised by many representatives from local agencies. Poor levels of service, poorly implemented policy, poor perceptions of services and a strong desire for more effective work with local communities were powerfully stressed:

The level and adequacy of support for victims and families suffering from racist victimisation is appalling and services are very fragmented (Customer Services Manager).

How do you deal with a community who feel that they have so much anger that they have to attack somebody?...What is lacking is engagement with communities...getting them to change, support and befriend people (Principal Hate Crime Officer).

Our report strongly supported the general thrust of these views and sought to show how greater understanding of both the impact of racist harassment on victims and the complex ways in which racist hostility works in local communities requires a rethinking and a renewal of policy and practice in this field. To facilitate this process a second report [19] was produced which examined a wide-ranging set of evidence and interventions and proposed the establishment of an explicit 'racism reduction' strategy in Leeds.

In examining the fit between this racism reduction agenda and local Race Hate Crime Strategy in Leeds it 
was clear that there were many gaps including a failure to develop preventative community-based interventions. On 31 January 2008 both these reports were presented to the board of Safer Leeds [20]. This was chaired by Councillor Les Carter, Conservative councillor for Adel and Wharfedale constituency in the city. His response to these two reports indicated that there was no point in carrying out such research, and that what was happening in this area of Leeds was purely local people being concerned about local housing in their area. This view took shape in new plans to reserve a quarter of council housing in Leeds for 'local' people, about 15,000 properties. Councillor Carter defended this saying, 'It is nothing to do with immigration', but, instead, a response to 'massive complaints' from 'people who seem to feel they are being moved away from their families. It has been a really big issue for a long time' [21]. This dismissal of the importance of engaging with racist hostility, racist victimisation and racist violence was not however shared by official representatives from public service agencies, including Safer Leeds itself, with a particular concern expressed that action needed to be swiftly taken to improve support for children who had been victims of racist violence.

The positive response was also evident through the commitment of key officers in relevant local agencies, and their work in the context of the newly established local Hate Crime (HC) Group. The lack of local coordination in response to racist incidents and strategic leadership had produced a sense of frustration. This was combined with a sense of being overwhelmed by the rising number of incidents and the strength of local hostility. The HC Group provided a means to move forward, developing a strategic approach and taking on board the range of recommendations made by the two research reports $[19,22]$. In particular, there was focus on generating wider community and institutional commitment to tackle racist violence. 26 BAME families who had suffered from racist harassment also sent a petition to the local MP, and highlighted their key concerns to the $\mathrm{HC}$ Group. These concerns included problems with communication and response from the Police, lack of positive action against perpetrators and lack of information from social housing managers about the level of racist incidents prior to taking on their tenancies.

This was contradicted by the local MP who believed that the two estates were less environmentally hostile now than they had been and attributed this to positive enforcement action by local services, the ALMO [23], the Police, the increased security and the threat of civil penalties.

I had no doubt, as the local MP, that the police did everything they could to eradicate the racist violence on the estate and to prosecute. The ALMO did all they could to find perpetrators and even seconded a member of staff to the community action group. Under no circumstances did I feel that either of them were complicit in the aggression towards asylum seekers and new families on the estate, they were very troubled by it. They were desperate to catch people in the act. [17]

Fifteen specific initiatives were taken by local agencies following on from this process and these were reviewed by Safer Leeds in 2009. Use was made of professional witnesses who operated undercover to identify race hate perpetrators, but with only limited evidence gathered and little enforcement action. Three arrests were made and there has been a reduction in race hate crimes in the locality, but this has also resulted from the cumulative impact of this and other interventions. Installation of fireproof letterboxes in properties at risk of attack has led to a significant reduction in related arson attacks and has been positively received by BAME residents. The education package associated with the 'Show Racism the Red Card' antiracist football based campaign, which has been put in place in local schools, has produced both a positive reaction from pupils and a poster campaign in the local area. Associated with this, has been the work with local clusters of schools to implement the Stephen Lawrence Education Standard, which embeds attention to race hate in the curriculum and the schooling context. Stop Hate UK (SHUK) has also held workshops both in local schools and with the local Youth Inclusion Project on race hate.

A Section 30 dispersal order giving the Police powers to disperse groups of two or more young people was granted from November 2007 to April 2008 and seems to have been one of the key factors in reducing levels of severe, threatening racist incidents, but may only have led to a displacement of tensions elsewhere. The local Women's Group developed productive face-to-face interaction with a refugee women's group through participation in a range of joint activities with positive feedback from both groups. The inclusion of black and minority ethnic representatives in the formation of a new residents' group also indicates a positive step forward in building intra-community cooperation. The establishment of scrutiny panels involving residents and multi-agency risk assessment groups to discuss cases of hate crime and improve victim support and action against perpetrators have both been reported as improving the confidence of local residents in the services provided by local agencies in this field. Implementation of swift initial response visits to victims of racial violence by an outreach worker and the Police have also assisted in this process.

By the autumn of 2008 this work was having a significant impact in reducing recorded racist incidents, with, for example, 27 incidents reported in October 2007 and zero in October 2008, improving success in detection rates and targeted enforcement activity and in improving residents' perceptions of safety. Yet there 
remains a core presence of strong racist hostility amongst some families and amongst some young people on these estates and there is, therefore, a significant threat of further harassment and violence.

In our 2011-2012 interviews it was acknowledged by the officer who had been in charge of the local Hate Crime Group at the time that our 2007 research reports had 'made a tremendous impact in raising awareness and empowering key individuals to act' and that there had been a major change in the local environment from one where black and minority ethnic families were routinely 'burnt out, beaten up and hounded out of the estate' to one where incidents continued, but were much less severe.

The most recent monitoring information confirms that there have been six incidents in a three month period in 2011 compared to approximately that number in one week in 2007. One main perpetrator is currently serving a three year sentence, and three extreme-right organisers who lived on the estate in 2007 have since moved/been moved out from this area. Hence, while in the May elections in 2008 many British National Party placards were in evidence in residents' front gardens across the estate, during the elections in May 2010 and May 2011, together with local BNP candidates, these had disappeared. While the successful criminal prosecution of individuals and action against extreme-right organisers was seen as having had an impact in small localities, an overemphasis on crime prevention, extremist ideologies and the role of particular individuals can risk the neglect of wider, underlying and durable experiences of racism. These strategies illustrate Lentin and Titley's ([2], p. 169) suggestion that race is buried or made invisible, because 'racism is understood as an irrational attribute or behaviour', an irrational sentiment exhibited by extremist individuals and, therefore, 'it has diminished purchase in a social vision that places rational and autonomous actors centre stage'.

While there were some positive reports of changing circumstances and action, there were also indications of further setbacks and challenges. The recent closures of a 'One Stop' shop and the local leisure centre, which was used by a variety of agencies and community groups, have reduced the already very limited services available on the estate and are likely to contribute to increased feelings of abandonment and neglect among local residents. These feelings were part of the complex set of factors which had led to a rise in resentment and hostility to others back in 2006-2007. Cuts were impacting directly on some support services for victims, for example the halt in funding for the support team operating from Stop Hate UK in Leeds, although other support services for victims were continuing to operate and funding had been maintained.

There was also recognition that the climate amongst local agencies across Leeds in 2011-2012, in relation to racist hostility and violence, was still one of denial, or 'racism fatigue', with a move to deny explicitly racist elements of incidents and move away from the language of 'race' through responses such as 'it's all just ASB' (anti-social behaviour), and the incorrect 'branding' of racism as a 'cohesion issue'. This was partly because this was seen as a 'job done'. The move away from a focus on racist violence to hate crime generally was also seen as indicative of this wider shift in agency perceptions. The rebranding and denial of racism characterises the 'post-racial' contemporary, where the terms of race have 'evaporated' and race is 'buried, alive' $[1,24]$. In this context, where race is silenced, privatised and removed from political agenda Kapoor ([25], p. 1) suggests, 'any progressive measures using race for the purposes of anti-racism fade from view.' Despite these factors, there was still evidence that a strong commitment to tackling racist incidents was a mainstream professional value amongst a range of staff from local agencies.

\section{Conclusion}

The ambivalent trends in responses to racist violence highlighted in the Leeds context are glocalised trends of today's 'post-racial' times, where there has been a wider shift from the politics and law of identities to the politics and law of human rights [26]. The logics of the post-racial incorporate a denial of the contemporary significance of racism and global racialisation beneath the rhetoric of liberal democracy, individualism, meritocracy and progress. In the UK 89 people have lost their lives in attacks with a racial element since the murder of Stephen Lawrence in 1993, and racist attacks regularly take place on the street, in people's homes, in taxis and taxi offices, in takeaways, restaurants, pubs and bars, as well as shops and religious institutions [27]. This is hardly a post-racist context. Even the US 'supercop' Bill Bratton, who recently advised Prime Minister David Cameron to assist in tackling gang crime and street crime in the wake of the recent riots in the UK, has acknowledged that it is not possible to arrest your way out of these problems and that underlying racial tensions need to be addressed [28]. Our message is a similar one, traditional criminal justice approaches have failed to reduce underlying racist hostility and associated racism. These embedded tensions and antagonisms can begin to be challenged, as this case study has demonstrated, and doing so can reduce such harassment and attacks. However, in the contemporary climate of austerity and cuts in services, together with prevailing post-racial thinking, the likelihood of such concerted action in the UK becomes increasingly remote. 


\section{References and Notes}

1. Goldberg DT. The post-racial contemporary. University of Seville, Seville, Spain; 2011. Unpublished public lecture.

2. Lentin A, Titley G. The Crisis of Multiculturalism: Racism in a neoliberal age. London, UK: Zed Books; 2011.

3. Chakraborti N, Gadd D, Gray P, Wright S, Duggan M. Public authority commitment and action to eliminate targeted harassment and violence. Manchester, UK: Equality and Human Rights Commission; 2011.

4. Leeds City Council. Tension Monitoring November 2006. Leeds, UK: LCC; 2006.

5. Leeds City Council. Recording and reporting hate crime in Leeds. Leeds, UK: LCC; 2006.

6. Duke C. Colour and Rehousing: A study of redevelopment in Leeds. London, UK: Institute of Race Relations; 1971.

7. Leeds City Council. Ethnic Monitoring of Housing Allocations. Leeds, UK: Dept. of Housing, Leeds City Council; 1985.

8. Law I, Davies I, Phillips D, Harrison M. Equity and Difference, racial and ethnic inequalities in housing needs and housing investment in Leeds. Leeds, UK: RAPP, University of Leeds; 1996.

9. Comrie J. The Housing Needs of African Caribbean Elders in Leeds [PhD thesis]. Leeds, UK: University of Leeds; 2007.

10. DETR. Quality and Choice: Decent Housing for All. London, UK: Department of the Environment, Transport and the Regions; 2000. Available from: http://www.gmlhousing.co.uk/documents/DETR\% 20 Quality\% 20and\% 20Choice\% 20-\% 20A\% 20Decent\% 2 0Home\% 20for\% 20All\% 202000.pdf (accessed on 17 April 2013).

11. Pawson $\mathrm{H}$, J ones $\mathrm{C}$, Donohoe $\mathrm{T}$, Netto $\mathrm{G}$, Fancy C, Clegg S, Thomas A. Monitoring the Longer Term Impact of Choice Based Lettings. London, UK: Department for Communities and Local Government; 2006.

12. Asylum-seekers are not housed through mainstream social housing provision. It is only once people gain refugee status that they may access the CBL bidding process.
13. Chahal K, Julienne L. We Can't All Be White. York, UK: JRF; 1999.

14. Amin A. Ethnicity and the multicultural city: Living with diversity. Environment and Planning A. 2002;34(6): 959-980.

15. Robinson D, Reeves K. Neighbourhood experiences of new immigration: Reflections from the evidence base. York, UK: J RF; 2006.

16. Beider $\mathrm{H}$. Community Cohesion: The views of white working class communities. York, UK: JRF; 2011.

17. Interview with the local Labour MP, Rt. Hon Hilary Benn MP for Leeds Central. 1 February 2012.

18. Rhodes J. The Banal National Party: The routine nature of legitimacy. Patterns of Prejudice. 2009;43(2): 142-160.

19. Law I. The Racism Reduction Agenda, building the framework, signposting good practice and learning the lessons. Leeds, UK: CERS; 2007.

20. Safer Leeds is a statutory partnership formed as a result of the Crime and Disorder Act 1998. The Safer Leeds Board is made up of representatives from the public, private and voluntary sectors. This is a consultative group that reviews the partnership plans and ensures that community consultation is coordinated effectively and reports to the citizens of Leeds.

21. Housing in Leeds. Big Issue. 27 May 2010.

22. Hemmerman L, Law I, Simms J, Sirriyeh A. Situating racist hostility and understanding the impact of racist victimisation in Leeds. Leeds, UK: CERS; 2007.

23. Arms Length Management Organisations are not-for-profit companies which provide housing services on behalf of a local authority.

24. Goldberg DT. The Threat of Race: Reflections on racial neoliberalism. Malden, MA, USA: Blackwell; 2009.

25. Kapoor N. The advancement of racial neoliberalism in Britain. Ethnic and Racial Studies. 2011;1-19.

26. Hepple B. The New Single Equality Act in Britain. The Equal Rights Review. 2010;5,11-24.

27. Athwal HB. Racial Violence: The buried issue. London, UK: Institute of Race Relations; 2010.

28. UK riots: Police should tackle racial tension, says 'supercop' Bill Bratton. The Guardian. 13 August 2011. 


\title{
The "I dle No More" Movement: Paradoxes of First Nations Inclusion in the Canadian Context
}

Terry Wotherspoon* and John Hansen

Department of Sociology, University of Saskatchewan, 9 Campus Drive, Saskatoon, SK S7N 0E8, Canada; E-Mails: terry.wotherspoon@usask.ca (T.W.); john.hansen@usask.ca (J.H.); Tel.: +1 3069666925 (T.W.); Fax: +13069666950 (T.W.)

* Corresponding author

Submitted: 14 April 2013 | In revised form: 2 June 2013 | Accepted: 27 J une 2013 | Published: 18 J uly 2013

\begin{abstract}
Idle No More, a recent protest movement initiated to draw attention to concerns by Indigenous people and allies about changes in Canada's environment and economic policies, has also raised awareness about social and economic conditions experienced by much of Canada's Indigenous population. While discourses and policies oriented to social inclusion are not as prominent in Canada as in Europe and several other contexts, these conditions and the strategies adopted by governments to address them are consistent with narrowly-framed inclusion policies. We provide an overview of what these conditions represent and how they have come to be framed in the context of the Idle No More movement. However, we extend our analysis to understand how the Idle No More movement and discourses of inclusion and exclusion alike have often been framed in ways that further limit solutions to the problems that they are oriented to resolve by stigmatizing and distancing Indigenous people, especially when they ignore or undermine distinct Indigenous rights and the foundations of formal Aboriginal status. We draw upon Indigenous concepts of justice and critical analyses of power relations in order to explore the contradictory locations and experiences associated with Indigenous inclusion in the Canadian context. We conclude by exploring the movement's contributions to broadened conceptions of inclusion that build upon alternative conceptions of socioeconomic participation and success.
\end{abstract}

Keywords: Indigenous people; social exclusion; social inclusion; social inequality

\section{Introduction}

News media in Canada and many other nations were replete with images in late 2012 and early 2013 of Indigenous people and their allies engaged in public rallies, flash mobs, marches, and occasional blockades that disrupted highway and rail traffic. Media exposure and public interest in the movement known as "Idle No More" (sometimes also referred to as "Canada's Native winter" in a nod to the "Arab spring" events) reached its 
peak in mid-J anuary with events leading to high level talks between a delegation of First Nations leaders and the nation's Prime Minister and senior cabinet members. These events became the focus of international attention, drawing support and media coverage of environmental and Indigenous issues around the world while encouraging parallel rallies and protests in the United States, United Kingdom, Australia, and several other places. While the outcome was somewhat anticlimactic-entailing a commitment by government leaders to hold further talks to recognize and modernize the terms of historical treaties signed between First Nations and the crown (represented by Canada's Governor General, who met separately with members from the First Nations delegation)-the entire scenario played out as political theatre that alternatively captivated and puzzled much of its audience.

These events, and the debates and controversies surrounding them, drew attention to many profound issues associated with the status and conditions of Canada's Indigenous people. Adding to a long series of grievances and frustrations about inattention to longstanding problems, concerns were mounting that recently announced government policies that could further undermine conditions in many Indigenous communities were implemented without measures to secure adequate representation and dialogue with members of these communities. In the tense and uncertain build-up to the top level meetings, attention was focused especially on a high profile hunger strike led by Theresa Spence, a Chief from a northern Ontario First Nation community seeking action to address poor housing conditions, lack of running water, inadequate sewage, and other major and longstanding problems. While the media focus and surrounding public conversations about the movement heightened awareness of matters about which many Canadians had little knowledge, they also drew attention away from or distorted and misrepresented many of the core issues as participants with diverse interests came to position themselves through attempts to set the agenda or steer developments in ways that aligned with their own interests. The specific origins of the movement called Idle No More lay with concerns about broader contemporary fiscal and environmental issues relevant to Indigenous and non-Indigenous people alike, but the roots of the movement extended back several generations.

The I dle No More movement is significant for giving focus to the complex phenomenon of social inclusion and its implications for Indigenous people in the Canadian context. In particular, the challenges to define and achieve what it means for Indigenous people to maintain Indigenous rights (formally defined as Aboriginal rights in Canada) as well as their identities as Indigenous people while gaining meaningful participation in the political, social and economic life of the Canadian nation take place within a multidimensional and often highly volatile landscape. This paper explores the emergence of and public reactions to the Idle No More movement as both a response to processes of exclusion that have posed historic and contemporary limits to the opportunities available to much of the Indigenous population to become fully incorporated into Canadian society and as a struggle by diverse groups and interests to redefine and re-establish the bases on which such inclusion may be achieved.

It is crucial to locate processes of inclusion and exclusion, in these respects, within a framework that takes into account practices and legacies associated with colonization as well as the struggles to define and realize the distinct legal status and rights of Indigenous people. This means that, while attention needs to be given to problems associated with full inclusion of much of the Indigenous population with respect to conventional indicators such as education, housing or employment, several distinctive features of the Indigenous experience require a more nuanced understanding than can be offered through conventional discourses and objectives related to inclusion. Full and equitable inclusion within Canadian society cannot occur without fulfilling the nation to nation relationship between Indigenous people and Canadian governments outlined in historic treaties and subsequent legislation. In presenting our analysis, we draw from and contrast alternative discourses presented by Indigenous scholars, elders, and community representatives, government documents, and representations of Indigenous people and Idle No More in mass media and popular accounts. We adopt elements of Pierre Bourdieu's analytical framework, highlighting especially how the diverse places occupied by Indigenous people within Canadian society are influenced by symbolic violence and interactions influenced by unequal allocations of social, cultural and economic resources and power. Inclusion, understood in this way, requires awareness of the diverse and often contradictory realities and significance associated with the Indigenous experience within the Canadian context. We acknowledge the contemporary dimensions of Idle No More as a fluid, dynamic social movement which is, at the same time, deeply connected with the quest to validate and realize longstanding notions of Indigenous justice and law. We begin with a description of the roots and aims of the Idle No More Movement, understood from Indigenous perspectives, before proceeding to more detailed analysis of the various forms of social exclusion and struggles for inclusion in the Canadian context.

\section{I dle No More Roots and Aims}

The Idle No More movement is widely interpreted to be a contemporary movement. However, while the movement of that specific name is relatively recent, it is grounded in longstanding historical roots located within struggles to define and maintain Indigenous identity and foster effective Indigenous nationhood [1]. Its core vision is articulated in terms of objectives to work with 
allies to recognize First Nations sovereignty and nationhood and to employ an effective nation to nation relationship to foster social justice and protect the environment and lands in a respectful way [2].

It represents much more than the events and activities taking place under that specific label. Its most immediate roots lie with an initiative undertaken not by formal Indigenous leaders, but from unofficial leadersthree Indigenous women and one non-Indigenous woman in Saskatchewan-in the course of discussing how their concerns about recent measures hidden in massive budget legislation could be translated into action. Their stance against provisions contained within Bill C-45 (a massive piece of supplementary budget legislation introduced to Parliament by Canada's federal government in early 2012), communicated through social media and connections among communities, awakened the people and alerted them to commitments to fundamental responsibilities.

The movement is important because it is rooted in old Indigenous laws that speak of our duty to protect the water and land for the future generations. It marks the re-awakening of an Indigenous tradition and culture grounded in respect for the environment, fostering resistance to the kinds of exploitation of land and water conveyed through many of the terms of Bill C-45. The legislation is widely described and denounced by critics as an omnibus budget bill because it contained, in addition to fiscal provisions, an extensive series of changes to more than sixty federal acts and regulations, including the Indian Act and other legislative provisions that affect lands and resources in Indigenous territories. The Bill, as suggested in its title, The Jobs and Growth Act, 2012, prioritizes the government's commitment to economic initiatives in part by removing what it considers barriers to development [3]. Many of the provisions of the legislation, including those that affected Indigenous people and their lands and resources, appeared, without prior notice, embedded within a comprehensive 450 page document. The changes and the manner in which they were imposed by the federal government violated principles of consultation and relations with the environment fundamental to Indigenous rights and heritage. Although significant in its own right, the legislation reinforced a pattern in which the government has ignored more formal obligations, including those specified in Articles 19 and 32 of the United Nations Declaration on the Rights of Indigenous Peoples to consult and cooperate with indigenous people in order to secure their free and informed consent prior to implementing legislation or undertaking projects that may affect Indigenous people or their lands and resources $[4,5]$.

Idle No More has provided a focal point that enables contemporary Indigenous people and their allies to connect with an aspect of Indigenous culture that signifies a heritage designed to respect the environment and to prevent others from devastating the natural world. Within the context of Indigenous law,
Indigenous people are unique in that they are distinct nations (recognized formally as First Nations) within a Western State who have their own consciousness of law. The Indigenous way in this law entails a reciprocal relationship with the earth, water, plants and animals; the terms of Bill C-45, by contrast, are contrary to these relationships, marking only one of several instances in which the current Canadian government has ignored the reality of those laws.

Perhaps one of the important aspects of Idle No More is the support it has received from social justice advocates, environmentalists and other groups. Social media enabled the movement to gain rapid momentum and widespread exposure while mobilizing large gatherings for many of its events. It may not be surprising to find support from concerned environmentalist and social justice advocates, but it does also suggest deeper commitments that link social and ecological justice proponents with other dimensions of Indigenous struggles signified by Idle No More. I dle No More and its supporters believe that it is in humanity's best interests to protect the water and land, a struggle that entails related support on broader fronts including Indigenous nationalist struggles for autonomy, struggles to uphold Indigenous laws, and struggles for social, political and economic justice.

For Indigenous people, Bill C-45 represents a form of ongoing colonialism. Idle No More is both a specific movement and an awakening to re-engage in the ages-old resistance against colonialism and imperialism. Intrinsic to that awakening is the people's sense of Indigeneity and humanity that emerges from the recognition that Bill C- 45 contains provisions that are likely to extend a colonial legacy in which Indigenous people have encountered numerous forms of oppression and inequalities. Based on most conventional indicators of social inclusion, much of the Indigenous population is among the most highly excluded and disadvantaged groups in Canada. Poverty rates among Indigenous people, overall, and especially among First Nations people living on reserves, are well above comparable levels for the population as a whole, as are incidences of other frequently-observed risk factors like unemployment, low education, poor health conditions, chronic illness and injury, suicide rates, and incarceration [6-8]. While the government has portrayed its resource-focused economic agenda as one that promises benefits from exploration, mining for oil and gas, and so-called development in Indigenous territories, there is extensive evidence to demonstrate that these benefits have not been experienced or shared equitably with Indigenous people and their communities [9].

The sections that follow will situate these issues in the context of historical factors and contemporary struggles in which social exclusion experienced by much of Canada's Indigenous population has fostered diverse understandings about and strategies to achieve meaningful inclusion. We examine the Idle No More movement within the framework of a relational under- 
standing of social inclusion, drawing from both western social theory and Indigenous perspectives in order to take into account relations of power, inequality and discourse as advanced through a relational understanding of social inclusion and exclusion.

\section{Socio-Legal Differentiation and Canada's Indigenous Population}

Before we continue the analysis, it is important to acknowledge several factors that have contributed to various forms of differentiation between Canada's Indigenous and non-Indigenous populations as well as within the Indigenous population. Indigenous people occupy various social positions, based in part on their distinct status (officially defined as Aboriginal people) in relation to non-Indigenous populations and with respect to specific categories of Aboriginal people within the nation's constitutional and legislative frameworks. Treaties signed with the British Crown prior to Confederation in 1867 and continuing to 1921, and subsequent comprehensive claims agreements (or "modern treaties") with the federal government, acknowledge the sovereignty of First Nations, as well as some Métis populations (mixed Indigenous and European heritage groups) and outline specific obligations of both parties to the treaties. The Indian Act and related legislation further defines "Indian" status and outlines rights and responsibilities related to those with Indian status, designating roles for the federal government in key areas, including education, social welfare, and health care which fall within areas of provincial jurisdiction for the general population. The Constitution Act (1982) and Charter of Rights and Freedoms further defines and reinforces rights for three groups of Aboriginal people, classified as First Nations, Métis, and Inuit. Many aspects of these legal definitions, including who is covered within them and what entitlements or obligations they carry, are subject to periodic contestation and revision. Frequent court challenges, political negotiation, and public protest have arisen for various reasons in efforts to clarify and resolve issues related to Aboriginal status (the terms and conditions of many treaties were violated or not honoured in practice, for instance, while negotiated treaties did not originally cover many Indigenous territories within Canada, leading to more recent land claims agreements and settlement protocols; there are also disparities and inconsistencies in the definitions, entitlements and responsibilities associated with distinct status groups). Resolution of these issues is further complicated by questions about who has the authority to represent, make decisions about, and provide programs and services for and on behalf of particular Indigenous groups. Gaps or inadequacies in key service areas, such as child and family welfare, education, public sanitation, and housing, have often been perpetuated for years because of federal and provincial disputes over which level of government is responsible for indi- viduals and families living in non-reserve or urban areas. More recently, Indigenous groups and other observers have identified inequalities in levels of funding and service provision as responsibilities have been devolved from federal government to First Nations jurisdiction. Compounding these issues, the Indian Act and other policies imposed European models of governance over First Nations living on reserves or affiliated with tribal agencies, creating structures of band and tribal government that ignore and sometimes conflict with longstanding patterns of governance and decision-making within Indigenous communities. These diverse categories and relationships have resulted in the emergence over time of several distinct organizations in which particular configurations of Indigenous populations are represented at band, regional, provincial and territorial, national, and sectoral levels, not all of which are recognized equally by one another or by federal government officials.

All of these factors mean that questions about what is meant by social inclusion, at what levels inclusion is to be achieved, and under whose terms or claims the meaning and nature of social inclusion comes to be understood, are likely to produce responses or outcomes that are highly uncertain, contested, and varied. The discourse of inclusion itself carries mixed significance for Indigenous people given their experiences with colonization and policies that have undermined their positions within Canadian society as well as their concerns that proposals to dismantle the Indian Act and related legislation could pose threats to the recognition of Indigenous knowledge, rights and status (see, e.g., $[8,10]$ ). Because of Canada's "long history of deeply entrenched racism," wrote the late Howard Adams, a prominent Metis scholar, "White supremacy, which had been propagated since the beginning of early European imperialism, became woven into Canadian institutions such as the church, the schools and the courts" [11]. In addition to divergent understandings concerning the implications of incorporation into dominant social institutions, there are many differing perspectives within Indigenous communities and among Indigenous scholars on the definition of and strategies to achieve Indigenous sovereignty within a nation to nation arrangement, especially in a global context in which the very meaning of nationhood is being challenged (see, e.g., [12-16]). Idle No More, in the search for common ground on many of these positions, reveals in the process the many paradoxes and contradictions also associated with these issues.

\section{Social I nclusion and the Production and Reproduction of Social I nequality}

A focus in both academic literature and policy analysis on questions related to social inclusion has drawn attention to the challenges posed by social inequality and the social, economic, and political consequences 
of social hierarchies within highly developed nations. Goals to achieve socially inclusive societies, along with related objectives to foster peaceful interaction, mutual recognition, and respectful dialogue, have a universal appeal ([17], p. 1). However, there are sometimes dangers that as policy discourses and instruments are realigned towards a focus on inclusion and exclusion rather than equality [18], priority is given to political containment and crisis aversion rather than to the true needs and aspirations of many segments of the population. In Canada, the predominant orientation to problems of social exclusion and inclusion within recent social policy has shifted from a liberal welfare state in the direction of what Banting ([19], pp. 419-423) calls "dis-embedded liberalism" representing a refocusing of policy emphasis away from measures to optimize income security for citizens and towards incentives driven by labour market participation and human capital development. These trends parallel a broader reframing of government activity in western welfare states from social expenditures to fiscal constraint and productive investment in productive enterprises while acknowledging the insecurity and disruption produced through globalization and market liberalization [18,20,21].

Federal, provincial and territorial governments in Canada have adopted numerous policy-related measures consistent with these liberal economic tendencies. Recent federal government policies have pushed this further by highlighting an economic agenda dominated by aggressive investment in profit-oriented activities, especially in oil and gas extraction, mining and other resource industries (see for example [22]), while restricting coverage of and eligibility for various forms of social assistance, restricting or realigning expenditures in education and other areas, and imposing demands for greater fiscal accountability in First Nations and other agencies to which government funds are transferred.

In order to offer an adequate understanding of how processes of social inclusion and exclusion are relevant to Indigenous populations in Canada, it is crucial to adopt a more nuanced conception of inclusion that takes into account Indigenous perspectives on knowledge and social engagement. This requires attention not simply to particular segments of the population that come to be posed as most vulnerable to marginalization and the consequences of such exclusion, but more importantly to how such exclusion and the inequalities in which it is embedded come to be produced and maintained within the social alignments and discourses that are the object of inclusive policies.

\subsection{Inclusion, Exclusion and Fields of Social Struggle}

Pierre Bourdieu's conceptualization of social life posed as fields of social struggle offers useful analytical tools that are compatible with a relational understanding of social inclusion $[23,24]$. It offers a way to address some of the conceptual and political issues not fully elaborated within some of the most widely adopted understandings of social inclusion in a manner that is compatible in significant ways with Indigenous experiences and perspectives on inclusion and inequality. Bourdieu draws attention to the observation that, while processes of social differentiation tend to foster hierarchical social structures that are relatively stable over time, these outcomes are neither strictly preordained nor based on the designs of any particular group. Bourdieu is especially concerned to explore how social actors located in specific social settings or locations position themselves to pursue the kinds of economic, social and cultural resources that are most highly valued within a given field, or domain of social life, while they are also engaged in defining the boundaries of the field and shaping the terms and conditions, or "rules of the game" by which the field is regulated.

Bourdieu's analysis, in common with the sociological exploration of social inclusion, was initially oriented to an understanding of the peculiar characteristics of modern French society, before being extended and adopted in a wide range of social contexts. However, whereas this analysis of social inclusion was rooted in Emile Durkheim's emphasis on social integration fostered by individual adaptations to the normative and performative obligations of the social order, Bourdieu's analysis of social fields focuses more fully on conflict and power relations, posing a more radical critique that suggests the way to new social possibilities (even if his work offers relatively limited guidance as to how things might become otherwise). The Durkheimian approach, allowing room for a soft critique of capitalism's worst consequences without calling for radical societal transformation [25], has tended to give way to an analytical looseness that has attracted an affinity especially among those promoting a "new" politics emphasizing a coalition of interests through the emergence of a middle or "third way" alternative to more radical left and right orientations. Social inclusion, in these policy discourses and orientations, is a matter of public concern largely because of its implications for problems of social cohesion and integration in a world in which global competition has potentially undermined longstanding loyalties to communities and nation-states. Inclusive strategies seek to reach, and reshape as productive citizens and workers, those individuals or groups deemed to be marginalized or disadvantaged within existing structural arrangements or whose economic and social status has become vulnerable in the course of dislocations produced by changing socioeconomic contexts $[25,26]$. While these discourses are often linked with genuine concerns to extend social justice and economic opportunity across the population, they also foster a temptation to pathologize risk and focus on exclusion as a consequence of the deficit inherent in those individuals or groups who are most vulnerable or at-risk. The terms and conditions under which exclusion and inclusion are determined are 
most likely to be established by those in positions of institutional or structural privilege rather than by those who are deemed to be excluded.

\subsection{The Symbolic Violence of State Policy}

State policies and related discourses help to frame national orientations to important spheres of activity, but they can also conceal and reinforce significant inequalities and interests. The dominant Canadian orientation to inclusion for Indigenous people, represented in the policies and pronouncements of the federal government as well as many provincial governments, is focused strongly on labour market integration. As a budget-related document, it is not surprising to see an economic focus in Bill C-45, but the implications of the legislation extend well beyond fiscal factors at the same time as other policy domains are defined predominantly in terms of economic interests. With respect to education, for example, Canada's Department of Aboriginal Affairs and Northern Development stresses that "The Government of Canada's overarching goal is to provide First Nation students with quality education that provides them with the opportunity to acquire the skills needed to enter the labour market and be full participants in a strong Canadian economy" [27]. This is a worthy goal but it cannot be achieved without a deeper understanding of, and action to address, the significant historical and contemporary factors that have made it difficult for many First Nations people to attain such skills. The language of full participation and equal opportunity, as posed in such policies, is not far removed from earlier policies of assimilation and cultural displacement, while failing at the same time to acknowledge the fundamental rights, traditions, and forms of knowledge that are essential to the achievement of the kinds of autonomy and identities essential to realize effective Indigenous nationhood.

This reduction of social complexity through a statemandated fiscal discourse represents what Bourdieu characterizes as symbolic violence with reference to the capacity within dominant groups or classes to impose meanings and assert them as neutral and legitimate while concealing the power relations through which they are asserted [23]. These processes, Lamont and Lareau ([28], p. 159) emphasize, contribute to social exclusion by monopolizing access to privileged positions and resources, representing "a power of legitimating the claim that specific cultural norms and practices are superior, and of institutionalizing these claims to regulate behavior and access to resources."

Social inclusion and exclusion are not marked by simple entry points into clearly defined or bounded statuses or positions; rather, they represent shifting reference points within and across particular social realms ([29], pp. 48-50). Bourdieu ([23], pp. 31-32) employs the notion of fields in sociological analysis in order to highlight how social inequalities may be reproduced over time within social structures that are nonetheless constituted by ongoing processes in a dynamic, fluid manner. These processes involve social participants who occupy distinct positions or social locations within various spheres of life, and who engage in both strategic actions and unconscious choices influenced by their positions in conjunction with particular configurations of social, cultural and economic resources upon which they are able to draw. Such resources, in turn, include not only material factors but also particular predispositions (forms of habitus) that include tacit knowledge as well as direct insights that influence their capacity for success in a given field. Each form of habitus is constituted by deeply engrained perceptions and understandings internalized though experience and socialization, especially in early life, but also cultivated through subsequent social positions or locations.

These differential positions and dispositions give rise to various, sometimes changing, alliances and oppositions as social participants within a particular field seek to define and pursue various types of objectives. In politics, law, education and other significant social fields, the meaning and nature of Indigenous identity and nationhood are themselves contested, at times within the Indigenous population as well as between Indigenous representatives and non-Indigenous groups. The diverse social positions and the varied experiences Indigenous people have had in relation to policies and practices associated with colonization, for instance (such as whether they or their family members attended residential schools, had treaty status, or resided on reserves), have contributed to the development of very different orientations to issues related to indigenous identity, rights and other crucial matters. Critics who pose frequently cited questions like "What is it that Indigenous people want?" or "Why can't they get their acts and lives together?" are missing the very straightforward reality that the Indigenous population, like the wider society of which it is part, is heterogeneous and changing, but it is also a product of a complex cultural and colonial heritage $[30,31]$.

Successful engagement within a given social field depends on having the appropriate predispositions, or habitus, required to negotiate the social relationships and understandings considered essential or legitimate within that field. While these may appear to be neutral or inevitable characteristics of given domains of social life, they are products not only of the positions people occupy within a specific field, but also of the capacity that people in those positions have to determine the boundaries, relationships and rules that define the field. The field of power is unique in that it overlaps with, and helps configure, all other fields, including the capacity to shape how different forms of capital may or may not be converted into one another. It is, Bourdieu ([23], p. 4) emphasizes, "the space of the relations of force between the different kinds of capital or, more precisely, between the agents who possess a sufficient amount of one of the different kinds of capital to be in 
a position to dominate the corresponding field, whose struggles intensify whenever the relative value of the different kinds of capital is questioned."

This conceptual framework is instructive for understanding the status and political aspirations of Indigenous populations in Canada. Indigenous people, widely portrayed in policy documents and social analysis as representing some of the most disadvantaged groups within Canada, have also long promoted visions of self-determination that are not confined to western or European-based notions of representation, integration and success. They encompass, through their heritage, contemporary status and aspirations, diverse predispositions, or forms of habitus through which they orient themselves to particular forms of capital, that combine deep cultural values that are aligned in disparate ways with dominant institutional practices and values, especially when understood in the context of Canada's dark colonial history.

These complex factors have helped to shape the Idle No More movement, which has provided a way to unite Indigenous people through a phenomenon that fosters opportunities for them to articulate their distinct status as Indigenous people in relation to demands associated with membership within the Canadian nation while solidifying their identity through connections with their Indigenous heritage. However, representative of diverse social positions and political aspirations represented among Indigenous populations, Idle No More has also been characterized by a variety of different, and sometimes conflicting, aims and orientations. Its proponents have articulated clearly its vision to serve as a socially and environmentally responsible grassroots movement dedicated to democratic practice and principles, but it has sometimes had difficulty establishing a clear public identity because so much of the media attention and external commentary has focused on actions of political leaders as well as more confrontational events, such as periodic blockages of transportation routes or industrial sites [32].

\section{Indigenous J ustice and I dle No More}

In the most general sense, recognition of Indigenous laws and culture, which are vital components of the Idle No More movement, provide a means by which to demonstrate alternatives that may be posed to current official policy directions. The basic cultural orientations of the movement are: a vision to protect the land and water that leads to sustaining rather than exploiting the environment; values that promote peace and social harmony; and the attribution of a social justice dimension that includes rather than excludes the community.

Idle No More expresses Indigenous nationhood in its broadest sense, interpreted as a community of Indigenous people who share a common culture, values, history, and traditions including cultural teachings and the justice practices that permeate Indi- genous communities. The purpose of Indigenous law, as Yazzie and Zion emphasize, "is not a process to punish or penalize people, but to teach them how to live a better life. It is a healing process that either restores good relationships among people or, if they do not have good relations to begin with, fosters and nourishes a healthy environment" ([33], p. 160). Commitment to sustaining a healthy environment is basic to Indigenous laws. Such laws, also called teachings, are the cornerstone of I dle No More.

According to the Cree Elder Dennis Thorne, the creator gave to Indigenous people laws to live by that were based on selective values and teachings, such as reciprocity, sharing and respect. The Indigenous laws and culture are as expressed by Dennis (cited in [34], p. 166):

I have to look at the foundation of our laws. When the creator first put the Indigenous people on this earth no matter what nation or what country they were given laws to live by. According to the Cree and the First Nations in Canada they were given a way of life they were given instructions on how to live they were given responsibilities on how to look after the land, the animals, and the water. You may hear some elders say that they were stewards of the land. What they mean is they made an agreement with the animals a long time ago. In the time when they could communicate with the animals they spoke the same language and the animals said that they would give their lives to us to eat if we respected them and looked after them. To give something back, the first hunt the first kill, whether it was animals or fish, the four legged to give something back in order to respect the life that they gave.

Dennis refers here to the spiritual connection to the land: "they were given laws to live by", and also points out the responsibility Indigenous people have to "look after the land, the animals, and the water", also indirectly illustrating the importance of protecting the environment. Dennis maintains that:

Today is a big issue about environment. There wasn't from our thinking that the environment turned out the way it did. It was from another way of looking at life and other worldview that is not ours so today we all have to suffer. And if we take another look at our laws I think we can help them understand that our laws are not based on greed... Ours is based on good health, help, understanding and happiness. Our laws are for those four things only, for the survival of the people, for the survival of medicines, the survival of animals, the winged ones. So these laws are not only to protect the earth, but all humans all life (cited in [34], p. 167).

Subsequent notions pertaining to the environment reveal that Indigenous laws have invariably influenced Idle No More as the guiding principles behind the movement. 
J ohn Martin, a prominent Elder from Northern Manitoba, observes that Indigenous people have a different law that is in harmony with nature:

There are two laws, the law of nature with the creator and the law of manmade. Anything that has to do with nature we know we have to be careful in how we conduct ourselves, how we treat people, anything like that in how we treat it...You see in life, in our way, which we are as a person, I am a Cree they say, but for me the word Cree doesn't mean anything to me. Being Inninew, I am a four directions person. That's what it means, Inninew it means four, I have my mind, my body, and also I have a spiritual being, I have feelings (cited in [34], p. 163).

This passage by Elder John Martin demonstrates the cultural responsibility that Indigenous people have to respect the laws of nature, that is, corresponding to the laws of the creator and to our commitment to conduct ourselves for the benefit of all existence. The way to this declaration is through our own identity and culture. The language of the Inninew (Cree people), in common with that of other Indigenous people, is crucial to understanding one's identity. The Cree word, Inninew (Cree people) for example, connotes a holistic understanding of identity. John explains that Inninew translates as 'a four directions person'-the mental, physical, spiritual and emotional human domains.

For John and Dennis, Indigenous laws and values are such that the environment is to be sustained out of respect for the future unborn, therefore speaking to a culture that espouses a deep connection to the land; the connection is manifest in responsibility to serve as "stewards of the land", a philosophy that has survived to the present day. This connection to the land is a core part of understanding the Idle No More movement, which is guided by traditional teachings in its more specific resistance to the omnibus Bill C- 45 passed by the Conservative government. In short, the Indigenous world has not forgotten its cultural laws and values, despite the fact the Indigenous people have experienced several generations of imperialism.

While Idle No More was initiated through Cree understandings of law, respect for the environment and cultural values, its rapid expansion across communities throughout Canada and beyond speaks to these deeper responsibilities. According to the Chickasaw law scholar James Youngblood Henderson, Indigenous societies established a holistic law system that was grounded in the ecosystem. He writes:

Most Aboriginal orders do not impose order on relationships by establishing rules that govern general categories of acts and persons and then using these rules to decide particular disputes. Instead they determine that harmony; trust, sharing, and kindness are the shared ends of the circle and then make choices that contribute to these goals...Aboriginal laws are more about respect for every process in an ecosystem than about power over them. Aboriginal law is the law of speaking softly, walking humbly and acting compassionately ([35], p. 273).

The holistic understanding of Indigenous laws embraces the ecosystem and the premises of harmony, reciprocity and trust, which encourages the people to protect the environment. In the Indigenous laws, therefore, wholeness is present that designates respect for nature and forms the basis of Idle No More.

These non-western conceptions of justice and law are linked with struggles that are prompting new understandings about what it means to be Indigenous in a Canadian context. One of the strengths of the Idle No More movement has been its capacity to foster greater understandings of identity and cultural relationships while reinvigorating Indigenous knowledge systems that have been undermined and devalued through colonization and subsequent policies and institutional frameworks. Connection with this cultural heritage provides a crucial basis for the recognition of Indigenous social and cultural resources that represent, in a Bourdieuian sense, forms of capital that are essential both as foundations for Indigenous identity and as resources in the struggle to establish alternatives to dominant economic and political directions in which Indigenous people and their interests have been largely subordinated despite official renouncement of the colonial past.

\section{Colonialism Past and Present}

Although Eurocentric historians and sociological theories of development typically interpret colonization as bringing progress and benefit to backwards and inferior people, in reality colonization brought great harm to Indigenous families and communities. Elizabeth Comack notes that "European colonizers to take control over the lives of Aboriginal people involved a number of strategies, including the signing of treaties, the Indian Act, the residential school system, the North West Mounted Police played an instrumental role in carrying out this colonial project or civilizing mission" ([36], p. 73). Employing Bourdieu's concepts, the colonial project was oriented to modifying the prevalent forms of habitus or dispositions within the Indigenous population while repositioning Indigenous people relative to newcomers and authorities within social and economic structures. Processes that served to devalue and subordinate Indigenous knowledge and cultural resources coexisted with policies and practices that were exclusive in nature, producing significant inequalities or barriers to advancement with respect to education, employment and other significant fields of social, economic and political life.

From mainstream perspectives, the era of colonialism may have ended between the late nineteenth 
and mid-twentieth centuries, when former British colonies such as Canada, New Zealand and Australia were granted independence. Indigenous peoples, though, remained under colonial rule. Yazzie notes that, "the original inhabitants of those lands, Australian Aborigines, Maoris of New Zealand, and the First Nations of Canada, did not get their independence" ([37], p. 43). Although post-colonial discourse claims that colonialism is a thing of the past, Indigenous thinkers recognize that colonialism is being continuously reproduced in various forms. Indigenous people have experienced hundreds of years of imperialism and social exclusion, resulting in a legacy with respect to outcomes and social practices that have been perpetuated to the present day. Comack observes that "colonialism has produced the social and economic marginalization of Aboriginal people in contemporary Canadian society" ([36], p. 81). Canada's Truth and Reconciliation Commission, established by the federal government in 2008 in order to investigate the activities and impact of the residential school system that delivered education to many Indigenous children and youth in Canada for over a century beginning in 1883, portrays the system as a colonial "assault" on Indigenous children, families, culture, leadership, and selfgovernance that continues to shape people's total life experience in communities across the nation ([38], pp. 25-26). The commissioners emphasize that it is not sufficient to know how "the schools were central to the colonization of the Aboriginal peoples of Canada", but, more fundamentally, we need to recognize that "the colonial framework of which they were a central element has not been dismantled" ([39], pp. $2-3)$. The passage and implementation of the terms of Bill C- 45 by the federal government in 2012 without consulting Indigenous nations represents further the processes of colonialism and social exclusion referred to by the commissioners. It is in this context that, from an Indigenous perspective, Prime Minister Stephen Harper's initial reluctance to meet with Chief Theresa Spence and acknowledge her demands represented further distancing between government and Indigenous positions reinforcing the exclusion of the latter. Such unilateral decisions to dismiss or exclude the Indigenous community while attending to other positions are taken as typical of colonial power relations that result in reproducing the marginalization of Indigenous people and communities.

In contrast to and in direct violation of Indigenous principles of law, the history of Western colonialism saw imperial states increase their power by imposing their laws on the Indigenous societies of continents outside Europe. A major manifestation of increasing State rule over Indigenous people in Canada was the criminal justice system. In her analysis of Canada's Indigenous justice system, Sutherland demonstrates that Western laws were used to subjugate and control Indigenous people:
Any resistance to these laws were made illegal and contributed to eroding indigenous political structures... it was illegal for First Nations people to go to court to sue the Government of Canada without previous permission from the government ...Some laws and policies were directed at the heart of First Nations' culture and spirituality. For example gatherings such as potlatches were outlawed while Christmas celebrations were encouraged...It was illegal to practice traditional healing...When attempts to disrupt economic, political, and spiritual infrastructures did not sufficiently assimilate 'Indians' children became the targets ([40], p. 6).

The passage demonstrates the role played by imperialistic Canadian laws to colonize Indigenous people who had no legal recourse to protect and maintain their culture. Since all power was placed in the colonizers' domain, Western state powers systematically overwhelmed Indigenous nations and denied them their most basic human rights. Such domination served not only to exclude Indigenous people from key spaces within the core fields of public life, but was also maintained by forms of symbolic violence that failed to acknowledge Indigenous knowledge and imposed new expectations about Indigenous identity, or habitus, within a Western framework.

\subsection{Shaping Indigenous Claims and Identities by Erasing Indigenous Memory and Nationhood}

Henderson shows how Canadian laws have been used to marginalize and exclude Indigenous people, observing that, "in Canadian thought, for example, Aboriginal nationhood, rights, and treaties are banished from mainstream culture and law and replaced by the theory of two founding nations: the English and the French" ([35], p. 65). Such social exclusion is typical of colonial practices that omit Indigenous contributions. He emphasizes, further, that colonizers aim to "obscure Aboriginal memory. To strip Indigenous people of their heritage and identity, the colonial education and legal systems induce collective amnesia that alienates Indigenous peoples from their elders, their linguistic consciousness, and their order of the world" ([35], p. 65). We explore the erosion of Indigenous memory and the symbolic violence these processes represent with reference to examples drawn from the fields of education and criminal justice, but these domains are embedded within a much broader set of dynamics. Nobles, for instance, observes with respect to state apologies for historical injustices that such actions seek to "alter the terms and meanings of national membership," thereby contributing to prospects for a more inclusive society [41]. These terms, nonetheless, are highly contested and linked to processes that, while reframing historical memory, can also reinforce or foster exclusion in other respects.

The Idle No More movement and the widespread 
support it has received is indication that Indigenous memory still exists. Whereas Bill C-45 illustrates how colonization continues in practice, if not in name, the response it has generated in the form of Idle No More suggests a move towards reclaiming the terrain on which postcolonialism may be established. Yazzie observes that:

Postcolonialism will not arrive for Indigenous peoples until they are able to make their own decisions. Colonialism remains when national legislatures and policy makers make decisions for Indigenous peoples, tell them what they can and cannot do, refuse to support them, or effectively shut them out of the process ([37], p. 43).

Similarly, Smith advises, "Many indigenous intellectuals actively resist participating in any discussion within the discourses of post-coloniality. This is because post-colonialism is viewed as the convenient invention of Western intellectuals which reinscribes their power to define the world" ([42], p. 14). In this context, Idle No More as a response to the Conservative government's Bill C-45 that represents, in the face of recurring broken promises by governments to engage in meaningful consultation with Indigenous people on matters that concern their land, communities and people, yet another unilateral decision that excludes Indigenous people and perspectives. Idle No More is the manifestation of resistance to colonialism.

\section{Social I nclusion and I ndigenous People in Canada}

In contrast with Europe and many other contexts, the language of social inclusion has not been employed widely beyond adoption by a few government departments and non-government organizations that work with federal and provincial agencies in Canada. Regardless of the discourse employed, however, federal, provincial and territorial governments are engaging in an extensive range of action plans in response to serious problems confronting Indigenous populations across the nation. An ongoing series of inquiries, studies and official documents, both before and after the wide-sweeping Royal Commission on Aboriginal Peoples produced its five volume report in the mid1990s, has drawn attention to the pressing need for action on numerous fronts. Collectively, these reports reveal Indigenous populations have a high degree of being excluded with respect to virtually every dimension around which social inclusion and exclusion is considered significant. Demonstrated concerns and calls for action in Indigenous communities correspond, for instance, with each of the factors associated with exclusion identified by Atkinson and Marlier in a report for the United Nations relative to both core indicators (encompassing income and material deprivation, productive role, education status, health, and housing conditions) and social factors (including access to rights and realms such as social and political participation, civil rights, security and justice, well-being, information and communication, and mobility, leisure and culture) ([43], p. 40).

There are several dangers, nonetheless, in approaching these issues too narrowly in terms of deprivation, disadvantage and exclusion. A deficit orientation, while drawing attention to many areas in which urgent action is necessary in order to alleviate pressing material and social needs, is limited insofar as it fails to take into account alternative ways in which success, capacities and inclusion may be understood, ignoring, in the process, the forms of exclusion entrenched within the assumptions and processes by which indicators and outcomes associated with inclusion come to be defined and sustained.

The sometimes perplexing and confounding politics and activities associated with the Idle No More movement are an expression of these complex relationships. As the preceding discussion of colonialism emphasizes, the Indigenous experience in Canada has frequently encompassed social inequality, racialization and social exclusion. The phenomenon of over-representation by Indigenous people in the criminal justice system, which has for several decades been the focus of periodic inquiries and reports by governments and other agencies in Canada, offers striking evidence of that exclusion. Since the colonization of the Indigenous world most Indigenous peoples living in colonial societies have experienced some form of social exclusion or racism. In an analysis of the concept of social exclusion, sociologist Elizabeth Comack, draws a parallel between Indigenous 'social exclusion' and 'colonialism.' There is extensive evidence of how discourses of colonialism, racism and social exclusion have been exhibited by the police, courts and others in the process of interpreting Indigeneity in accordance with racial constructs. Comack writes that, "Race and racism not only pervade the everyday lives of Aboriginal people, but also inform the wider public discourses and institutional processes...including the processes of law enforcement" ([36], pp. 13-14).

\subsection{Overlapping Layers of Social Regulation and Exclusion}

Indigenous people have been stereotyped as criminal types, lazy and inferior to the mainstream, and these gross distortions of Indigeneity are reflected in the phenomena of racialized policing. Comack, for instance, interviewed 78 Indigenous participants who reside in Winnipeg's North End or inner city. What she found in the participants' collective narrative was the commonly held notion that Winnipeg police officers have routinely racialized, degraded and dehumanized Indigenous people. Comack observes, "Aboriginal men are regularly stopped by police, sometimes on a weekly basis, and asked to account for themselves" ([36], p. 
210). The same racial stereotyping is demonstrated when police assume that Indigenous males are drug dealers or gangsters while Indigenous women are seen as prostitutes ([36], p. 25). In fact, participants reported that the police have referred to them in terms of 'squaw', 'dirty Indian', or 'fuckin Indian'. These kinds of insults are a powerful means of degrading Indigenous people. However, reinforcing the limited social and cultural capital to combat such symbolic violence, Comack's participants were powerless to do much about because Indigenous people are viewed as not credible and their complaints on police misconduct are not taken seriously.

The racialization of Indigenous people has invariably led to social exclusion from society's core institutions, including employment, education, housing, policing, and many other sites. Imperialism and racialization in the criminal justice system has been an important factor contributing to over-representation of Indigenous people in the justice system: its tools were the police, courts and racialization. The Canadian Criminal J ustice Association observes that Indigenous people, "especially in the north spend less time with their lawyers....are less likely to have legal representation in court proceedings...and they often plead guilty because they feel intimidated by court proceedings and want them over with" ([44], p. 38). These kinds of practices demonstrate that the criminal justice system treats Indigenous people as marginal and therefore helps to explain their over-representation in the prisons. A federal report released in 2012 reveals that Indigenous men and women are significantly over-represented in Canada's federal penitentiaries; according to Howard Sapers, Canada's ombudsman for incarcerated human beings, these proportions are expanding rapidly, especially in the Prairie Provinces where Indigenous people are most highly concentrated: "Of the growth, 52 per cent has come from the Prairies. It's the fastest-growing region in the country and aboriginal offenders account for most of the increase and account for 43 per cent of the offenders in that region" $[45,46]$.

It has been said of the prison system that it obstructs the potential for healing and therefore reproduces a cycle of crime. As Braithwaite advises:

Prisons are schools for crime; offenders learn new skills for the illegitimate labor market in prison and become more deeply enmeshed in criminal subcultures. Prison can be an embittering experience that leaves offenders more angry at the world than when they went in ([47], p. 1738).

For Braithwaite the prison experience develops crime skills and increases bitterness therefore it is not surprising that recidivism rates are high. To be more concrete, The Commission on First Nations and Métis Peoples and Justice Reform observes that "empirical evidence in the U.S., Canada, and Europe over the last 30 years shows longer sentences do not reduce recidivism" and "longer sentences may increase recidivism" ([48], pp. 9-41). The Commission goes on to state that "Canada is a world leader in incarcerating 118 per 100,000 general population" ([48, p. 9-41). In its tendency to remove people from community and social participation, especially in the absence of programs and initiatives to foster reintegration in the community upon release, it is clear that the criminal justice system does not advance social inclusion as a priority in its dealings with Indigenous offenders.

These patterns are consistent with what Michel Foucault recognized more generally as the failure of prisons in observing that "those leaving prison have more chance than before of going back to it; convicts are, in a very high proportion, former inmates" ([49], p. 265). Foucault maintains that the "prison cannot fail to produce delinquents by imposing violent constraints on its inmates; it is supposed to apply law, and to teach respect for it; but all its functioning operates in the form of an abuse of power" ([49], p. 266).

These phenomena represent more widely observed disconnections that Indigenous people often encounter between predispositions developed early in life, rooted in their family and cultural heritage, and those expected or expressed in relationships with dominant Canadian institutions. Even concepts related to social inclusion, rooted in Western epistemologies tend to diverge from discourses associated with Indigenous people and their experiences. Consequently, there are limits to the extent to which these concepts, and especially the methodologies employed to determine indices of social inclusion and exclusion, are able to encompass important dimensions of Indigenous people's realities. Responding to panel presentations at a conference on social inclusion in Canada, for instance, Inuit audience members observed particular actions or statuses in northern Indigenous social contexts take on different meanings than when interpreted from a southern, urban vantage point:

One pointed out that when Inuit drop out of high school, they often go out on the land and provide for their people in a valuable way, but this is not captured in the research. She added that Inuit are not highly represented in post-secondary education because going to a southern university is like going to a different country for Inuit-and because it is not their tradition for parents to provide for this education. The participants stressed that Inuit as well as other Aboriginal people must be a part of all policy, research and legislation [50].

This passage demonstrates that the formal high school education is irrelevant to some Inuit who drop out in high numbers in comparison to the mainstream. The Canadian middle class standards and ideals mean little to the practical life of the Inuit and other northern Indigenous learners. We would have to see that the basis of mainstream schools, which is to teach the language, values and culture of the colon- 
izer, at the same time treats the culture, language and ways of the Inuit as marginal. Therefore, it is not surprising that the Inuit youth see little connection between the subjects taught in the high school and their practical life in the community. In other words, the situation represents a mismatch between curriculum and Inuit society. In mainstream society education conveys learners' goals for employment and success. However, the Inuit youth see their responsibilities to provide for their people by going out on the land as more relevant than sitting in a classroom. Since they are concerned for the future well-being of their communities these Inuit youth drop out of high school. Understood in this way, the problem lies not so much with the youth as with the difficulties posed for them to identify with the education system provided by the colonizer and which has historically been used to force Indigenous people to deny their own culture and assimilate into the mainstream. Perhaps the youth just want to be themselves, that is, to live on the land and continue life as Indigenous peoples. In any case, many of the old people still teach the youth the importance of being able to 'walk in two worlds.' This is in part the foundation of a vision established over four decades ago in which Canadian First Nations articulated principles of "Indian control of Indian education" [51] in order to integrate the kinds of education required for success in the contemporary world with appreciation for the kinds of traditional Indigenous values and practices that might encourage youth to spend time on the land as part of a socially inclusive curriculum.

\section{I dle No More: Struggles to Reposition Indigenous Representations and Rights}

One of the paradoxical features of the Idle No More movement has been its capacity to forge strong linkages as well as divisions. Some critics have dismissed Idle No More as a form of Indigenous radicalism that is hostile to the interests of other Canadians. Although more sharply focused than the earlier Occupy movements in New York and many other cities, Idle No More has also exposed some parallel internal divisions and divergent interests among its participants. Much of the media attention was focused on Chief Theresa Spence, who initiated the high profile hunger strike (or low liquid diet), and the other formal leaders of First Nations organizations across the country who variously led or protested meetings with senior Canadian government officials. This exposure heightened the profile given to several important priorities and grievances within Indigenous communities, but it also fostered images of internal bickering, indecisiveness and hypocrisy. Information based on an audit requested by the federal government was leaked to media outlets suggesting that Spence and other band counsellors were highly remunerated at a time in which large amounts of band spending intended to address education, housing and other critical infrastructure needs were not adequately documented [52].

These developments have provoked extensive rhetoric across both mainstream and social media sites, often denigrating both individuals like Spence and Indigenous people more generally for their apparent sense of entitlement, irresponsibility, and lack of accountability. Comments like the following draw upon and reinforce stereotypical opinions concerning Indigenous people based on racialized assumptions using meritocracy as the standard.

[My] house doesnt rot because i take care of it because i worked for it. Not the goverments job. That reserve has recieves over $\$ 425$ million from the federal goverment and the mine there blocking. Calling people names and saying they dont understsnd doesnt do much to help your position (sic [53]).

There is nothing wrong with Bill C-45. Everyone calls for Accountability by the government but generally we as citizens forget we need to be accountable for our own lives. The Government's job is not to find you a job, feed your kids and buy you a house. It's [sic] job is to ensure our economy is strong enough for you to do that on your own [54].

It's all great that people want more, but generally people don't hold themselves accountable...Free giveaways will not help the country, we all have to do our part [55].

Stereotypes rooted in colonial power relations remain embedded with these comments, akin to the pervasive inequalities observed in the previous section regarding the criminal justice system. The denigration of Indigenous people as lazy, apathetic and indifferent both ignores and reinforces the impact of longstanding experiences of systemic discrimination and colonization. The racialized interpretations continue colonial practices ("blaming the victim", "divide and conquer") that criticize Indigenous people for their impoverishment while embracing the misguided premise that Canada is a meritocracy in which social and economic status are presumed to have little to do with race, class and gender in the reproduction of social inequality. Indigenous people are portrayed in these discourses as dependent on government largesse and are otherwise deserving of nothing else than the direction to take responsibility for their own "problems".

At the same time, Idle No More has fostered alternative discourses and social alignments. The highly charged racialized discourses have created opportunities to raise consciousness among Indigenous people and other Canadians regarding the impact of racism as well as the conditions which have fostered it. Idle No More is a movement that has been spurred and embraced most strongly by relatively young and articulate segments of the Indigenous population who are adept at integrating educational success and the 
powers of social media with experiences and lessons derived from previous generations. As a consequence, the core activities such as maintenance of a website and Facebook page and organization of public events are predominantly urban-based while the movement has been highly successful in mobilizing support from a wide spectrum of Indigenous and non-Indigenous communities. The spirit of the movement is perhaps best exemplified in the initiative undertaken by a group of young people who walked 1600 kilometres from their Cree community in northern Quebec to Ottawa in winter conditions to draw awareness to social conditions in Indigenous communities and reconnect with their land and heritage. The group, which began with seven walkers, had increased to as many as four hundred by the time it was greeted by thousands of cheering supporters on its arrival in Ottawa in late March. Some of the group members indicated that the walk had helped them address serious personal issues such as depression and suicidal thoughts [56]. The march also proved inspiration for many others across the nation, as reflected in blog commentaries on media reports such as the following:

I am impressed by these young people. What a journey! I love how they found a way to demonstrate their beliefs-it connects them to their culture (the route and way of traveling) and the land to their protest. It will have long term positive affects [sic] on their lives. I wish them all well and safe travels [57].

Congrats! All young should witness this courage, endurance and sense of community. I hope this experience showed them what great opportunities can lie ahead in this great land [58].

While not all comments were as supportive or positive, the initial responses suggest that educational moments have created opportunities to embrace a pathway towards the kinds of meaningful inclusion Indigenous people are seeking in the Canadian context.

\section{Conclusion}

Although the Idle No More movement seems to have disappeared from the media, it is in fact very much alive and vital in and beyond Indigenous communities. Idle No More has not disappeared but has demonstrated its deep roots as part of an established system of cultural teachings and values that advocate respect for the environment that has been continuously reproduced to the present time. Idle No more speaks of modern Indigenous interpretations of development that are rooted in the ideology of future wellbeing of succeeding generations. Indigenous peoples across Canada and their supporters in many nations openly protested against Bill-C-45 because of the importance of sustaining the environment within Indigenous cultures and knowledge systems, revealing Idle No More as a manifestation of Indigenous values and its fundamental teaching to take care of the land and water. The focal points for the movement, however, reach well beyond a single piece of legislation and the manner in which it was implemented.

We have discussed Idle No More with reference to diverse frameworks and bodies of literature, including the analysis of social inclusion, Bourdieu's concepts of habitus, field and forms of capital, and Indigenous conceptions of knowledge and justice in order to understand the potential implications the movement has for Indigenous people and for Canadian society. Inclusion has different meanings and implications for diverse populations, representing differential positioning within relations of power as well as in struggles to define and gain access to the kinds of social and cultural resources that influence the kinds of social, economic and political positions occupied by members of these populations. For Canada's Indigenous people, these issues have often been posed as making a choice or being forced to shed Indigenous identity and cultural roots or risk being marginalized, despite a legal framework that recognizes Indigenous rights and nationhood. The falseness of this dichotomy and what it represents is belied by a historical experience of colonization and more recent barriers to meaningful social and economic participation, combined with a political environment in which Indigenous rights are ignored or remain contested.

The phenomena described in this paper point to a double failure, on the part of governments and other official agencies, but they also suggest the emergence of dual promise. They reveal, at the same time, the importance of understanding and approaching social inclusion as a complex, multidimensional phenomenon that is defined and approached in diverse and sometimes conflicting ways by different populations. Some of Canada's Indigenous people are gaining entry into and prominence within the social, economic and political structures of Canadian society, but substantial barriers continue to limit the extent to which full inclusion has been possible for the majority of Indigenous people. Government policies and the practices related to them have persistently fallen short both in fostering conditions by which Indigenous people have been able to gain meaningful engagement in many aspects of Canadian life and in providing a solid foundation on which Indigenous aspirations for self-determination can be fulfilled. They have also rekindled counter-discourses grounded in misunderstanding of these relationships, often reinforcing hostility and overt racism. The promise, by contrast, lies with the awakening in the communities, potentially drawing together youth and elders, reaching across an extensive breadth of the Indigenous experience in Canada, ranging from upwardly mobile urban professionals, seasonal resource industry workers and those who have given up hope of meaningful employment, communities whose lives depend on relations with the land, victims 
of abuse and criminalization, and many others. By drawing attention to these issues, even in the face of negative criticism, they have helped foster dialogue and understanding that are essential for moving forward in validating Indigenous knowledge and identities and clarifying and achieving a nation to nation arrangement. While the directions and outcomes associated with these dialogues remain highly uncertain, they highlight what must occur in order for any effective, progressive change with respect to Indigenous people's status in relation to Canadian society. There are dangers that Idle No More may fragment regardless of how governments and other agencies respond to it, akin to the failure experienced by numerous previous efforts to bring together and respond adequately to the voices of those who represent the full diversity of Indigenous positions and perspectives. At the same time, there are signs that it can be as resilient as the Indigenous knowledge and traditions that were not extinguished by colonialism, in part because it is deeply informed by and respectful of those traditions, while at the same time mobilizing and motivating younger generations. It suggests a way forward, to the extent that the authority grounded in Indigenous knowledge can be integrated with the kinds of legitimacy accorded a cohort of Indigenous people moving into influential positions within Canadian institutional life while seeking validation of their rights and heritage as Indigenous people. It also requires that we pay careful attention to the changing positions of and coalitions engaged in by Indigenous people and their allies in terms of their significance for Canadian and other societies.

As a movement and culture challenging the destruction of the environment, Idle No More builds upon people's sense of humanity that emerges from a conscious awareness of natural laws and the realization that Indigenous peoples have suffered unjustly from social exclusion and colonization. It has practical and political significance for the choices and directions taken by the Canadian state and its people, with the potential to inform specific policy deliberations as well as the understanding of relations of ruling and resistance that shape these options. As a grassroots social

\section{References and Notes}

1. Coulthard G. Idle No More in Historical Context. Decolonization: Indigineity, Colonization and Resistance. 24 December 2012. Available from: http://decol onization. wordpress.com/2012/12/24/idlenomore-in-hi storical-context/\#more-50 (accessed on 13 February 2013).

2. Gordon J. Manifesto. Idle No More. 13 January 2013. Available from: http://idlenomore.ca/about-us (accessed on 28 May 2013).

3. Parliament of Canada. Statutes of Canada 2012. Chapter 31. A second act to implement certain movement, its genesis and direction can inform and be informed in a reflexive manner by the variously failed or successful trajectories of other major social movements in North America and other parts of the world (see, e.g., [59]). It obliges us to acknowledge and act upon our responsibilities, as people who represent one or the other party to living treaties, while focusing our attention at the same time to our wider responsibilities as human beings. For those interested in questions of social inclusion, it points to complex questions that researchers and policy-makers in many contexts must pay attention to regarding who defines inclusion and what inclusion signifies for those in different social and economic positions.

The movement reminds us that any future research agenda concerning Indigenous social inclusion and exclusion has a responsibility to uphold Indigenous perspectives. Traditional knowledge and cultural resources, along with longstanding responsibilities to the land, resources and other people, lie at the core of those perspectives. We have observed Idle No More's capacity for unity, despite the efforts of participants and observers both within and outside the movement to steer it in various alternate directions. The movement has shown that Indigenous people are conscious of their inherent laws and demonstrated that a profound responsibility is to uphold those laws for the benefit of future generations. It has mobilized young generations in unique ways, stirring new interest in the teachings of the elders and their relevance for today. Idle No More has demonstrated the need to promote open communication between governments, Indigenous people and mainstream Canadian citizens. For academic researchers as well as political observers, ongoing attention is needed to explore both the roots and possible futures of the movement and the kinds of influence, if any, it will generate over time. It reminds us that the achievement of inclusion can only be understood in terms of the capacity to incorporate and offer validation for a variety of perspectives, experiences and socioeconomic outcomes all oriented to the objective to foster a viable and sustainable way of living.

provisions of the budget tabled on March 29, 2012 and other measures. Ottawa, Canada: Parliament of Canada; 14 December 2012.

4. United Nations. United Nations Declaration on the Rights of Indigenous Peoples. New York, NY, USA: United Nations; 2008.

5. Houle SM. INM: Seeing Only Bill C-45 Helps Harper's Plans Be Realized. Idle No More website. 5 May 2013. Available from: http://idlenomore.ca/articl es/resources/selected-readings/item/222-inm-seeing-0 nly-bill-c-45-helps-harper\% E2\% 80\% 99s-plans-be-real ized (accessed on 27 May 2013).

6. Cannon M, Sunseri L, editors. Racism, Colonial- 
ism, and Indigeneity in Canada: A Reader. Don Mills, ON, Canada: Oxford University Press; 2011.

7. Garner R, Carrière G, Sanmartin C. Longitudinal Health and Administrative Data Research Team. The Health of First Nations Living Off-Reserve, Inuit, and Métis Adults in Canada: The Impact of Socioeconomic Status on Inequalities in Health. Ottawa, Canada: Minister of Industry, Statistics Canada; 2010.

8. Wotherspoon T. Aboriginal People, Public Policy, and Social Differentiation in Canada. In: Juteau D, editor. Social Differentiation: Patterns and Processes. Toronto, Canada: University of Toronto Press; 2003. pp. 155-204.

9. Usalcas J. Aboriginal People and the Labour Market: Estimates from the Labour Force Survey, 2008-2010. Ottawa, Canada: Statistics Canada Labour Statistics Division; 2011.

10. Lutz JS. Makuk: A New History of AboriginalWhite Relations. Vancouver, Canada: UBC Press; 2009.

11. Adams H. Prison of Grass: Canada from the Native Point of View. Toronto, Canada: New Press; 1975.

12. Alfred T. Peace, Power, Righteousness: An Indigenous Manifesto, 2nd ed. Don Mills, Canada: Oxford University Press; 2009.

13. Denis JS. Transforming Meanings and Group Positions: Tactics and Framing in Anishinaabe-White Relations in Northwestern Ontario, Canada. Ethnic and Racial Studies. 2012;35(3):453-470.

14. Bird J, Land L, Macadam M, editors. Nation to Nation: Aboriginal Sovereignty and the Future of Canada. Toronto, Canada: Irwin Publishing; 2002.

15. Helin C. Dances with Dependency: Out of Poverty through Self-Reliance. Woodland Hills, CA, USA: Ravencrest; 2008.

16. Yashar DJ. Contesting Citizenship in Latin America: The Rise of Indigenous Movements and the Postliberal Challenge. Cambridge, UK: Cambridge University Press; 2005.

17. Hedetoft UR. Social Inclusion: Inaugural Editorial. Social Inclusion. 2013;1(1):1-2.

18. Giddens A. The Third Way: The Renewal of Social Democracy. Malden, MA, USA: Polity Press; 1998.

19. Banting KG. Dis-Embedding Liberalism? The New Social Policy Paradigm in Canada. In: Green DA, Kesselman, JR, editors. Dimensions of Inequality in Canada. Vancouver, Canada: UBC Press; 2006. pp. 417-452.

20. Esping-Andersen G. A Welfare State for the 21st Century. In: Giddens A, editor. The Global Third Way Debate. Cambridge, UK: Polity Press; 2001. pp. 134- 156.

21. Lister R. Strategies for Social Inclusion: Promoting Social Cohesion or Social J ustice? In: Askonas $P$, Stewart A, editors. Social Inclusion: Possibilities and Tensions. Basingstoke, UK: Macmillan Press; 2000. pp. 37-54.

22. Government of Canada. Responsible Resource Development-Overview. Canada's Economic Action
Plan. 2013. Available from: http://actionplan.gc.ca/en/ page/r2d-dr2/overview (accessed on 29 March 2013).

23. Bourdieu P. The New Capital. Appendix: Social Space and Field of Power. In: Bourdieu P. Practical Reason: On the Theory of Action. Stanford, CA, USA: Stanford University Press; 1998. pp. 31-34.

24. Bourdieu P, Passeron J-C. Reproduction in Education, Society and Culture. Beverly Hills, CA, USA: Sage; 1979.

25. Levitas R. The Inclusive Society? Social Exclusion and New Labour, 2nd ed. Basingstoke, UK: Palgrave Macmillan; 2005.

26. Daly $M$, Silver $H$. Social Exclusion and Social Capital: A Comparison and Critique. Theory and Society. 2008;37(6):537-566.

27. Department of Aboriginal Affairs and Northern Development Canada. Education. Available from: http:// www.aadnc-aandc.gc.ca/eng/1100100033601/1 100100033605 (accessed on 24 May 2013).

28. Lamont M, Lareau A. Cultural Capital: Allusions, Gaps and Glissandos in Recent Theoretical Developments. Sociological Theory. 1988;6(5): 153-168.

29. Lareau A, Horvat EM. Moments of Social Inclusion and Exclusion: Race, Class, and Cultural Capital in Family-School Relationships. Sociology of Education. 1999;72(1):37-53.

30. King T. The Inconvenient Indian: A Curious Account of Native People in America. Toronto, Canada: Doubleday Canada; 2012.

31. Palmater PD. Beyond Blood: Rethinking Indigenous Identity. Saskatoon, SK, Canada: Purich Publishing; 2011.

32. Hawboldt A. Don't Let Me Be Misunderstood: Idle No More Founder Sets the Record Straight. Verb 2013;228(February):4-5.

33. Yazzie R, Zion JW. Navajo Restorative J ustice: The Law of Equity and Harmony. In: Galway B, Hudson J, editors. Restorative Justice: International Perspectives. Monsey, NY, USA: Criminal J ustice Press; 1996. pp. 157-174.

34. Hansen JG. An Exploration of Swampy Cree Restorative Justice. PhD Thesis, Department of Curriculum Studies in Education, University of Regina, SK, Canada; 2010.

35. Henderson JY. Postcolonial Ledger Drawing: Legal Reform. In: Battiste $M$, editor. Reclaiming Indigenous Voice and Vision. Vancouver, BC, Canada: UBC Press; 2000. pp. 161-171.

36. Comack E. Racialized Policing: Aboriginal People's Encounters with the Police. Halifax, Canada: Fernwood Publishing; 2012.

37. Yazzie R. Indigenous Peoples and Postcolonial Colonialism. In: Battiste $M$, editor. Reclaiming Indigenous Voice and Vision. Vancouver, BC, Canada: UBC Press; 2000. pp. 39-49.

38. Truth and Reconciliation Commission of Canada. Interim Report. Winnipeg, MB, Canada: Truth and Reconciliation Commission of Canada; 2012.

39. Truth and Reconciliation Commission of Canada. 
They Came for the Children: Canada, Aboriginal Peoples, and Residential Schools. Winnipeg, MB, Canada: Truth and Reconciliation Commission of Canada; 2012.

40. Sutherland J. Colonialism, Crime, and Dispute Resolution: A Critical Analysis of Canada's Aboriginal J ustice Strategy. 2002. Available from: http://www.me diate.com/articles/sutherlandJ.cfm (accessed on 5 May 2008).

41. Nobles M. The Politics of Official Apologies. Cambridge, UK: Cambridge University Press; 2008.

42. Smith LT. Decolonizing Methodologies: Research and Indigenous Peoples. London, UK: Zed Books; 1999.

43. Atkinson AB, Marlier E. Analysing and Measuring Social Inclusion in a Global Context. New York, NY, USA: United Nations, Department of Economic and Social Affairs; 2010.

44. Canadian Criminal Justice Association. Aboriginal Peoples and the Criminal J ustice System. 2000. Available from: www.ccja-acjp.ca/en/aborit.html (accessed on 13 January 2003).

45. Brosnahan M. Record-high Prison Numbers Sparking Violence. CBC News. 27 August 2012. Available from: http://www.cbc.ca/news/politics/story/ 2012/08/27/prison-numbers-crowding.html (accessed on 18 September 2012).

46. Office of the Correctional Investigator, Government of Canada. Spirit Matters: Aboriginal People and the Corrections and Conditional Release Act. Final Report. Ottawa, Canada: Office of the Correctional Investigator of Canada; 2012.

47. Braithwaite J. A Future Where Punishment Is Marginalized: Realistic or Utopian? UCLA Law Review. 1999; 46(6): 1727-1750.

48. Commission on First Nations and Métis People and Justice Reform. Legacy of Hope: An Agenda for Change. Final Report Volume 1. 2004. Available from: www.justicereformcomm.sk.ca (accessed on 14 March 2013).

49. Foucault M. Discipline and Punish: The Birth of the Prison. New York, USA: Vintage Books; 1977.

50. Canadian Council on Social Development. Social Inclusion and Communities at Risk: Canada's Aboriginal Peoples. 2003 Social Inclusion Conference
Proceedings. Available from: http://www.ccsd.ca/ev ents/inclusion/proceedings/aboriginal.htm (accessed on 13 February 2013).

51. National Indian Brotherhood. Indian Control of Indian Education. Ottawa, Canada: National Indian Brotherhood [Assembly of First Nations]; 1972.

52. By contrast, relatively little media was focused on observations within the audit report that there had been some improvement in financial accounting practices during Spence's term as Chief. See: Schwartz D. Inside Attawapiskat's financial troubles. CBC News. 9 January 2013. Available from: http://www.cbc.ca/ news/canada/story/2013/01/09/f-attawapiskat-finance s-faq.html (accessed on 30 May 2013).

53. "LM". Posted on Entitled No More Facebook page. Available from: https://www.facebook.com/whe resthemoneygoing (accessed on 12 February 2013).

54. "Sean". Posted on CBC Live Blog. Available from: http://www.cbc.ca/news/politics/story/2013/01/ 30/politics (accessed on 30 J anuary 2013).

55. "Guest". Posted on CBC Live Blog. Available from: http://www.cbc.ca/news/politics/story/2013/01/ 30/politics (accessed on 30 J anuary 2013).

56. Canadian Broadcasting Corporation (CBC). Cree walkers speak at Parliament Hill after Idle No More trek: 'Journey of the People' ends with crowds cheering aboriginal youth. Available from: http://www. cbc.ca/news/canada/ottawa/story/2013/03/25/ottawa -walk-nishiyuu-journey-ends-ottawa-parliament-victori a.html (accessed on 25 March 2013).

57. "Philip". Posted on CBC Live Blog. Available from: http://www.cbc.ca/news/canada/ottawa/story/ 2013/03/25/ottawa-walk-nishiyuu-journey-ends-ottaw a-parliament-victoria.html (accessed on 25 March 2013).

58. "Lraymond". Posted on CBC Live Blog. Available from: http://www.cbc.ca/news/canada/ottawa/st ory/2013/03/25/ottawa-walk-nishiyuu-journey-e nds-ottawa-parliament-victoria.html (accessed on 25 March 2013).

59. Wood LJ. Direct Action, Deliberation, and Diffusion: Collective Action after the WTO Protests in Seattle. New York, NY, USA: Cambridge University Press; 2012. 


\title{
Disability and Health: A Research Agenda
}

\author{
Hasheem Mannan ${ }^{1,2, *}$ and Malcolm MacLachlan ${ }^{2,3}$ \\ ${ }^{1}$ Nossal Institute for Global Health, University of Melbourne, Victoria, Australia; \\ E-Mail: hmannan@unimelb.edu.au; Tel.: +61 390356184; Fax: +61 393476872 \\ ${ }^{2}$ Centre for Global Health \& School of Psychology, Trinity College Dublin, Dublin, Ireland; \\ E-Mail: mlachlan@tcd.ie (M.M.) \\ ${ }^{3}$ Centre for Rehabilitation Studies, Stellenbosch University, South Africa \\ * Corresponding author
}

Submitted: 12 April 2013 | In revised form: 29 July 2013 | Accepted: 30 July 2013 |

Published: 12 August 2013

\begin{abstract}
Disability is not a 'health problem'; however some people with disabilities do have increased health needs, and all people with disabilities have the same right to access health services as others. The number of people living with disabilities is increasing, due partly to increasing numbers of people living with the consequences of chronic communicable and noncommunicable diseases. Based on recommendations of the World Report on Disability, which provides the parameters for research, this paper sets out a research agenda calling for a considerable research programme on social, civil, and economic impacts of living with disability, arising from whatever cause, including communicable and non-communicable diseases; significant global health policy revisions; identification of constraints and facilitators in access to healthcare for people with disabilities; development of a robust evidence base for implementing the new guidelines on community-based rehabilitation; innovations in addressing human resource challenges faced by disability and rehabilitation service-providers; development of enabling technologies that focus on individuals' aspirations and social gain; preparedness for responding to the needs of people with disabilities in disaster situations; and the application of disability metrics to strengthen health systems.
\end{abstract}

Keywords: disability; health metrics; health policy; public health; research agenda

\section{Introduction}

There is an urgent need to improve the collection, analysis, synthesis and dissemination of data on disability in a way that is both accurate and comparable across different settings, countries and populations [1].
In the early 2000s, the World Health Organisation (WHO) reconceptualised disability-moving away from the individualised deficit 'medical model' and embracing the idea of disability as an interaction of personal and societal factors [2], where its most salient features are activity limitations and participation restrictions, 
rather than unalterable diagnostic categories or bodily impairments (Figure 1). This conceptualisation provided support for the impetus for people with disabilities to enhance their own activity and their participation in society; encouraging emancipatory initiatives and contributing to the idea that disability is a human rights issue. While disability is not a 'health problem', some people with disabilities do have increased health needs associated with their disability, and all people with disabilities have the same right to access health services as everyone else [3]. The number of people living with disabilities is likely to increase, due in part to a greater number of people living with the consequences of chronic communicable and non-communicable diseases. If we are to seriously address the health rights and needs of people with disabilities, what are the critical research challenges that need to be addressed in the next decade? We recognise that disability and health is a very broad topic; ranging across illness, disease and rehabilitation to wellbeing, positive living and empowerment. While we have an interest in highlighting here some service-related aspects of health, we also note that research on health has to be much broader than this.

Previously, research questions have been generated by expert opinion exercises that included persons with disabilities and their representative organizations $[4,5]$. We recognise that the health needs of persons with disabilities represent only one component of their diverse service entitlements. However, this research agenda provides a conceptual framework, not only to address the very legitimate right to health of persons with disabilities [6], but also offers an opportunity to leverage greater research attention for aspects of community based rehabilitation which are complementary to health, such as assistive technology and natural disaster management. The research agenda outlined here has been presented to and incorporates various stakeholders including persons with disabilities, their representative organisations and various government ministries responsible for rights of persons with disabilities at forums such as AfriNead (African Network for Evidence to Action on Disability) [7] and the dissemination workshops of Project EquitAble across South Africa, Malawi, Namibia, and Sudan [8].

The United Nations Convention on the Rights of Persons with Disabilities (UNCRPD) [3] has been the most widely and rapidly ratified United Nations Convention, entering into international law in 2008. The response from the health sector has also been impressive: WHO, International Labour Organization (ILO), United Nations Educational, Scientific, and Cultural Organization (UNESCO), and International Disability and Development Consortium (IDDC) collaborated on Guidelines for Community Based Rehabilitation [9], seeking to bring principles of common practice to this widely used philosophy; but also, importantly, recognising the cross-sectoral inter-dependency of such programmes (Figure 2). In so doing, these Guidelines are one of the clearest expositions of the Bamako Call to Action on Research for Health for a much broader perspective on research for health [10].

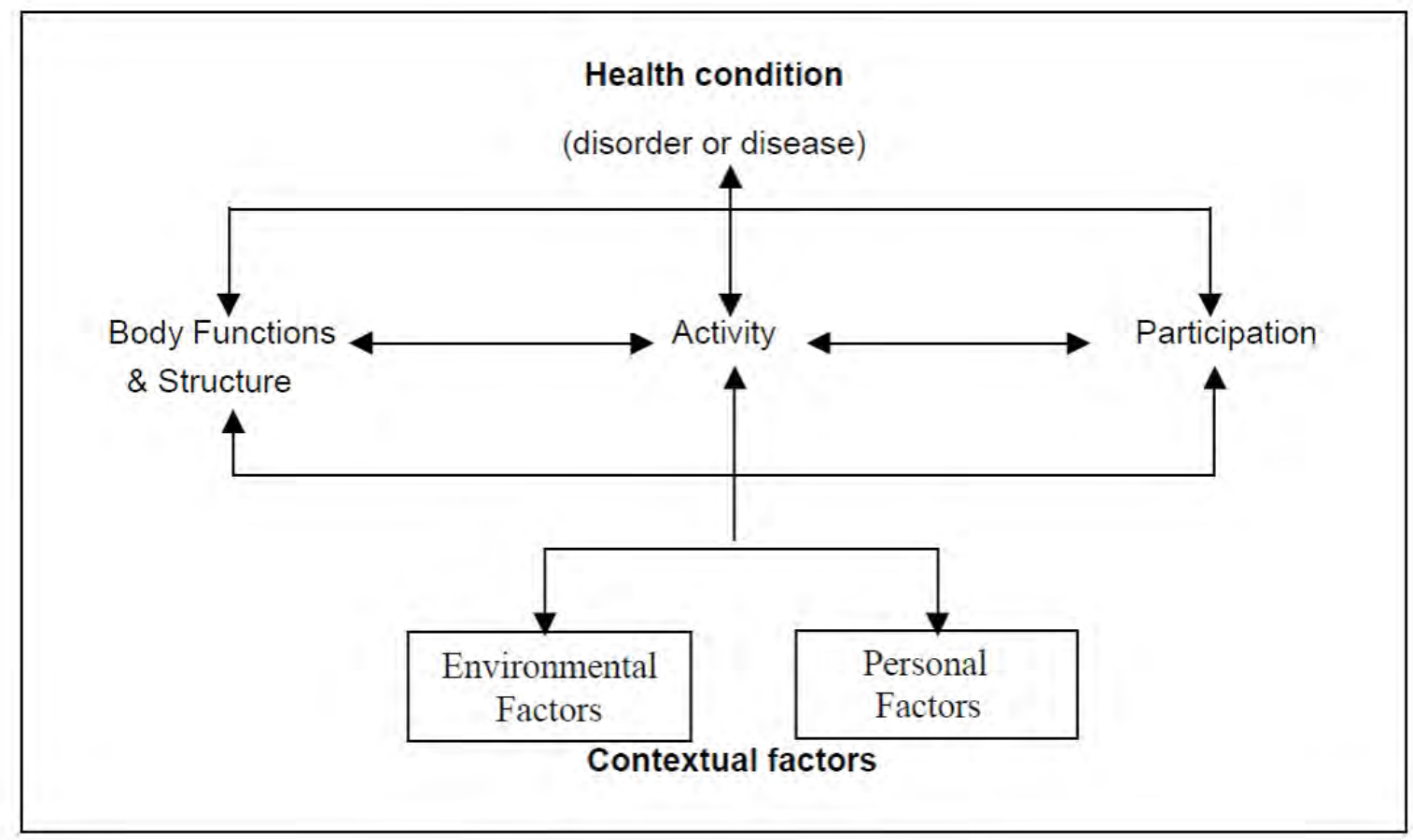

Figure 1. Model of disability that is the basis of International Classification of Functioning, Disability and Health (ICF). 


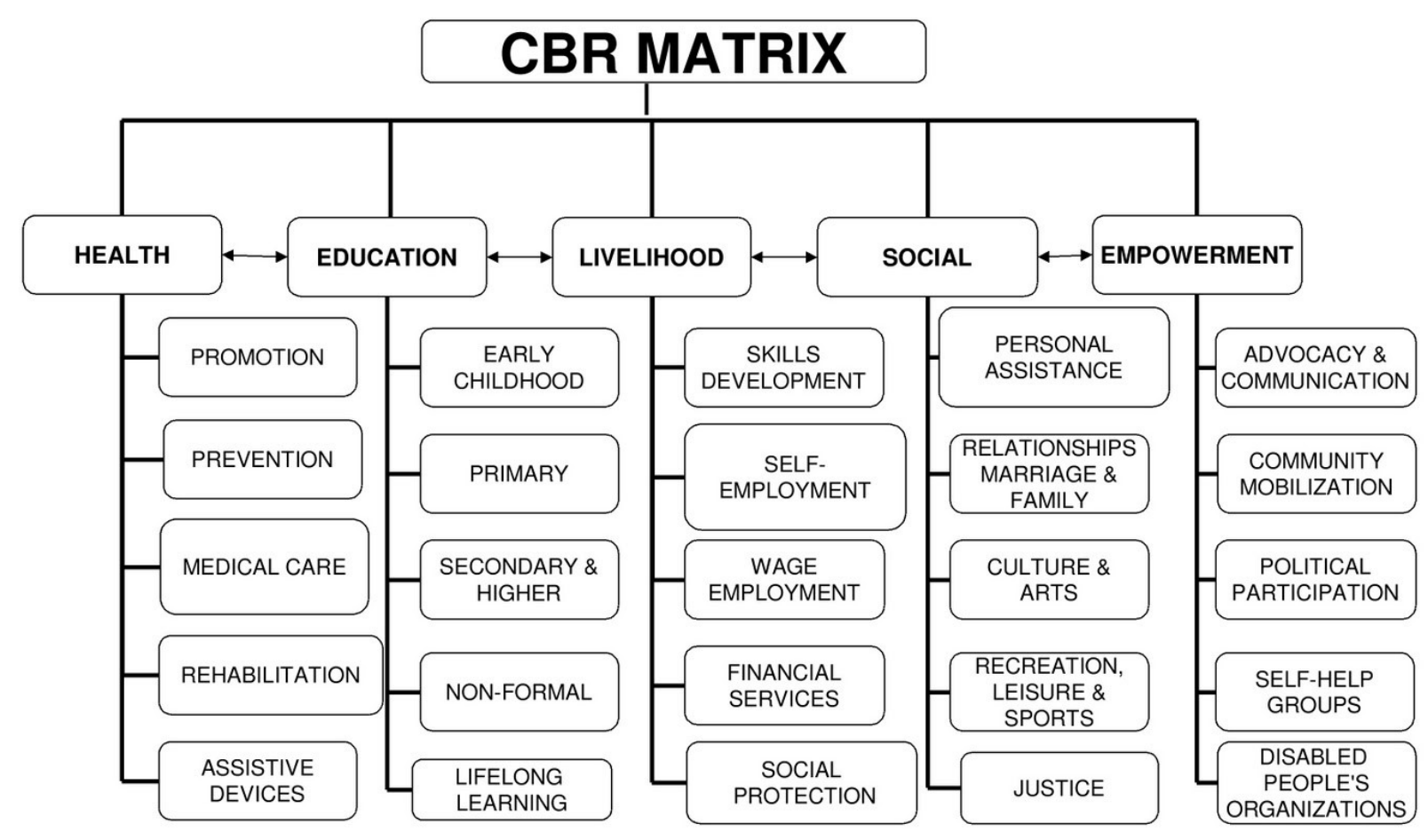

Figure 2. Community based rehabilitation matrix.

In 2011, WHO and the World Bank published the first ever World Report on Disability, estimating that $15 \%$ of the world's population-over 1 billion peopleexperience some type of disability; with $80 \%$ of these people living in low-income countries [11]. The report is a sobering 'state of the knowledge', identifying some of the major challenges that must be addressed (Table 1). Disability is also the focus for the United Nations Children's Fund (UNICEF) 2013 State of the World's Children Report [12]. All of these policy initiatives recognise the lack of and need for a greatly enhanced evidence-base. During the last decade, there has been a radical revision in the conceptualisation of disability, a crescendo of international policy initiatives and reports, and an increasing number of people living with disability. All of this calls for an ambitious research agenda, addressing the interface between disability and health, for the decade ahead. We generate a list of research topics, in line with the nine umbrella recommendations made in the World Report on Disability, which could enable fulfilling the potential for the above initiatives to improve the health and lives of perhaps the world's largest marginalised group. Empirically-derived research priorities-especially those incorporating the participation of marginalised groups $[4,5]$-constitute a critical contribution to research agenda setting in this area. However they should not be seen as the 'last word'. There is also a place for conceptually derived agenda, especially if they can complement the recent World Report on Disability, which other research agenda setting pre-dates. Our contribution is therefore offered as complimentary and hopefully encouraging of further interest, debate and research in this critical area, which requires different perspectives and ideas to maintain its vibrant nature.

\section{Public Health}

Public health has traditionally focused on the prevention of mortality, morbidity, and disability [13] and eschewed the challenge of helping people with disabilities to live full lives [14]. Medical technologies and public health interventions have beckoned what Oeffinger et al. [15] describe as-an epidemic of survival; escaping death through living with disability. This may have been truer in richer countries, but is becoming increasingly the case in poorer countries too.

Table 1. Main recommendations of the World Report on Disability.

Enable access to all mainstream systems and services

Invest in programmes and services for people with disabilities

Adopt a national disability strategy and plan of action

Involve people with disabilities

Improve human resource capacity

Provide adequate funding and improve affordability

Increase public awareness and understanding about disability

Improve the availability and quality of data on disability

Strengthen and support research on disability 
A vast majority of the leading 20 health conditions associated with disability are non-communicable diseases [11]. For instance, disabilities arising from diabetes complications can lead to productivity loss and life-long care $[16,17]$. Also, the increased availability of antiretroviral drugs (ARVs) to treat HIV/AIDS will make it a lifespan condition; with many people living with HIV, including children, developing different types of impairments and functional limitations [18], as well as participation restrictions $[19,20]$. Thus, a considerable research programme on social, civil and economic impacts of living with disability arising out of both communicable and non-communicable diseases is now needed.

\section{Health Policy}

Policies need to specifically promote the human rights of people with disabilities - this obligation is founded on international human rights standards. The UNCRPD [3] established a legally-binding human rights and moral context for action on health as a human right for persons with disabilities. The UNCRPD stipulates that 'States Parties undertake: To take into account the protection and promotion of the human rights of persons with disabilities in all policies and programmes' (art. 4) [3]. As the UNCRPD is about rights of citizenship, empowerment and wellbeing, we would see it all as relevant to our broad conceptualisation of health; while noting that particular Articles refer to health service provision, such as Articles on 'Respect for privacy' (art. 22), 'Health' (art. 25), and 'Habilitation and rehabilitation' (art. 26). Although the UNCRPD is now enshrined in international law-requiring both national policies and international aid policies to align with it-its provisions do not magically appear in such documents. Such policies have proved quite resistant to the inclusion of previous UN Conventions aimed at addressing marginalisation $[21,22]$. However, health policies explicitly built on equity, that take steps to address specific exclusionary practices, will prioritise vulnerable and marginalised groups $[23,24]$, while those that simply embrace 'all people', or 'all citizens', may implicitly privilege 'some' over others. A programme of research and policy revision is needed that can help to translate high-level declarations into specific policy commitments in national policy level documents $[25,26]$. Research must address not just what form of words is needed but also how persons with disabilities can advocate for and influence the policy revision process both in health and Poverty Reduction Strategy Papers, which set the broader national policy context in which health initiatives must work [27].

\section{Access to Healthcare}

While there has been considerable recognition in healthcare of the importance of equity, this has not been the case for accessibility; yet health services cannot hope to be equitable if they are not equally accessible. Persons with disabilities are among those who have the greatest difficulties accessing services; both the constraints and facilitators require a health systems approach that can trace and strengthen 'pathways to care' and the related services that support this $[28,29]$, such as transport and education. Due to the broad range of health care needs and their difficulties accessing health services, research agenda documenting the experiences of persons with chronic diseases and disabilities would serve as a good probe of the effectiveness of health systems [6].

\section{Community-Based Rehabilitation}

The Community-Based Rehabilitation: CBR Guidelines [9] come after decades of the application of CBR in a myriad of fashions, through varied mechanisms and in hugely differing contexts. In consequence, we have very little idea of what works well, where it works, how or why [30]. With the Guidelines already being implemented through quite different interpretations, we urgently need to establish a programme of implementation that oversees and allows for organisational, country and contextual differences, but also facilitates comparable data collection, through the establishment of a range of 'common goods' concerned with CBR training, support, monitoring, evaluation and research. The establishment of a Global Programme of Research on Disability and Inclusive Development would be an effective mechanism to achieve this.

\section{Human Resources for Health}

WHO's Maximizing Positive Synergies Collaborative Group [31] noted a global deficit of trained health workers of over 4 million, but failed to acknowledge or address the significant human resources for health (HRH) crisis especially in the provision of services for people with disabilities [32]. It is now widely accepted that promoting and protecting health requires the effective interaction of various public service sectors, such as health, social welfare and education. The CBR Guidelines also require a skill mix not available in any existing profession, indicating the need to develop a new alternative cadre that could embrace this skill mix and support existing professions, but through a much shorter and more focused training. Indeed the World Report on Disability [11] notes that-developing standards in training for different types and levels of rehabilitation personnel can assist in addressing resource gaps (p. 266), particularly in impoverished countries, where there is a proportionally high number of persons with disabilities. Research on health system strengthening and the necessary human resources to achieve it, should therefore reflect an intersectoral ethos. Until now, much of the research on the effectiveness of alternative cadres has focused on technical specialists. Future research needs to focus 
on generalists, who have the potential to braid together inter-sectoral aspects of health and therefore make a very important human resources contribution to overall health system strengthening, thus enhancing the accessibility of services.

\section{Enabling Technologies}

Technologies from wheel chairs to prosthetic limbs have accelerated in complexity and sophistication in recent years, but sometimes technical advances have exceeded the personal gains of their users, and failed to overcome participation restrictions [33]. Stigma, including self-stigma, remains a problem that prevents people achieving their full potential. However, around $90 \%$ of people in low-income countries who need assistive/enabling technologies are unable to acquire these technologies [11]. Access to even simple tech- nologies can have dramatic effects and has been shown to be predictive of enjoyment of human rights and increased capabilities, even in very poor settings [34]. A great deal more research on appropriate and affordable enabling technologies is now needed, along with how technological advances can support personally meaningful gains.

\section{Disability and Disaster Response}

Handicap International [35] has sought to make responses to disasters much more inclusive of persons with disabilities. They conceptualise the relationship between some of the key elements being expressed as: Disaster Risk $=$ Hazard $\times$ Vulnerability $/$ Capacity. The Humanitarian response sector is increasingly recognising the need for evidence-based practice, a need being addressed, at least in part, by Evidence Aid [36].

Table 2. Census questions on disability endorsed by the Washington Group.

\section{Introductory Phrase}

The next questions ask about difficulties you may have doing certain activities because of a HEALTH PROBLEM

1. Do you have difficulty seeing, even if wearing glasses?

a. No - no difficulty

b. Yes - some difficulty

c. Yes - a lot of difficulty

d. Cannot do at all

2. Do you have difficulty hearing, even if using a hearing aid?

a. No - no difficulty

b. Yes - some difficulty

c. Yes - a lot of difficulty

d. Cannot do at all

3. Do you have difficulty walking or climbing steps?

a. No - no difficulty

b. Yes - some difficulty

c. Yes - a lot of difficulty

d. Cannot do at all

4. Do you have difficulty remembering or concentrating?

a. No - no difficulty

b. Yes - some difficulty

c. Yes - a lot of difficulty

d. Cannot do at all

5. Do you have difficulty (with self-care such as) washing all over or dressing?

a. No - no difficulty

b. Yes - some difficulty

c. Yes - a lot of difficulty

d. Cannot do at all

6. Using your usual (customary) language, do you have difficulty communicating, for example understanding or being understood?
a. No - no difficulty
b. Yes - some difficulty
c. Yes - a lot of difficulty
d. Cannot do at all 
Table 3. Research challenges for disability and health.

Public Health Identifying public health approaches that enhance participation of persons with disabilities in their economic, civic, social and political life.

Health Policy Revising existing policies and development of new policies that address the human rights of people with disabilities, and including people with disabilities in these processes.

Healthcare Access Identifying the constraints and facilitators for access to health care, and incorporating these into a systems-strengthening approach.

Community Based

Rehabilitation

Developing a global programme on disability and inclusive development that will facilitate the collection of comparable data and provide 'common goods' for CBR training, support, monitoring, evaluation and research.

Human Resources for Health

Development of a new cadre for community based rehabilitation, with a broad skill mix and an ethos of evidence-based practice, whose practice can contribute to a developing evidence base.

Enabling Technologies Developing contextually appropriate and affordable enabling technologies that can facilitate personally meaningful gains for their users.

Disability and Disaster Response

Establish and evaluate systems and personal coping responses to disaster situations for people with disabilities, chronic illness and the elderly.

Disability Metrics

Develop and apply standardised disability metrics that can be used to strengthen over-all health systems.

While this is a high profile area, very little research has addressed just how persons with disabilities can cope with and survive disaster situations, which of course includes many elderly people and people with chronic illnesses. Many government agencies are failing to adequately plan for, as well as include, persons with disabilities in disaster management processes; this creates significant inequities in access to immediate responses, as well as long-term recovery resources, for those people who have disabilities prior to the occurrence of the disaster as well as those who acquire a disability as a result of the disaster [37].

\section{Disability Metrics Strengthening Health Systems}

The discussion paper of the World Conference on Social Determinants of Health [38] states that-to monitor health inequities and social determinants, data must be separated, analysed, and compared-or-disaggregated according to the main factors known to be associated with health inequities; these social-stratifiers include disability. The old adage-what gets measured, gets done-indicates the importance of establishing easy to use and widely adopted measures of disability. The approach to disability measurement taken by Washington Group (Table 2) has also been incorporated into the UN Principles and Recommendations for Population and Housing Censuses [39]. In fact, the health service experiences of persons with disabilities could be an excellent probe of the degree of equitable access to health services, because if persons with disabilities are receiving appropriate and timely care and support, then it is likely that so too are other people [6].

\section{Conclusions}

Table 3 summarises the themes that require an upscaling of research if we are to address the healthrelated needs, rights and aspirations of the estimated one billion people who have a disability. Many of the types of problems faced by people with disabilities are similar across different settings, but their extent differs massively; often being life-threatening and usually life-diminishing in the context of extreme poverty. Thus, we have set out the above research agenda that calls for a considerable research programme on social, civil, and economic impacts of living with disability arising out of the full range of causes of disability, including communicable and non-communicable diseases; significant global health policy revisions; inquiry of constraints and facilitators in access to healthcare for people with disabilities; development of a robust evidence-base for implementing the new guidelines on community-based rehabilitation; innovations in addressing the human resource challenges faced by disability and rehabilitation service-providers; the development of enabling technologies that focus on individuals' aspirations and social gain; preparedness for responding to the needs of persons with disabilities in disaster situations; and the application of disability metrics to strengthen health systems. There is an urgent need to establish robust and generic indicators and metrics for disability, to address stigma and promote the participation of persons with disabilities, for the benefit of all. 
We need research that focuses not just on what to do, but also on how to do it; the organisational and systems factors that mediate such interventions, and the varied contextual factors that moderate outcomes. Community responses to disability should embrace an 'inclusive development ethos' where improved services and opportunities for some, go in tandem with the same aspirations for all. A collaborative global network of Centres of Excellence in Disability and Health, funded by pursuing competitive calls for proposals, such

\section{References}

1. World Health Organization. Disability-Report by the Secretariat. Sixty-Sixth World Health Assembly, Provisional Agenda Item 13.5 (A66/12; 11 March 2013). Geneva, Switzerland: WHO; 2013. Available from: http://apps.who.int/gb/ebwha/pdf_files/WHA66/ A66_12-en.pdf (accessed on 29 July 2013).

2. World Health Organization Classification, Assessment, Surveys and Terminology Team. International Classification of Functioning, Disability and Health: Final Draft. Geneva, Switzerland: WHO; 2001. Available from: http://www.sustainable-design.ie/arch/ ICIDH-2Final.pdf (accessed on 29 July 2013).

3. United Nations. Convention on the Rights of Persons with Disabilities and Optional Protocol. New York, NY, USA: United Nations; 2006. Available from: http://www.un.org/disabilities/documents/convention/ convoptprot-e.pdf (accessed on 29 July 2013).

4. Tomlinson M, Swartz L, Officer A, Chan KY, Rudan I, Saxena S. Research Priorities for Health of People with Disabilities: An Expert Opinion Exercise. Lancet. 2009;374(9704):1857-1862. doi:10.1016/S01 40-6736(09)61910-3.

5. Llewellyn G, Makuwira J, Madden R, Brentnall J, Lukersmith S, Mpofu E, Bundy A, Veitch C, Broom A. Developing a Disability and Development Research Agenda for Asia and the Pacific. Melbourne, Australia: CBM; 2010. Available from: http://www.addc.org.au/ content/resources/20100930-developing-a-disability-a nd-development-research-agenda-for-asia-and-the-pa cific/267 (accessed on 29 July 2013).

6. MacLachlan M, Mannan H, McAuliffe E. Access to Health Care of Persons with Disabilities as an Indicator of Equity in Health Systems. Open Medicine. 2011;5(1):10-12.

7. African Journal of Disability. African Network for Evidence-to-Action on Disability (AfriNEAD). Available from: http://www.ajod.org/index.php/ajod/pages/view/ historic (accessed on 29 July 2013).

8. EquitAble. EquitAble: Enabling Universal and Equitable Access to Healthcare for Vulnerable People in Resource Poor Settings in Africa. Available from: http://www.equitableproject.org (accessed on 29 July 2013).

9. World Health Organization (WHO), United Nations Educational, Scientific and Cultural Organization as those of the Australian Government National Health and Medical Research Council [40] and the Economic and Social Research Council (ESRC) [41], is needed to generate a representative, comparable and robust evidence-base over the next decade; one in which people with disabilities are also among the researchers.

\section{Conflict of interest}

The authors declare that no conflict of interest exists.

(UNESCO), International Labour Organization (ILO), International Disability and Development Consortium (IDDC). Community-Based Rehabilitation: CBR Guidelines. Geneva, Switzerland: WHO; 2010. Available from: http://www.who.int/disabilities/cbr/guide lines/en/index.html (accessed on 29 July 2013).

10. The Lancet. The Bamako Call to Action: Research for Health. Lancet. 2008;372(9653):1855.

11. World Health Organization, World Bank. World Report on Disability. Geneva, Switzerland: WHO; 2011. Available from: http://whqlibdoc.who.int/publica tions/2011/9789240685215_eng.pdf (accessed on 29 July 2013).

12. United Nations Children's Fund (UNICEF). The State of the World's Children 2013: Children with Disabilities. New York, NY, USA: UNICEF; 2013. Available from: http://www.unicef.org/sowc2013/files/ SWCR2013_ENG_Lo_res_24_Apr_2013.pdf (accessed on 29 July 2013).

13. Lollar DJ, Crews JE. Redefining the Role of Public Health in Disability. Annual Review of Public Health. 2003;24:195-208. doi:10.1146/annurev.publ health.24.100901.140844.

14. Anderson G, Horvath J. The Growing Burden of Chronic Disease in America. Public Health Reports. 2004;119(3):263-270. doi:10.1016/j.phr.2004.04.005.

15. Oeffinger $\mathrm{KC}$, Eshelman DA, Tomlinson GE, Buchanan GR. Programs for Adult Survivors of Childhood Cancer. Journal of Clinical Oncology. 1998;16(8): 2864-2867.

16. Siegel K, Venkat Narayan KM. The Unite for Diabetes Campaign: Overcoming Constraints to Find a Global Policy Solution. Globalization and Health. 2008; 4(3). doi:10.1186/1744-8603-4-3.

17. Sinclair AJ. Diabetes, Disability and Frailty-A Need for Greater Recognition and Focused Research. British Journal of Diabetes \& Vascular Disease. 2012; 12(3):109. doi:10.1177/1474651412450593.

18. Cameron DL, Nixon S, Parnes P, Pidsadny M. Children with Disabilities in Low-Income Countries. Paediatrics \& Child Health. 2005;10(5):269-272.

19. Myezwa H, Stewart A, Musenge E, Nesara P. Assessment of HIV-Positive In-Patients Using the International Classification of Functioning, Disability and Health (ICF) at Chris Hani Baragwanath Hospital, Johannesburg. African Journal of AIDS Research. 2009;8(1):93-105. 
20. Groce NE, Rohleder P, Eide AH, MacLachlan M, Mall S, Swartz L. HIV Issues and People with Disabilities: A Review and Agenda for Research. Social Science \& Medicine. 2013;77:31-40. doi:10.1016/j.soc scimed.2012.10.024.

21. MacLachlan M, Khasnabis C, Mannan H. Inclusive Health. Tropical Medicine \& International Health. 2012;17(1):139-141.

22. Amin M, MacLachlan M, Mannan H, El Tayeb S, El Khatim A, Swartz L, Munthali A, Van Rooy G, McVeigh J, Eide A, Schneider M. EquiFrame: A Framework for Analysis of the Inclusion of Human Rights and Vulnerable Groups in Health Policies. Health \& Human Rights. 2011;13(2):1-20.

23. Mannan $H$, Amin $M$, MacLachlan $M$. The EquitAble Consortium. The EquiFrame Manual. Dublin, Ireland: The Global Health Press; 2011. Available from: http://www.sintef.no/Projectweb/Equitable/WP2 --Review-and-Analysis-of-Health-Policies/The-EquiFra me-Manual (accessed on 29 July 2013).

24. Turnbull HR, Wilcox BL, Stowe MJ, Umbarger GT. Matrix of Federal Statutes and Federal and State Court Decisions Reflecting the Core Concepts of Disability Policy. Journal of Disability Policy Studies. 2001; 12(3):144-176. doi:10.1177/104420730101200303.

25. MacLachlan M. Community Based Rehabilitation and Inclusive Global Health: A Way Forward. Statement to the United Nations Commission for Social Development, New York, 2 February 2012. New York, NY, USA: United Nations; 2012. Available from: http://search.un.org/search?ie=utf8\&site=un_org\&ou tput=xml_no_dtd\&client=UN_Website_en \&num $=10 \&$ l r=lang_en\&proxystylesheet=UN_Website_en\&oe=utf8 $\& q=$ maclachlan $\% 2 C+$ malcolm\&Submit=Go (accessed on 29 July 2013).

26. MacLachlan M, Amin M, Mannan H, El Tayeb S, Bedri N, Swartz L, Munthali A, Van Rooy G, McVeigh J. Inclusion and Human Rights in Health Policies: Comparative and Benchmarking Analysis of 51 Policies from Malawi, Sudan, South Africa, and Namibia. PLoS ONE. 2012;7(5):e35864. doi:10.1371/journal.pone.00 35864.

27. Wazakili M, Massah B, Mji G, MacLachlan M. Did What? Research Project in Brief: A-PODD (African Policy on Disability and Development) in Malawi. Dublin, Ireland: The Global Health Press; 2011. Available from: http://global-health.tcd.ie/docs/In_Brief_APODD_in_Malawi\%20\%20PDF\%2018\%20Nov.pdf (accessed on 29 July 2013).

28. Trani J-F, Browne J, Kett M, Bah O, Morlai T, Bailey N, Groce N. Access to Health Care, Reproductive Health and Disability: A Large Scale Survey in Sierra Leone. Social Science \& Medicine. 2011;73(10): 1477-1489. doi:10.1016/j.socscimed.2011.08.040.

29. Eide $A H$, Loeb $M E$, editors. Living Conditions among People with Activity Limitations in Zambia: A National Representative Study (SINTEF Report). Blindern, Oslo: SINTEF Health Research; 2006. Available from: http://www.sintef.no/upload/Helse/Lev
ek\%C3\%A5r\%20og\%20tjenester/ZambiaLCweb.pdf (accessed on 29 July 2013).

30. Mannan H, Boostrom C, Maclachlan M, McAuliffe $E$, Khasnabis C, Gupta N. A Systematic Review of the Effectiveness of Alternative Cadres in Community Based Rehabilitation. Human Resources for Health. 2012;10(1):20. doi:10.1186/1478-4491-10-20.

31. World Health Organization Maximizing Positive Synergies Collaborative Group. An Assessment of Interactions between Global Health Initiatives and Country Health Systems. Lancet. 2009;373(9681):21372169. doi:10.1016/S0140-6736(09)60919-3.

32. MacLachlan M, Mannan H, McAuliffe E. Staff Skills not Staff Types for Community-Based Rehabilitation. Lancet. 2011;377(9782):1988-1989. doi:10.101 6/S0140-6736(10)61925-3.

33. Gallagher $\mathrm{P}$, MacLachlan $M$. Thinking through Enabling Technologies: Guidelines for Development and Implementation. In: MacLachlan $\mathrm{M}$, Gallagher $\mathrm{P}$, editors. Enabling Technologies: Body Image and Body Function. Edinburgh, Scotland: Churchill Livingstone; 2004. pp. 259-264.

34. Borg J. Assistive Technology, Human Rights and Poverty in Developing Countries: Perspectives Based on a Study in Bangladesh. Lund, Sweden: Lund University; 2011. Available from: http://lup.lub.lu.se/ luur/download?func=downloadFile\&recordOId $=17638$ 55\&fileOId=1766394 (accessed on 29 July 2013).

35. Handicap International, London School of Hygiene and Tropical Medicine, International Centre for Eye Health. Access to Services for Persons with Disabilities in Challenging Environments. Lyon, France: Handicap International; 2010. Available from: http:// www.handicap-international.fr/fileadmin/documents/ publications/AccessToServicesAmman.pdf (accessed on 29 July 2013).

36. Evidence Aid. Evidence Aid: Providing resources for decision-makers before, during and after disasters and other humanitarian emergencies. Available from: http://www.evidenceaid.org (accessed on 29 July 2013).

37. United Nations Enable. Disability, Natural Disasters and Emergency Situations. Available from: http://www.un.org/disabilities/default.asp?id=1546 (accessed on 29 July 2013).

38. World Health Organization. Closing the Gap: Policy into Practice on Social Determinants of Health. Discussion paper: Annex 2. Proceedings of the World Conference on Social Determinants of Health, Rio de Janeiro, Brazil, 19-21 October 2011. Geneva, Switzerland: WHO; 2011. Available from: http://www.socialprotection.org/gimi/gess/RessShowRessource.do? ressourceId=27141 (accessed on 29 July 2013).

39. Madans JH, Loeb ME, Altman BM. Measuring Disability and Monitoring the UN Convention on the Rights of Persons with Disabilities: The Work of the Washington Group on Disability Statistics. BMC Public Health. 2011; 11(4):1-8. doi:10.1186/1471-2458-11-S4-S4.

40. Australian Government National Health and Med- 
ical Research Council. Centres of Research Excellence (CRE). Canberra, Australia: NHMRC; 2013. Available from: http://www.nhmrc.gov.au/grants/apply-funding/cen tres-research-excellence-cre (accessed on 29 July 2013).

41. Economic and Social Research Council. Centres and Large Grants Competition. Swindon, UK: ESRC; 2013. Available from: http://www.esrc.ac.uk/fundingand-guidance/funding-opportunities/3672/Centres_an d_Large_Grants_competition.aspx (accessed on 29 July 2013). 


\title{
Social Capital and Stratification of Young People
}

\author{
Alireza Behtoui ${ }^{1,2}$ \\ ${ }^{1}$ Institute for Migration, Ethnicity and Society (REMESO), Department of Social and Welfare Studies, \\ Linköping University, 60174 Norrköping, Sweden \\ ${ }^{2}$ Department of Social Anthropology, Stockholm University, Universitetsvägen 10, 11418 Stockholm, Sweden; \\ E-Mail: alireza.behtoui@socant.su.se; Tel.: +46 8163810; Fax: +46 8158894
}

Submitted: 12 April 2013 | In revised form: 25 June 2013 | Accepted: 31 July 2013 |

Published: 12 August 2013

\begin{abstract}
This paper addresses the impact of social capital on the status attainment process of young people at the start of their careers and examines how social class, gender and ethnicity affect the accumulation of social capital and thereby labour market stratification of young people. A sample of young Swedes graduating from vocational schools and universities between 2005 and 2006, was surveyed via the telephone about their experiences acquiring jobs. Two research questions are posed: (i) Which characteristics (class, gender and ethnicity) affect young people's access to more social capital? (ii) How is social capital rewarded in the labour market? The results show that being female, coming from the lower social classes and being a member of a stigmatized immigrant groupare associated with a substantial social capital deficit. When socioeconomic and demographic backgrounds as well as the human capital of respondents are controlled, social capital is positively associated with salary level. The results indicate that social capital is a significant factor in the stratification process of young people.
\end{abstract}

Keywords: education; occupation; social capital; young people

\section{Introduction}

Proponents of the meritocratic approach argue that, when societies evolve from traditionalism to industrialism, the criteria of 'achievement' necessarily replace the criteria of 'ascription' in all forms of social selection. Merit, defined as ability plus effort, shown through one's formal educational achievements and labour market experience, is the criterion used for allocating individuals to different positions. Consequently, what you can do rather than who you are (as defined by your class, gender or ethnicity/race) is the factor determining your position in the social hierarchy [1]. In more recent models of status attainment, education is seen as the mediating factor between socioeconomic background and labour market outcomes such as salary or occupational status. As empirical findings demonstrate, educational achievements are strongly dependent on ascribed resources (for Sweden, see [2]).

In status attainment research, less attention has been paid to social processes in the more informal private spheres of life (such as friendship, partnership and neighbourhood) that lead to inequalities. More precisely, how being embedded in resource-poor social 
networks and consequently having less access to social capital may negatively affect individuals' educational attainment and labour market outcomes. Studies which incorporate social capital as an additional factor to explain social status have shown that 'when the mediated effects of parental status through social capital are taken into account, ascribed status might be just as important, if not more so, than achieved status' ([3], p. 165).

To investigate the impact of social capital on the labour market stratification process, this study, conducted in Sweden, uses data on the job-entry process of a group of young people who completed their studies in 2005-2006 and started working. These data have the advantage of focusing on social capital in the first phase of the individuals' working lives, when social capital is more ascribed than achieved, that is, when strong kinship and social origin ties, rather than workrelated ones, are more important [4]. On the other hand, the data have the disadvantage that they contain information about the wages of young people (as a proxy for their status attainment) only at the start of their careers, while in many cases the biggest steps in occupational careers are taken later, such as when people leave their first jobs and take up new ones.

Most prior research on the effect of social capital on stratification processes was conducted in countries with unregulated labour markets, such as United States (for a review see [5]). It seems likely that resources in one's social networks may play a greater role in these countries than in a highly regulated market such as that of Sweden, which has a nationwide system of public employment agencies, with at least one office in each municipality. The National Labour Market Board regularly publishes information about job openings. Furthermore, employers in Sweden are required by law to report vacancies to employment offices. Considering these characteristics, the question is; given the same educational achievements, can we detect differences between the quality of jobs obtained by young people at the start of their careers dependent upon access to more social capital?

Furthermore, active membership of civic associations has traditionally been a well-known avenue for social mobility of young people from lower class backgrounds in Sweden $([6]$, p. 300). If we assume that membership of such associations is a source of social capital and that such membership "could offset some of the impact of social and economic disadvantages" ([7], p. 18), then the Swedish context could provide an interesting case study in this area.

To investigate the impact of social capital on the labour market positions of young people at the start of their careers, the following research questions are posed:

1. Which characteristics of young people (such as socioeconomic background, educational level, gender, birthplace and marital status) enhance or hinder access to social capital? Or, who has better, and who has worse, access to social capital?

2. How well is social capital rewarded in the labour market?

\section{Theoretical Framework}

According to neoclassical economics (which focuses on the optimizing individual agent which has much in common with the meritocratic approach), workers are paid according to their productivity, and a worker's productivity depends on the quality and quantity of 'human capital' an individual has acquired through formal education and/or professional training [8].

As earlier empirical studies demonstrated, there is a strong correlation between social origin and academic achievement (for school-mediated modes of reproduction of the social structure, see [9]). Besides, in the labour market the full economic and social rewards of education depend on social capital [10]. People with strong educational credentials have the potential to obtain higher status jobs, but if they are not born into higher social groups and/or lack the 'proper' contacts, they cannot obtain a full return on their education. Social capital 'procures a competitive advantage by providing higher return on investment' ([11], p. 195).

Social capital has been defined on both the micro (individual) and the macro (collective) levels, with consequent theoretical and methodological developments on two different tracks ([12], p. 3). Putnam, the most cited author in social capital research, is the central representative of the first type, i.e. research in which the unit of analysis is the community, the region or the entire nation ([12], p. 3).

The concept of social capital applied at the micro or individual level has been defined differently in various fields. Coleman's definition of social capital stresses its social control function and is mainly used within the field of educational research. Coleman's chief interest has been the effects of social capital in creating human capital, in the family and in the community [13].

Researchers who come close to Bourdieu's definition of social capital [14] emphasize instead the advantages which individuals accrue as a result of connections with others in their network who may help them with advice, further connections, information, loans, and so on for 'access to employment, mobility through occupational ladders, and entrepreneurial success' ([15], p. 12). In this research tradition, social capital deals with the process of production and reproduction of social inequality in the labour market, and is defined as a resource accumulated as a result of historical relations of power. Accordingly, the probability of accumulating and maintaining social capital increases in proportion to the amount of economic and cultural capital in the individual's network [16]. Lin [17] and his colleagues, link social status to social resources in the individual's net- 
work, and emphasize that the very potency of one's network depends, above all, on the position that one occupies in the social hierarchy.

A central claim of this research tradition concerns conflict and power. In the labour market, for example, one's position depends not only on whether one fulfils the formal educational demands of a job, but also on how one stands relative to other applicants in terms of other requirements [18]. As a result, one group's social capital gain may mean another group's social capital loss [19].

Those who are connected to better-placed individuals have access to better information about job openings. Such connections offer greater influence and higher social credentials, as, for example, when wellplaced contacts are cited as referees in a job-seeker's application [16]. In some cases powerful network members can also create a position for someone [20]. Network members may reinforce identification, act as role models and enhance the job-seeker's confidence and self-esteem. As Brown et al. [21] put it, 'people will not only tend to limit the range of jobs they apply for to the jobs they feel (correctly or otherwise) they have a chance of getting, but also to what they think is appropriate'. Finally, network connections can provide emotional and instrumental support, which contributes to an individual's physical and mental wellbeing [22].

Drawing on Bourdieu's discussion of the concept of social capital [14], one can argue that social capital is manifested in different states: embodied, objectified or institutionalised. As Denord François et al. ([23], p. 91) put it, 'in reality these states are intertwined in various ways'. On embodied social capital Bourdieu writes ([14], p. 109): 'Manners (bearing, pronunciation, etc.) may be included in social capital insofar as, through the mode of acquisition they point to, they indicate initial membership of a more or less prestigious group'. Through participant observation in selection interviews for recruitment, Jenkins [24] coins the concepts of 'acceptability' and 'employability' which indicate this state of social capital [25].

Objectified social capital is group or network membership and to operationalise it Bourdieu ([14], p. 103) suggests measuring 'the size of the networks of connections as well as the volume of the capital (economic, cultural, or symbolic) possessed by connections'. There are several methods of assessing resources in an individual's social network. The 'position generator' method employed in this study is more commonly used in research on occupational attainment and getting desirable labour market outcomes (such as higher occupational prestige or wages). Using this method, researchers choose a sample of occupations from the full range of the hierarchical structure of society (from very low to high prestige). Respondents are asked if among their acquaintances, close friends or relatives, there is anyone who has one of the jobs indicated on a list. By mapping these ties (both weak and strong), this method explores the entire network. Under this method, the occupations of contacts are assumed to reflect important aspects of their social location, such as their power, class background and educational status. Another approach for measuring the objectified state of social capital is the 'name generator' method which can provide a rich record of a small number of closer relationships of respondents [26]. This method is very useful for some research purposes such as studying the outcomes of social capital in work organization (for discussion about these methods see Lin and Erickson [27]).

The institutionalized state of social capital consists of formalised contact patterns and active membership of political, religious and civic organizations, which 'guarantees a particular form of social relationship in a lasting way' ([14], p. 105). Such activity enables individuals to obtain resources that are sometimes beyond the family environment. Particularly if they are members of a subordinate group, using the 'collective resources' of organizations compensates for disadvantaged backgrounds ([28], p. 119). Active membership of unions and political parties in the left bloc in Sweden, for example, has been a well-known avenue for enhancing the careers of people with a working-class background ([6], p. 300). As Arneil [29] suggests, despite the exclusionary practices of the mainstream organizations of dominant groups, when subordinate groups begin to organize themselves and become agents in civic associations, they can (through, among other things, socialcapital building) challenge the basic premises of the current balance of power (see also [30]).

In addition, as Wang ([31], p. 22) mentions, activity in voluntary organisations can signal to a prospective employer young people's attitudes to 'responsibility', and their aim of increasing 'social skills' and obtaining knowledge 'not learned in a classroom' (see also [18]).

\section{Previous Research}

Granovetter's Getting a Job [20] showed that finding jobs through informal job-search methods (i.e. via social networks) is very common and important. Further development in this field is associated with Nan Lin [32], whose 'social resource theory' holds that networks themselves are not the same as social resources. In other words, using social networks per se provides no relative advantages in the competition for better jobs [17]. In the first stage of the development of social resource theory, the composition of a network and the resources accessible through it were measured by the occupational standing of the contact (activated to locate the job), on the assumption that using highly prestigious contacts was linked to higher wages or higher-status occupations. Further research led to a relaxation of the assumption that 'a particular contact in the job-search process is the same as "social resources"'. Social resources, Lin [16] suggested, can improve one's labour market outcomes even if 
one does not find a job through social networks (see also Lin and Erickson [33]). Consequently, the focus shifted from the use of personal contacts in general (and a specific contact in particular) to the pool of resources embedded in a job-seeker's social network. The quality of the job obtained should be linked to social resources in the individual's network, regardless of the job-finding methods used and of whether or not a specific contact has been involved [16]. Reviews of numerous studies show that access to social capital provides occupational gains (for a review see Lin and Erickson [27]).

Substantive empirical studies have examined the role of credentials ('human capital') in the job-obtaining processes of young people. However, as Cain [34] demonstrates, labour market studies within the frame of 'human capital' theory can explain only a small percentage of the variation in wages and labour market positions of individuals from different groups.

Even though scholars have mentioned that social capital is important specifically for young people who are dealing with the transition from school to work [35], there are not many studies which use quantitative data to examine the impact of social capital at the beginning of a person's working life. Flap and Boxman [4] studied 365 graduates from higher vocational training in the Netherlands. They showed that young people more often search for jobs informally when they possess more social capital (measured by position-generating and name-generating methods) and this has a significant impact on their incomes. Jokisaaria and Nurmib [36] studied 409 graduates from polytechnic schools in Finland. They measured respondents' social capital against the people with whom they had discussed important matters related to their personal work goal and demonstrated that the higher the status of the social contacts, the higher their job status and job satisfaction was. Using the same dataset, Jokisaari [35] examined whether supervisor-level or employee-level ties before getting a job are related to the social integration of respondents when they enter an organisation. The results confirm the hypothesis. Wang [31], using a sample of 2,971 students from the National Education Longitudinal Study, (U.S. Department of Education, NELS: $88 / 00)$, reported that social capital in college, measured in terms of participation in extracurricular activities and participation in voluntary organisations, played a significant and positive role in getting students a more satisfying job and a higher salary.

\section{Data}

The data for this study were gathered via a telephone survey carried out in 2009-2010. Interviews lasted approximately 20-25 minutes each. Different groups of young people who graduated in 2005-2006 from vocational schools and universities were asked about their experiences in looking for employment. Through this design it was possible to study the rate of return on investment in education for young people with different life experiences.

Young people in the first group graduated from vocationally-oriented secondary school programmes [37]. The programmes that are included in this kind of education are the following: (i) Hotel, restaurant and catering (Hotell och Restaurangprogrammet), (ii) Health and nursing (Omvårdnadsprogrammet), (iii) Business and administration (Handels- och Administrationsprogrammet), and (iv) Construction (Byggprogrammet). The percentages of the all the uppersecondary students in Sweden who are enrolled in these programmes are, 4.3, 3.9, 5.3 and 4.7 respectively.

Individuals in the second group are graduates from the following undergraduate programs: (i) Teacher Education, (ii) Nursing, (iii) Social Work, (iv) Social and Cultural Analysis, (v) Political Science and Economics, (vi) Business and Economics, and (vii) Culture, Society and Media Production.

The third group consists of graduates in three prestigious university programs: (i) Psychology, (ii) Master of Science in Technical Physics, and (iii) Industrial Economics and Management.

Previous studies (for example, [38]) maintain that children from privileged social groups are more likely to enrol in such prestigious courses, which are normally longer and more attractive, and require high grades for admission, than those courses selected by members of the second group (for a definition of, and discussion about the issue of prestigious courses in Swedish universities, see [39]).

Universities in Sweden are not yet ranked according to status, as they are in, for example, the USA and the UK. But certain newly established universities or university colleges can award only undergraduate degrees [40]. Respondents in the present study were selected from graduates of a traditional university in a middlesized city in Sweden. Those with vocationally-oriented secondary school qualifications were also residents of the city where the university campus is located. The quality of secondary schools with vocational programs in this city is likewise comparable with that of other schools with the same programs in others cities in the country [41]. Therefore, we can assume that our respondents are representative of undergraduate students and vocationally-oriented secondary school pupils of the country.

Because of the favourable labour market conditions in Sweden at the time, (with an unemployment rate of about 6 percent for those aged $24-45$ years and 14 percent for those aged 20-24 years), many of the young people in this study succeeded in obtaining jobs. The labour market situation in the regions where this research was carried out was among the most favourable in the country. Furthermore, the young adults in this study are mainly what Bardley and Devadson ([42], p. 123) call 'stickers', that is, those who had already selected the 'right' education and had identified 
a career objective after they ended their full-time education. In other words, on completing their full-time education (graduating from the vocational, undergraduate and prestigious courses), they are a positively selected group among young people in general.

Of the individuals on the school and university registers that we obtained for this study, 67 percent of the university-educated and 56 percent of those who completed secondary-school courses participated in the survey. About 20 percent refused to participate; the remainder (i.e. 13 and 24 percent) could not be contacted at their last known addresses or telephone numbers. Lack of time was the main reason given by the majority of those with university degrees who declined to participate in the survey. In contrast, individuals with secondary school qualifications gave no clear reason for their refusal, but we speculate that they avoided interviews because they had no secure job positions. Hence, it seems that our survey has failed to include individuals at the two extremes, that is, those with the best and the worst labour market outcomes therefore the results must be interpreted with caution.

Since respondents included very few unemployed persons, nine of them, with a secondary school education but who had never had a job, were dropped. Those few (14) individuals who were temporarily out of the labour market (on maternity or paternity leave or taking other kinds of short breaks) were asked about their most recent jobs. Furthermore, 38 individuals older than 40 years at the time of the interviews were also excluded from the final sample, because inclusion of such mature graduates might have skewed the results.

It is possible to compare the final sample of 438 individuals with the original lists only in respect of gender and, to some extent, immigrant background by their names. The final sample was highly representative in terms of gender (with a slight overrepresentation of women) but individuals with immigrant backgrounds were slightly under-represented. (Details about the representativeness of the final sample regarding the gender and immigrant background of respondents for each course are available from the author on request).

\section{Measurements}

At the different stages of this study, the following variables are included: Gender (Female) is coded female $=1$ and male $=0$. Socioeconomic background of respondents (labelled "SEB") is a composite measure and includes information on prestige scores of the occupational positions and years of education of respondents' parents. The variable is constructed by performing a factor analysis (principal component) on the aforementioned four variables (parents' educational level and occupation), and consequently is a standardized measure (mean $=0 ; \mathrm{sd}=1.0$ ).

Young people with an immigrant background in this study are individuals who have two foreign-born parents. In this category those who are native-born of foreign parentage are defined as "second generation" and those who are born abroad but have completed secondary school in Sweden are defined as "1.5 generation" [43]. In addition, two different regions of origin of individuals with immigrant backgrounds are distinguished: north-west countries (NW), which comprise north-west Europe and North America, and countries outside north-west Europe and North America (ONW), which account for rest of the world [44]. Such a distinction is based on the results of earlier Swedish studies which show that immigrants from ONW countries are in many cases residents of stigmatized neighbourhoods, are concentrated in inferior parts of the labour market, and are exposed to a higher risk of suffering from discrimination [45]. Consequently, four categories of origin are generated by country of birth in this study: SV are children of native-born parents; the $\mathrm{NW}_{2}$ group comprises children of immigrants from "north-western Europe and North America"; $\mathrm{ONW}_{2}$ and $\mathrm{ONW}_{1.5}$ are children of immigrants from countries "outside north-western Europe and North America". All individuals in our sample have completed secondary education in the Swedish educational system. ONW 1.5 is the only group whose members were born abroad. There were also five individuals from the $\mathrm{NW}_{1.5}$ group in the final sample, who were dropped.

Respondents' educational achievements are measured at three educational levels (vocationally oriented secondary school, university undergraduate and highstatus tertiary education) completed by respondents at the time of the survey. Another control variable is respondents' age (a continuous variable).

To measure the objectified state of social capital this study employs the position-generator method. A list of 21 occupations ranging from high to low in the hierarchical structure of Swedish society was developed [46]. Respondents were asked: "Of your relatives, close friends, or acquaintances, is there anyone who has a job listed in the following table?" If the response was 'yes', the respondent was asked whether she or he knew this person before searching for their current job. If a respondent knew the contact after getting their current job, the contact was dropped to make sure that the resources in the respondent's networks belonged to the period prior to getting their current job.

The following indicators are suggested as measurements of resources in the networks (objectified social capital):

(i) extensity or the number of positions (from the list of occupations ) that were attainable, reflects the diversity of positions, and their embedded resources;

(ii) upper attainability i.e., the highest status job, among contacts of the respondent, indicated the best possible resources in the social network; 
(iii) heterogeneity: the range of positions (distinction between the highest and lowest attainable positions), and

(iv) the composition of resources or average status of the contacts indicated typical resources [16].

Extensity indicates the quantity of ties that give access to occupations, while the other three characteristics indicate the quality of access or the volume of capital possessed by networked individuals. In line with earlier studies, we can assume that the variables' extensity, upper reachability, range and average were observable measures of the unobserved variable "objectified social capital" [16]. A factor analysis (with principal component methodology, varimax rotation, and a criterion of an eigenvalue equal to or greater than 1 yielded a single factor solution. Thus, a factor score based on the four indeces was constructed for each individual (see Table A1 in the Appendix).

To measure the institutionalised state of social capital of young people in this study we asked them about their active membership of civil society organizations. We presented respondents with a list of nine types of organization and asked them whether they had been an active member of: pupils' councils, political parties, student organizations, religious groups, sports associations, scout associations, charities (e.g. Amnesty, Save the Children and the Red Cross), immigrant organizations or other organizations. Membership of immigrant organizations had a positive impact neither on their access to social capital nor on their salaries, and was therefore excluded. The dummy variable "voluntary association" shows whether a respondent had been an active member of any of these organizations $(=1)$ or not $(=0)$.

\section{Results}

Table 1 and Table 2 summarize respondents' characteristics in terms of socioeconomic background, gender and immigrant background.

As is evident from Table 1 , there is a clear association between respondents' socioeconomic background (parents' education and job status) and their educational achievements. The results of estimated logistic regression models (not shown here, but available on request), demonstrated that, in line with previous studies, the probability of having a university degree or a degree from a prestigious program is strongly associated with respondents' class background; in other words, the higher the status of respondents' socioeconomic backgrounds, the greater their educational achievements.

Equally, the monthly salaries of respondents show a significant correlation with their educational levels. The average occupational status of those who are in respondents' networks (an indicator of their access to objectified social capital) and their active membership of voluntary organisations (an indicator of the state of their institutionalised social capital) are also correlated with their class background.

Table 1. Summary of sample characteristics for three educational levels, means (S.E.) or percent.

\begin{tabular}{lccc}
\hline Educational level & $\begin{array}{c}\text { Secondary } \\
\text { school }\end{array}$ & $\begin{array}{c}\text { Tertiary } \\
\text { education }\end{array}$ & $\begin{array}{c}\text { High-status tertiary } \\
\text { education }\end{array}$ \\
\hline $\mathrm{N}$ & 144 & 210 & 84 \\
$\%$ & 32.9 & 47.9 & 19.2 \\
Age & $\mathbf{2 2}(0.56)$ & $\mathbf{3 0}(3.6)$ & $\mathbf{3 0}(2.1)$ \\
Highest Edu. (Y) of parents & $\mathbf{1 2 . 8}(2.4)$ & $\mathbf{1 3 . 6}(2.6)$ & $\mathbf{1 4 . 9}(2.1)$ \\
Parents' job status & $\mathbf{3 9 . 9}(13)$ & $\mathbf{5 1 . 1}(16.6)$ & $\mathbf{5 9 . 3}(14.8)$ \\
Average job status of contacts & $\mathbf{3 7 . 4}(7.3)$ & $\mathbf{4 8 . 9}(21.7)$ & $\mathbf{5 6 . 3}(9.7)$ \\
Member of a social org. (\%) & $\mathbf{6 5}(0.47)$ & $\mathbf{8 4}(0.36)$ & $\mathbf{9 1}(0.27)$ \\
Income/month, adj. for working & $\mathbf{1 9 , 7 1 2}(4,366)$ & $\mathbf{2 3 , 7 7 8}(3,624)$ & $\mathbf{3 5 , 2 6 2 ( 5 , 5 3 1 )}$ \\
Hours, Swedish Crown (SEK) & & & \\
\hline
\end{tabular}

Note: The means tests indicate a significant difference between groups at $1 \%$ level. ANOVA and post hoc tests show that the differences between three groups concerning all means are statistically significant at $5 \%$ level. 
Table 2. Summary of sample characteristics on the subject of gender and origin, percent or means (standard deviation).

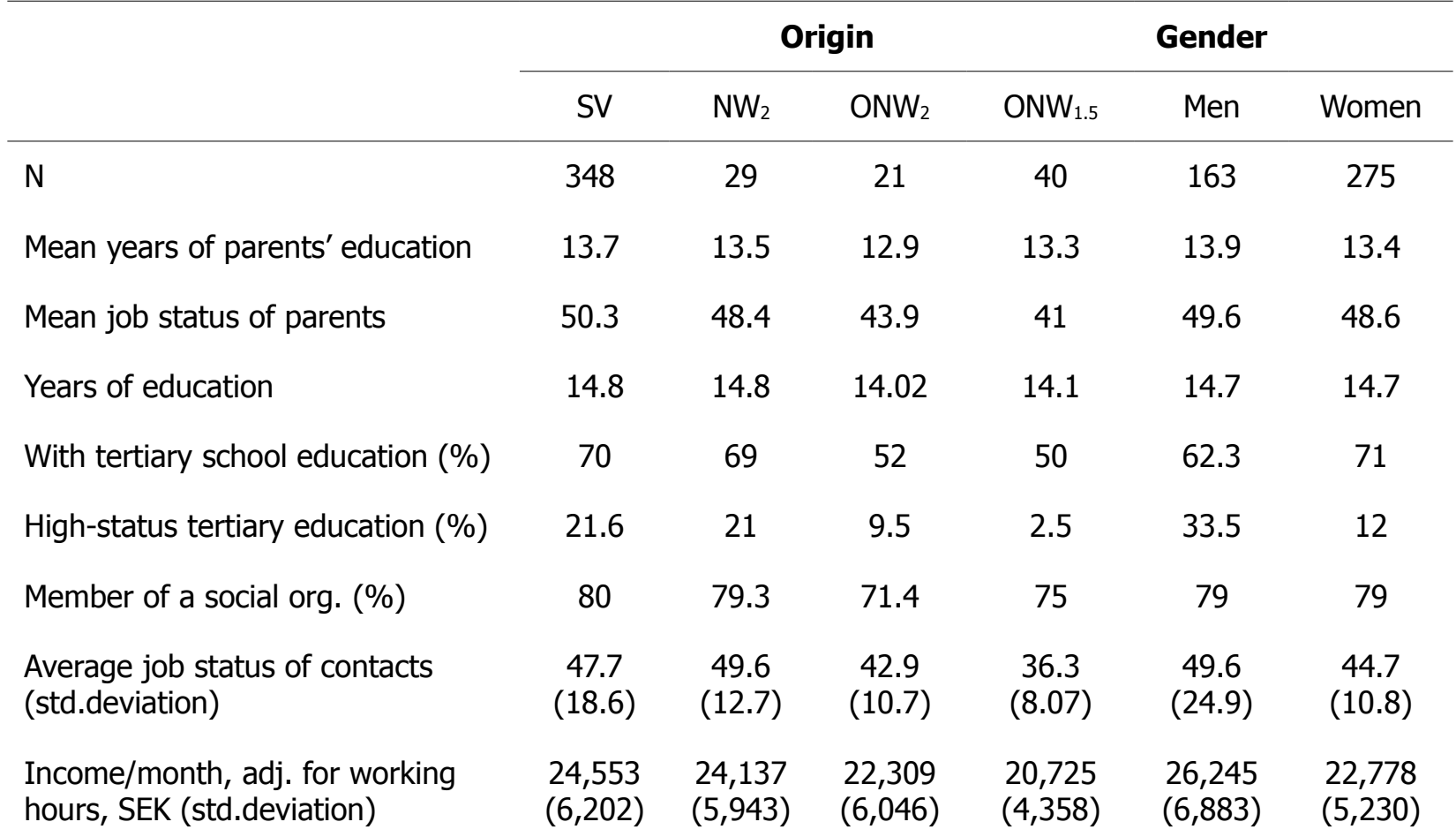

Note: The means tests indicate a significant gender difference at $1 \%$ level for variables 'income' and 'status of contacts'. ANOVA and post hoc tests, show that the mean differences between ONW ${ }_{1.5}$ and the reference group (SV) are statistically significant at least at $5 \%$ level for variables 'Mean job status of parents', 'Years of education', 'High-status tertiary education', 'Average job status of contacts' and 'income'. Other differences are not statistically significant.

Table 2 demonstrates that, even if the socioeconomic backgrounds of men and women in this sample are nearly equal, men are more likely to have a highstatus tertiary degree and earn higher salaries.

Furthermore, descriptive statistics show that the education of parents of respondents with different immigrant backgrounds is almost the same as that of the SV group, but parents born in ONW countries have lower-status jobs. Children of immigrants born in ONW countries are likely to be less evident among those with university degrees in prestigious programs, to have less social capital and to have lower monthly wages.

\subsection{Access to Objectified State of Social Capital}

To explore the factors that contribute to the distribution of objectified social capital, a series of regression analyses has been estimated with this variable as the dependent variable. As presented in Table 3, the socioeconomic background of respondents has a positive and significant impact on access to objectified social capital. Having a university degree and credentials from a high-status program is also associated with more resources in an individual's social network. The same positive impact holds for age.
Being female (rather than being male) is negatively associated with access to social capital in this sample. For those from immigrant backgrounds, there is a modest and non-significant negative association between being a member of the $\mathrm{NW}_{2}$ or the $\mathrm{ONW}_{2}$ group and having greater social capital. This negative relationship is excessive and significant in the case of the ONW $_{1.5}$ group. A possible explanation is that the $\mathrm{NW}_{2}$ and $\mathrm{ONW}_{2}$ groups and their parents have lived in Sweden for a longer period of time than the $\mathrm{ONW}_{1.5}$ group. The non-significant effect for the $\mathrm{NW}_{2}$ and $\mathrm{ONW}_{2}$ groups may also reflect the small number of individuals in these groups or the specification of this dataset. As expected, the age of respondents is equally important, because the older respondents are more educated or have additional years of labour market experiences, which potentially enhance their access to more social capital (see also Flap and Boxman [4]).

The effect of active membership of voluntary organizations on access to more objectified social capital is investigated in Model 4. The result demonstrates that active participation in organizations is a positive and significant factor for access to well-resourced networks [47]. 
Table 3. Access to objectified state of social capital, OLS regression, partial (and standardized) coefficients, $\mathrm{N}=438$.

\begin{tabular}{|c|c|c|c|c|}
\hline & Model 1 & Model 2 & Model 3 & Model 4 \\
\hline Socioeconomic background & $\begin{array}{c}\mathbf{0 . 4 6} * * * \\
(0.46)\end{array}$ & $\begin{array}{c}\mathbf{0 . 2 7} * * * \\
(0.27)\end{array}$ & $\begin{array}{c}\mathbf{0 . 2 6} * * * \\
(0.26)\end{array}$ & $\begin{array}{c}\mathbf{0 . 2 3} * * * \\
(0.23)\end{array}$ \\
\hline \multicolumn{5}{|l|}{ Education level (secondary ref.) } \\
\hline University degree & & $\begin{array}{c}\mathbf{0 . 8 6} * * * \\
(0.43)\end{array}$ & $\begin{array}{c}\mathbf{0 . 8 6 * * *} \\
(0.43)\end{array}$ & $\begin{array}{c}\mathbf{0 . 8 4} * * * \\
(0.42)\end{array}$ \\
\hline High status tertiary degree & & $\begin{array}{c}\text { 1.12*** } \\
(0.44)\end{array}$ & $\begin{array}{c}\text { 1.01*** } \\
(0.40)\end{array}$ & $\begin{array}{c}\mathbf{0 . 9 6 * * *} \\
(0.38)\end{array}$ \\
\hline Age & & $\begin{array}{c}\mathbf{0 . 0 2 6 * *} \\
(0.12)\end{array}$ & $\begin{array}{c}\mathbf{0 . 0 2 6 * * *} \\
(0.12)\end{array}$ & $\begin{array}{c}\mathbf{0 . 0 2 3} * * \\
(0.11)\end{array}$ \\
\hline Female & & & $\begin{array}{c}-0.20 * * * \\
(-0.10)\end{array}$ & $\begin{array}{c}-0.20 * * * \\
(-0.10)\end{array}$ \\
\hline \multicolumn{5}{|l|}{ Birthplace (SV ref.) } \\
\hline $\mathrm{NW}_{2}$ & & & $\begin{array}{l}-0.10 \\
(-0.03)\end{array}$ & $\begin{array}{c}-0.10 \\
(-0.03)\end{array}$ \\
\hline $\mathrm{ONW}_{2}$ & & & $\begin{array}{c}-0.03 \\
(-0.007)\end{array}$ & $\begin{array}{c}-0.02 \\
(-0.005)\end{array}$ \\
\hline $\mathrm{ONW}_{1,5}$ & & & $\begin{array}{c}-\mathbf{0 . 6 9} * * * \\
(-0.20)\end{array}$ & $\begin{array}{c}-\mathbf{0 . 6 9} * * * \\
(-0.20)\end{array}$ \\
\hline Voluntary association activity & & & & $\begin{array}{c}\mathbf{0 . 3 3} * * * \\
(0.14) \\
\end{array}$ \\
\hline $\mathrm{R}^{2}$ adj. & 0.22 & 0.48 & 0.53 & 0.54 \\
\hline
\end{tabular}

Note: $* * *$ denotes significance at $1 \%$ level and $* *$ at $5 \%$ level.

\subsection{Wages as a Proxy for Status Attainment}

The last analytical task is to assess the impact of social capital on the (logged) monthly salaries of respondents as a proxy for their status. As mentioned above, the wage gap between different categories of employment for young people is not great in the first phase of their labour market careers. The wage divergence accelerates in the later phases. Furthermore, when considering such an outcome, we should bear in mind that the Swedish wage structure, in general, has been "one of the most compressed in the OECD" ([48], p. 510).

The first model in Table 4 assesses the effect of demographic variables, that is, gender and immigrant background, on young graduates' salaries. Being female generates a lower wage (15 percent) than being male. Being a descendant of immigrants is also associated with a lower wage than being born to natives (by 3,12 and 42 percent). These effects are however not statistically significant for the $\mathrm{NW}_{2}$ and $\mathrm{ONW}_{2}$ groups.

In the second model in Table 4 the socioeconomic background variable is added to the equation, which indicates a positive and significant association between belonging to a higher class and earning a higher wage.

In the third model the effect of 'education' variables is examined. Having a university degree or a degree from a prestigious tertiary program shows a significant and positive association with earning a higher wage. Given the respondents' educational level, the impact of age on salary is non-significant.

The addition of education variables reduces the coefficients for immigrant and class backgrounds, which indicates that part of the wage differences is due to the lower educational attainment of the descendants of immigrants.

In the last model in Table 4, the two indicators of social capital are incorporated into the wage equation (objectified and institutionalised social capital). Social capital variables demonstrate a significant and positive association with higher wages. Social capital seems to be a significant contributing factor to earning a higher wage, even after education and other variables are controlled. 
Table 4. Determinants of (LN) monthly salary, OLS regression, partial (and standardized) coefficients, $\mathrm{N}=438$.

\begin{tabular}{|c|c|c|c|c|}
\hline & Model 1 & Model 2 & Model 3 & Model 4 \\
\hline Female & $\begin{array}{c}-0.15 * * * \\
(-0.18)\end{array}$ & $\begin{array}{c}-0.14 * * * \\
(-0.17)\end{array}$ & $\begin{array}{c}-0.14 * * * \\
(-0.17)\end{array}$ & $\begin{array}{c}-0.12 * * * \\
(-0.14)\end{array}$ \\
\hline \multicolumn{5}{|l|}{ Birthplace (SV ref.) } \\
\hline $\mathrm{NW}_{2}$ & $\begin{array}{l}-0.03 \\
(-0.02)\end{array}$ & $\begin{array}{l}-0.01 \\
(-0.01)\end{array}$ & $\begin{array}{l}-0.01 \\
(-0.01)\end{array}$ & $\begin{array}{l}-0.001 \\
(-0.001)\end{array}$ \\
\hline $\mathrm{ONW}_{2}$ & $\begin{array}{l}-0.12 \\
(-0.07)\end{array}$ & $\begin{array}{l}-0.08 \\
(-0.04)\end{array}$ & $\begin{array}{l}-0.006 \\
(-0.03)\end{array}$ & $\begin{array}{l}-0.002 \\
(0.001)\end{array}$ \\
\hline $\mathrm{ONW}_{1,5}$ & $\begin{array}{c}-0.42 * * * \\
(-0.31)\end{array}$ & $\begin{array}{c}-0.36 * * * \\
(-0.27)\end{array}$ & $\begin{array}{c}-0.27 * * * \\
(-0.20)\end{array}$ & $\begin{array}{c}-0.19 * * * \\
(-0.14)\end{array}$ \\
\hline Socioeconomic background & & $\begin{array}{c}0.12 * * * \\
(0.31)\end{array}$ & $\begin{array}{c}0.03 * * \\
(0.09)\end{array}$ & $\begin{array}{l}0.005 \\
(0.01)\end{array}$ \\
\hline \multicolumn{5}{|l|}{ Education level (Secondary ref.) } \\
\hline University degree & & & $\begin{array}{c}0.36 * * * \\
(0.45)\end{array}$ & $\begin{array}{c}0.24 * * * \\
(0.31)\end{array}$ \\
\hline High-status tertiary degree & & & $\begin{array}{c}0.60 * * * \\
(0.61)\end{array}$ & $\begin{array}{c}0.47 * * * \\
(0.47)\end{array}$ \\
\hline Age & & & $\begin{array}{l}0.006 \\
(0.07)\end{array}$ & $\begin{array}{l}0.002 \\
(0.03)\end{array}$ \\
\hline Objectified state of social capital & & & & $\begin{array}{c}0.12 * * * \\
(0.30)\end{array}$ \\
\hline $\begin{array}{l}\text { Institutionalised state of social } \\
\text { capital }\end{array}$ & & & & $\begin{array}{c}0.12 * * * \\
(0.12)\end{array}$ \\
\hline $\mathrm{R}^{2}$ adj. & 0.13 & 0.22 & 0.55 & 0.61 \\
\hline
\end{tabular}

Note: $* * *$ denotes significance at $1 \%$ level and $* *$ at $5 \%$ level.

Adding the social capital variables further reduces the coefficients of gender [49], immigrant and class backgrounds. This means that the disadvantage suffered by subordinated groups arises partly from lack of access to networks with valuable resources. Social capital variables also reduce the education coefficients, which may indicate that the economic rewards from education credentials in the labour market depend in part on the social capital of individuals [51].

\section{Summary and Discussion}

Young people of different socioeconomic backgrounds are unequally represented in various levels of the Swedish educational system. Those with well-educated parents with high-status jobs are more likely to have a university degree. Our results also demonstrate that part of the observed wage gap between young people from different class and ethnic back- grounds can be explained by educational variables.

In this study the position-generated method is used to measure the objectified state of social capital. Resources in individuals' networks consist of their contacts not only with extended family members and close friends (strong ties) but also with acquaintances (weak ties).

Active membership of organizations is measured separately in this study as an indicator of the institutionalised state of social capital, both in order to investigate its effect on access to more valuable resources in respondents' networks and its impact on the status of individuals beyond resources in their social networks. These findings confirm our suggestion about the significance of membership in civic associations in the Swedish context. Such membership is both a source of objectified social capital and an aid in terms of career development of the members of subordinated groups. 
Respondents with more favourable socioeconomic backgrounds, with higher educational achievements and with membership of voluntary organizations have access to more objectified social capital. There is evidence in this sample that gender and a stigmatized immigrant background hinder access to objectified social capital. Consequently we can conclude that access to networks with valuable resources is not equally distributed.

Our finding that, even after education and other variables are controlled for, social capital (measured in its objectified and institutionalised states) is a significant contributing factor to having higher status in the labour market, indicates that social capital is a partial mediator between educational attainment and labour market status even in the highly regulated Swedish labour market. This also confirm Bourdieu's ([14], p. 110) assertion that: 'Educational qualifications never function perfectly as currency. They are never entirely separable from their holders', and that an academic degree is 'worth what its holder is worth, economically and socially' ([52], p. 79). As we have observed the value of educational credentials increase or decrease in proportion to the value of their bearer.

When after control for 'human capital' variables, social capital variables are taken into account, the wage difference between males and females decreases. The same goes for the wage gap between young people with various educational backgrounds (as proxy for their class background) and the wage gap between the children of natives and those of stigmatized immigrants (both shrink still further). This means that the labour market disadvantages of young people from subordinated groups partly reflect unequal access to social capital. As was suggested earlier, the benefits of social capital to one group in competitive situations (such as obtaining a job or promotion) actually enable this group to exclude others from access to scarce resources. In other words, in a hierarchically ordered society some individuals are connected to resource-rich networks, while others, because of their lower socioeconomic status, their gender or a stigma of race/ethnicity etc., lack similar access to influential networks [53].

The fact that, after controls have been done for the socioeconomic and demographic background as well as the education of respondents, social capital demonstrates a positive association with the young

\section{References and Notes}

1. Bell D. On meritocracy and equality. The public Interest. 1972;29:29-68.

2. Erikson $\mathrm{R}$, Jonsson JO. Ursprung och utbildning: Social snedrekrytering till högre studier: Huvudbetänkande. Stockholm, Sweden: Fritze; 1993.

3. Lai G, Lin N, Leung S-Y. Network Resources, contact resources, and status attainment. Social net- people's wages, and indicates that social capital is likely to be a significant contributing factor to the process of stratification. In other words, the disadvantaged position of subordinate groups (young females and children of lower social classes and stigmatized immigrants) is not only due to what Loury [54] defines as discrimination in contract (the unequal treatment of individuals on the basis of their subordinated identity in formal transactions, e.g. in the recruitment processes). It is also a consequence of discrimination in contact, which means the unequal treatment of persons on the basis of class, gender and 'ethnic' background in the context of more informal, private spheres of life e.g. friendship or partnership [54].

Since social capital, along with educational credentials, is an essential factor for recent graduates in getting an appropriate job, Jokisaari ([35], p. 186) suggests that 'disadvantaged groups need help to access resources beyond their immediate social circles, such as through the provision of sponsors and mentors in career development and ties to institutions'.

Certain limitations restrict the generalizability of these findings. First of all, our analysis includes only individuals who already have a job, although we know from previous studies that entry into working life is a big problem for some young people, particularly young men from working-class families [55]. Another limitation of this study is the response rate of the survey. Therefore, some estimates may suffer from upward or downward bias.

We need further studies to understand how young people with various backgrounds optimize the benefits from their formal education. The next step is to move beyond measuring resources in a person's social network based on fixed socioeconomic and demographic characteristics. Using qualitative research methods would help us to understand the process of social capital accumulation and the ways such resources transmit and affect social inequalities.

\section{Acknowledgements}

Funding from FAS, The Swedish Council for Working Life and Social Research is gratefully acknowledged. The author also thanks colleagues Anders Neergaard and Erik Olsson and others who read and commented on earlier drafts.

works. 1998;20(2):159-178.

4. Flap $H$, Boxman E. Getting started: The influence of social capital on the start of the occupational career. In: Lin N, Cook K, Burt RS, editors. Social capital: Theory and research. New York, NY, USA: Aldine de Gruyter; 2001.

5. Marsden PV, Gorman EH. Social Networks, Job Changes, and Recruitment. In: Berg IE, Kalleberg AL, editors. Sourcebook of labor markets: Evolving struc- 
tures and processes. New York, NY, USA: Kluwer Academic; 2001. pp. 467-502.

6. Broady D. Sociologi och epistemologi. Pierre Bourdieus författarskap och den historiska epistemologin. Stockholm, Sweden: HLS Förlag; 1991.

7. Field J. Social capital. 2nd ed. Oxon, UK/New York, NY, USA: Routledge; 2008.

8. Borjas GJ. Labor economics. New York, NY, USA: McGraw-Hill; 1996.

9. Ball S. Class strategies and the education market: The middle classes and social advantage. London, UK: Routledge/Falmer; 2002.

10. Bourdieu P. The state nobility: Elite schools in the field of power. Cambridge, UK: Polity; 1996.

11. Bourdieu P. The social structures of the economy. Oxford, UK: Polity; 2005.

12. Portes A. The Two Meanings of Social Capital. Sociological Forum. 2000;15(1): 1-12.

13. Coleman JS. Social Capital in the Creation of Human Capital. American Journal of Sociology. 1988;94:95-120.

14. Bourdieu P. The forms of capital. The sociology of economic life. Boulder, CO, USA/Oxford, UK: Westview Press; 2001.

15. Portes A. Social capital: Its origins and applications in modern sociology. Annual Review of Sociology. 1998;24:1-12.

16. Lin N. Social capital: A theory of social structure and action. Cambridge, UK/New York, NY, USA: Cambridge University Press; 2001.

17. Lin N. A Network Theory of Social Capital. In: Van Deth JW, Castiglione D, Wolleb G, editors. The Handbook of Social Capital. Oxford, UK: Oxford University Press; 2008.

18. Brown $P$, Hesketh $A$. The mismanagement of talent: Employability and jobs in the knowledge economy. Oxford, UK/New York, NY, USA: Oxford University Press; 2004.

19. Erickson $\mathrm{BH}$. Good networks and good jobs. In: N Lin, Cook K, Burt RS, editors. Social capital: Theory and research. New York, NY, USA: Aldine de Gruyter; 2001.

20. Granovetter MS. Getting a job: A study of contacts and careers. Cambridge, MA, USA: Harvard University press; 1974.

21. Brown P, Hesketh AJ, Williams S. Employability in a knowledge-driven economy. Journal of Education and Work. 2003;16(2):107-126.

22. Song L, Lin N. Social capital and health inequality: Evidence from Taiwan. Journal of Health and Social Behavior. 2009:50(2):149-163.

23. Denord F, Hjellbrekke J, Korsnes O, Lebaron F, Le Roux B. Social capital in the field of power: The case of Norway. The Sociological Review. 2011;59 (1):86-108.

24. Jenkins R. Racism and recruitment: Managers, organisations, and equal opportunity in the labour market. Cambridge, UK: Cambridge University Press; 1986.
25. The embodied state of social capital is hard to measure using methods other than participant observation.

26. Burt RS. Structural holes: The social structure of competition. Cambridge, MA, USA: Harvard University Press; 1992.

27. Lin N, Erickson BH. Social Capital: An International Research Program. Oxford, UK: Oxford University Press; 2008.

28. Bourdieu P, Wacquant LJD. An invitation to reflexive sociology. Cambridge, UK: Polity; 1992.

29. Arneil B. Diverse communities: The problem with social capital. Cambridge, UK: Cambridge University Press; 2006.

30. Mulinari D. Women friendly? Understanding gendered racism in Sweden. In: Melby K, Ravn A-B, Wetterberg CC, editors. The Limits of Political Ambition? Gender Equality and Welfare Politics in Scandinavia. Bristol, UK: Policy Press; 2008. pp. 167-182.

31. Wang Y. The Effects of Cumulative Social Capital on Job Outcomes of College Graduates. PhD Thesis. Blacksburg, VA, USA: Virginia Polytechnic Institute; 2008.

32. Lin N. Access to Occupations through Social Ties. Social Networks. 1986;8(4):365-385.

33. Lin N, Erickson BH. Theory, Measurement, and the Research Enterprise on Social Capital. In: Lin N, Erickson BH, editors. Social Capital: An International Research Program. Oxford, UK: Oxford University Press; 2008.

34. Cain GG. The Economic Analysis of Labor Market Discrimination: A Survey. In: Layard R, Ashenfelter $\mathrm{O}$, editors. Handbook of labor economics. Amsterdam, The Netherlands: Elsevier Science Publishers BV; 1986.

35. Jokisaari M. From Newcomer to insider? Social networks and socialisation into working life. In: Helve $\mathrm{H}$, Bynner J, editors. Youth and Social Capital. London, UK: Tufnell Press; 2007.

36. Jokisaari M, Nurmi J-E. Company matters: Goalrelated social capital in the transition to working life. Journal of Vocational Behavior. 2005;67(3):413-428.

37. Approximately 98 percent of those who leave compulsory schools in Sweden move on to upper secondary schools. Both vocational and academic courses at this level take three years. The 14 vocationallyoriented courses, which involve the students working, at least 15 percent of the time in the workplace, prepare pupils for the labour market but also offer the possibility of enrolling in higher education.

38. Reay D, David ME, Ball SJ. Degrees of choice: Social class, race, and gender in higher education. Stoke-on-Trent, UK: Trentham Books; 2005.

39. Berggren C. Horizontal and vertical differentiation within higher education-Gender and class perspectives. Higher Education Quarterly. 2008;62(1-2): 20-39.

40. Löfgren Martinsson M. Högre utbildning och arbete med personal- och arbetslivsfrågor - om professionalisering och utveckling av anställningsbarhet. 
Lund, Sweden: Pedagogiska institutionen, Lund University; 2008.

41. Berr D. Öppna jämförelser 2011. Gymnasieskola. Stockholm, Sweden: Sveriges kommuner och landsting; 2011.

42. Bradley $H$, Devadason R. Fractured transitions: Young adults' pathways into contemporary labour markets. Sociology. 2008;42(1):119-136.

43. Portes $A$, Rumbaut RG. Legacies: The story of the immigrant second generation. Berkeley, CA, USA: University of California Press; 2001.

44. Countries defined as NW in this study are: Denmark, Finland, Norway, Ireland, UK, France, Italy, Germany, Netherlands, Belgium, Spain, Austria, Ireland, Luxembourg, Switzerland, Japan, Canada, Australia, New Zealand and the United States. The rest of the world is defined as ONW.

45. Özcan, G. Essays on labor market disparities and discrimination: Imigration, education and gender. PhD Thesis. Stockholm, Sweden: Department of Economics, Stockholm University; 2001. p. 27s.

46. To select the occupations in this list I followed Lin and Erickson ([27], p. 9) who suggest: "choose occupations from different sectors of the economy, to represent some horizontal as well as vertical differences in occupational resources. It is important to choose occupations with clear, widely understood titles that appear in the society's census".

47. Here we have assumed that active membership of a voluntary association increases the valuable resources in one's social network, thereby creating more objectified social capital. Given the cross-sectional nature of the data, it is impossible to verify the causal sequence between the two variables. Therefore we should not rule out the possibility that the objectified state of social capital enhances voluntary association activity.

48. Granqvist $L$, Regnér $H$. Decentralized wage formation in Sweden. British Journal of Industrial Relations. 2008;46(3):500-520.

49. In the case of women in this sample we have found that after including all control variables in Model 4 a wage gap of 12 percent remains. This gap is likely to be the result of other mechanisms, like gender discrimination and the high level of gender segregation in the Swedish labour market [50].

50. Gonäs L, Karlsson JC. Gender segregation: Divisions of work in post-industrial welfare states. Burlington, VT, USA: Ashgate; 2006.

51. All dependent variables in Table 3 and Table 4 were tested for multicolinearity before inclusion in the models.

52. Bourdieu P, Passeron JC. The inheritors: French students and their relation to culture. Chicago, IL, USA: University of Chicago Press; 1979.

53. Moren-Cross JL, Lin N. Access to social capital and status attainment in the United States: Racial/ ethnic and gender differences. In: Lin N, Erickson $\mathrm{BH}$, editors. Social capital: An international research program. Oxford, UK/New York, NY, USA: Oxford University Press; 2008. pp. 364-379.

54. Loury GC. The anatomy of racial inequality. Cambridge, MA, USA: Harvard University Press; 2002.

55. McDowell L. Redundant masculinities? Employment change and white working class youth. Oxford, UK: Blackwell; 2003. 
Table A1. Summary of position-generated indexes and position generator in the sample.

\section{Variables, mean}

Extensity (number of positions accessed)
Upper reachability (prestige of highest access
Range of prestige
Average positions accessed
Accessed positions (prestige score) \%

Medical doctor (89)

Lawyer (87)

Civil engineer (81)

59.3

Local politician (66)

25.0

Journalist (66)

27.1

Police officer (63)

41.9

Local government official (56)

41.3

Secondary schoolteacher (55)

43.9

Nurse (52)

63.8

Primary schoolteacher (48)

65.5

Foreman (42)

47.6

Librarian (40)

Office clerk (37)

Farmer (36)

Childcare workers in kindergarten (35)

Machinery worker (33)

Assistant nurse (32)

Cook (31)

Shop assistant (27)

Cleaner (16) 


\title{
Social Class and Social Capital in China and Britain: A Comparative Study
}

\author{
Yaojun Li \\ Institute for Social Change, University of Manchester, Humanities Bridgeford Street, Oxford Road, Manchester, \\ M13 9PL, UK; E-Mail: Yaojun.Li@manchester.ac.uk; Tel.: +44 1612750274; Fax: +44 1612754762 \\ Submitted: 16 June 2013 | In revised form: 3 August 2013 | Accepted: 8 August 2013 | \\ Published: 16 August 2013
}

\begin{abstract}
We use the China General Social Survey (2005) and the Home Office Citizenship Survey (2005) to study civic engagement and neighbourhood trust in China and Britain in this paper. We focus on class differences in participation in sports/recreation, religion, children's/adult education and public-welfare activities, and trust in the neighbours. We find higher levels of civic involvement in Britain but greater neighbourhood trust in China. This is mainly due to structural differences. China has a large proportion of peasants who have very low levels of civic involvement but very high levels of neighbourhood trust. Among the non-peasant population, the two countries have similar levels of class differences in civic (except religious) involvement. There are small class differences in China on neighbourhood trust, but marked effects in Britain. Overall, there is a greater similarity than difference in class effects in both civic engagement and social trust in the two countries. While differences in demographic attributes (and China's specific institutional arrangement, the household registration system, or hukou) account for some of the observed patterns, we also find more pronounced class than demographic effects in the two countries. Class plays a major role in the development of social capital.
\end{abstract}

Keywords: Britain; China; civic engagement; class; hukou; neighbourhood trust

\section{Introduction}

Much research has been conducted on civic engagement and social trust, particularly in Britain and the USA. Yet, little is known about civic life and trust in China or how it is compared with that in developed countries such as Britain. This paper seeks to make a contribution to this respect. The two countries have different histories, socio-economic structures and political institutions impacting upon the two domains of social life. Britain has a long civic history but China's civic life is in its infancy. Even less known are the structural forces shaping civic engagement and social trust in the two countries. From a sociological perspective, we may expect both similarities and differences impinging upon the development of social capital. The similarity may be the common class determinant and the difference may be due to China's lack of civic tradition, its lower level of socio-economic development and its unique institutional arrangement 
(the household registration system, or hukou in Chinese) that can be expected to affect not only people's life chances such as social and geographic mobility but also life choices in civic involvement and social trust. Yet given the rapid economic development, the growing socio-economic disparity and the burgeoning civic life in China in the last three decades, a comparative study of the state and the drivers of social capital may be feasible, as is attempted in this paper.

This paper is structured as follows. In the next section, we give a brief review of the literature on social capital, paying particular attention to the civic tradition of the research paradigm. We also discuss some socio-political differences in the two countries that might have a strong bearing on the development of social capital. After that we give an account of the data and methods to be used for this research, followed by the presentation of results. The paper will conclude with a discussion of the implications of the findings.

\section{Debate on Social Capital}

There has been much debate on social capital in the last two decades. Scholars have argued about the nature and origin of social capital [1], the rise and fall of voluntary life in capitalist countries, particularly in the USA and Britain [2-5], the causes and consequences of voluntary involvement [6-8] and so on. Research on formal civic engagement in developing countries such as China is, however, limited although considerable research has been conducted on the instrumental aspects of informal social connections $[9,10]$.

Yet, in spite of the debate, a consensus is readily found about the nature of social capital in the writings not only by the well-known scholars in the area $[2,9,11,12]$ but also by those following a particular strand of the research paradigm. Briefly, most researchers in the area agree that social capital pertains to social resources residing in social connections. The disagreements are mainly on the manifestations and consequences associated with different kinds of social connection. Thus one finds striking similarities in the definitions of social capital: as 'the aggregate of the actual or potential resources which are linked to possession of a durable network of more or less institutionalised relationships of mutual acquaintance and recognition' ([11], p. 51); as 'resources embedded in one's network or associations' ([9], p. 56); as aspects of a social structure that facilitate 'certain actions of individuals who are within the structure' ([12], p. 302); and as 'connections among individuals-social networks and the norms of reciprocity and trustworthiness that arise from them' ([2], p. 19). It is fairly clear that Bourdieu, Coleman and Lin emphasize the stratification/instrumental functions of social connections whilst Putnam places greater importance to the expressive/civic values of formal and informal social involvement. We confine the following discussion on the civic tradition of this research paradigm.

In the civic tradition of social capital research, Putnam's work is the most influential. His notion of social capital is comprehensive and yet imprecise: comprehensive because it covers most of the research agenda in this area, and imprecise because it contains both causes (connection) and consequences (trustworthiness) in the same definition which has led to much controversy. He also views both connection and trust as consisting of different layers. With regard to connection, there are formal and informal social involvements. The former refers to membership and activity in civic organizations which are related neither with the state nor with employers (although some employers do have civic programmes in operation). This kind of civic activity has the function of community building and the participants in the voluntary activities are called 'machers' who are 'all-around good citizens' ([2], p. 94). In communities rife with volunteers, not only the machers but onlookers, passers-by and other members all benefit from the social cohesion, solidarity and generalized reciprocity that are engendered in the process. The cost of conducting socio-economic activity is reduced and the quality of life is enhanced. The latter, informal involvement, refers to the good-will and various acts of spontaneous and generous giving of time, effort and money to neighbours, friends, colleagues and others, fostering the flow of soul, or 'schmoozing' as Putnam calls it. Both formal and informal social networks facilitate the development of bonding and bridging ties, with the former referring to in-group solidarity and the latter to out-group linkage, which increase social interaction (although too much bonding might have a 'dark side' as Putnam also acknowledges), enhance mutual understanding, and strengthen community cohesion.

While there is general consensus about social capital inhering in social connections, there is less agreement about trust. We noticed that Putnam uses the term 'trustworthiness' rather than 'trust' as a defining characteristic of social capital, and warns of using 'trust' uncritically as an indicator. Unwarranted trust, he says, might simply mean 'gullibility' ([13], p. 668). Yet while his definition points to ego-based trust (one's own trustworthiness), his analysis is based on alter trust, that is, trust in fellow citizens ([2], pp. 139-141), a practice widely followed by most other researchers. The slippage is consequential for surveybased research. Trustworthiness refers, as he says, to the readiness to act in pursuance of the obligation of reciprocity but it is hard to validate this from survey responses. A person may be highly trustworthy in dealing with friends, colleagues and neighbours but acts cautiously or even unethically in dealing with strangers, or s/he may be utterly untrustworthy in personal behaviour but still proffers a trustful view in the response. One cannot therefore infer about a person's trustworthiness from survey responses. Yet, at a more general level, it may be fairly safely assumed 
that if a large proportion of people in a region or a country report that most people can be trusted, we can be quite confident about the general social atmosphere of that area in contrast to the situation in another place where most people regard one another with suspicion. Thus whilst an individual's credibility cannot be judged solely on the basis of his/her response to the survey item on generalised trust, aggregate responses in this regard do speak about the social character of a society.

More refined distinctions can be made with regard to alter trust: trust at the macro, meso and micro levels [14]. The first is the afore-mentioned trust in one's fellow citizens, which Putnam calls 'thin' trust to differentiate it from 'thick' trust in people with whom one deals in daily encounters, particularly among family and friends (micro-level trust). Putnam holds that thin trust 'rests implicitly on some background of shared social networks and expectations of reciprocity' and thick trust is 'embedded in personal relations that are strong, frequent, and nested in wider networks' ([2], p. 136). For decades, social and political scientists have relied on the survey question: 'Do you think that most people can be trusted or that you cannot be too careful?' Note here that the response modes to this question are set as mutually exclusive, but the question actually taps both attitudinal and behavioural aspects of trust. Being careful in dealing with strangers does not necessarily prevent one from forming a generally favourable judgement about the overall social milieu in which one finds oneself, while trusting fellow citizens does not presume carelessness in one's own behaviour [15]. Furthermore, neither response to this question says much about one's own trustworthiness as earlier noted. Thus, trust in fellow citizens, being careful in one's own activities and being trustworthy are different dimensions. On the other hand, a case could be, and indeed is often, made that information on generalised trust is valuable in aggregate analysis. A society with higher levels of generalised trust is usually one with better governance [16], less corruption and lower crime [17], higher economic growth [18] and better personal and public health [19]. Such associations are becoming more firmly established from findings based on large-scale datasets such as the European Social Survey or the World Value Survey.

An ongoing debate on the relationship between civic engagement and trust is concerned with which of the two has the causal priority. Putnam, following Tocqueville, holds that civic engagement is the 'school of democracy' where people learn from shared civic activities how to work together, solve collective problems, form a closer and more dynamic community and, in the process, become more trusting: 'those more engaged in community life are both more trusting and more trustworthy' ([2], p. 137). Yet it could also be the case that it is not civic activity that fosters trust but it is those who are innately trustful who are more likely to participate in civic activities in the first place. While analyses based on contemporaneous data cannot make causal inferences about trust from participatory activities, research using panel data can shed some light. For instance, using the British Household Panel Survey, Li, Pickles and Savage [20] show that, controlling for prior levels of trust, civic engagement does not make people more trusting. Similar findings are shown in Switzerland [21] and France [22], but not in Japan [23] which has fewer civic associations than other developed countries ([24], p. 501).

If civic engagement does not necessarily lead to greater trust, the question is turned to other possible sources. According to Uslaner [25], generalised trust is moralistic in nature, a value passed over generations and learned through early childhood. If one's grandparents or parents are more trusting, people will grow up with the world view that 'most people can be trusted'. This view also tallies with Putnam's observation that thin trust reflects one's life experience and with the survey findings that those from higher class origins, particularly the second-generation middle class, tend to display greater levels of generalised trust, in contrast chiefly with the second-generation working class ([26], p. 405; [27]). This may reflect the greater confidence of the most privileged groups in society in dealing with people in different situations, reinforced by their command of greater socio-economic-cultural resources and their safer working and living conditions protecting them from the harsh realities faced by the disadvantaged groups who may place greater trust in their bonding ties.

With regard to 'thick' trust at the micro level, that is, trust in one's family and friends, research shows that it has shrunk just as thin trust has much dissipated ([2], pp. 140-141). Pahl and Pevalin [28] and McPherson, Smith-Lovin and Brashears [29] show that people in the USA and in Britain have 'hunkered' in their social relations, with smaller circles of friends who are increasingly drawn from kin rather than from friends, colleagues or neighbours. The evidence on both strands of trust lends support to the thesis of declining social capital in the two countries.

Between thin and thick trusts, one may think of a meso-level trust, that is, trust in people in one's neighbourhood. Indeed, while thin trust in the generalized others (fellow citizens) may seem too nebulous to ordinary people and thick trust in family and friends could be generally taken as a given, the meso-level trust is regarded by some researchers as a better measure of community cohesion [30]. Most people's daily encounters are limited and they may have little knowledge about the trustworthiness of most, let alone all, of their fellow citizens, and their working life may be rife with competition. Trust in the neighbourhood could avoid these issues and it might also be seen as an indicator of one's own trustworthiness. People who trust most of their neighbours tend to have good relations with them through honest behaviour, generous help and frequent exchange of fa- 
vours, and are in turn accepted as being trustworthy by their neighbours. Untrustworthy people are unlikely to make friends or maintain good relations with neighbours. This kind of trust does not depend on one's socio-economic position as much as the macro level trust does. Given these and other considerations, one may argue, as do Heath and Laurence [30], that the meso-level trust is a better instrument than thin or thick trust for measuring social cohesion. In this paper, we adopt this approach and use neighbourhood trust together with civic engagement as the core elements of social capital in the two countries ([31], see [32-34]).

Having discussed civic engagement and social trust at some length, we now have a brief look at the socio-cultural underpinnings of social capital. Sociologists researching on social capital usually look at socio-economic differences in its generation. Here the general consensus is that formal civic engagement and generalised trust are conditional upon the socioeconomic resources at one's disposal. Take research on British social capital as an example. Although Hall [3] and Li, Savage and Pickles [4] disagree about the trends of social capital in the country, with the former claiming a vibrant and healthy civic life and the latter claiming a general decline, they do agree about the pronounced and increasing social division underlying the changes. As class-based research on China's civic engagement and social trust is limited, we know of no such analysis of Chinese civic life or trust (although see brief discussions in $[35,36]$ ).

A comparative study of civic life in Britain and China has considerable challenges. The two countries have many differences in terms of civic traditions, political institutions and levels of economic development. Britain has a democratic polity and a liberal economic system with a long tradition of civic engagement spanning over one hundred years [3,37]. Successive governments in Britain have adopted 'civicfriendly' policies. The current government is trying to build a 'Big Society' in order to 'mend the broken Britain' [38]. China's situation is rather different. With a state socialist polity and a dual economic structure (a growing market sector accounting for around $80 \%$ of the GDP but a strong state sector holding monopoly powers in key economic areas), civic engagement in China has rarely been officially endorsed or encouraged. Even in present-day China, the state grip on the voluntary sector is still firm, although much more relaxed than in the first three decades after the founding of the People's Republic of China in 1949. Furthermore, as Fei [39] observed long ago, China does not have a tradition of civic engagement, and Chinese social life is clan-based with a clearly-defined radius of trust extending, like a ripple, from family, kin, friends, neighbours, fellow-villagers/townspersons, fellow workers, to others.

A second difference relates to the shape of the class structure. Formal civic engagement is, as observed in previous research $[3,4,37]$, closely related to the state of economic and political life. Britain has a large middle class which has helped offset the civiceroding forces of the market. The decline in civic culture could, among other things, be traced to the marked changes in the occupational structure with the contraction of the working class and its involvement in trade unions and working-men's clubs. Middle-class civic participation tends to be spontaneous and individualistic. In the early 1970s when the British economy was in buoyancy, the working class enjoyed a healthy and vibrant civic life. Yet, with the state retrenchment, the collapse of heavy industry and the privatization of economic activity, the working-class collective strengths via trade unions have all but disappeared [40].

It is not possible to trace such trends in China, due to the lack of data. However, the rapid economic development in the last thirty years and the loosening of the ideological control by the state would lead us to expect a burgeoning civic life, especially in the urban areas where people may spontaneously organize themselves to solve problems engendered by the withdrawal of public services, the gnawing pains of economic transition, and the institutionally-backed inequality. For instance, during the economic restructuring, millions of urban workers, especially women, were laid off, many even in their thirties or forties. In search of a relatively meaningful and constructive life in the face of economic transition, growing competition and increasing inequality, many people would set up recreational, educational or mutual-help groups. Similarly, over 200 million peasants have moved into cities to find a job and better life for themselves and their children. How to spend their spare time and help with children's education is of chief importance to them.

We would also expect a growing civic life in China as a result of overall rising prosperity. From 1980 to 2005, the average real annual income in China increased at a rate 6.4 times as high as that of the world average ([41], p. 1489). Between 1970 and 2010, China's HDI (Human Development Indicator, developed by the United Nations Development Programme [42]) rose from 0.349 to 0.718 , ranking the country 75th place out of 135 countries with comparable data, above the regional average. Yet, with the rising prosperity comes increasing social inequality, with the Gini coefficient jumping from 0.35 in 1980 to 0.45 in recent years (some even estimated it to be over 0.5 ), much higher than the 0.37 in the UK ([42], p. 26). In 2005, the per capita income in Shanghai (the richest place in China) was 7.6 times that in Guizhou (the poorest province in China). Boasting one of the most rapidly developing economies in the world, China is now finding itself with increasing unease and embarrassment (the overwhelming goal of the Chinese Communist Party and the Socialist system is to provide equality for the Chinese people, which is enshrined in the country's Constitution) as one of the most unequal 
and increasingly polarised societies. Within China, people of all walks of life and government at all levels are aware of the growing social inequality, and building a 'harmonious society' has become a state policy, with even the top leadership now calling for a 'scientific social management' [43] including a bigger role for the voluntary sector. More people with more money would also mean a more active civic milieu with a sizeable number among the growing middle and upper classes making contributions to voluntary, including fund-raising, activities to help the poor, fight against natural disasters, and enhance the public welfare in general.

Sociological analysis of social capital in China could hardly proceed without taking into account the most significant political institution, namely, the household registration system (hukou). This system, instituted in 1955 to regulate population migration, job assignment and resource allocation, has placed the rural and the urban sectors into the greatest social divide. A person's hukou status is determined at birth, following that of the mother. Most people in the countryside thus have rural hukou, and are destined to be peasants except for the few who could escape such a fate, usually via higher education or joining the army and becoming an officer. Although the system has been gradually loosened in recent years, particularly in small cities, access to urban hukou in big, particularly metropolitan, cities still remains an insurmountable barrier for most people born in the countryside. This system, absent in Britain, is not only an obstacle for social mobility, but also a hindrance for civic engagement: the two are closely linked. The institutionally-enforced lack of upward mobility chances, coupled with a clan-based and inward-looking tradition and culture, may produce an abundance of bonding ties but stifles formal voluntary activities.

There are many other differences between the two countries which cannot be covered here due to space limit. Yet one other difference has to be mentioned as it has a direct influence upon social capital generation. China is led by the Chinese Communist Party (CCP) with around 80 million members. As the predominant political force in the country with exclusive powers, the CCP members have more socio-economic resources than the population at large and are also expected to be 'vanguards' in political life and to serve as role models in socio-economic life. As civic engagement cannot be separated from the socio-political life in a country like China, any study of social capital would be incomplete without taking into account the role played by the CCP membership, just as with hukou. We shall therefore take both as China-specific factors in addition to the common socio-demographic factors in the analysis.

There are surely many other differences between the two countries which we do not have space to cover here. Even the factors outlined above-differences in civic tradition, socio-economic development and the unique combination of the CCP rule and the household registration (hukou) system in China, which is not only absent in Britain and other developed countries, but also in other countries of the developing world-would make the comparative study being undertaken here approximate to a 'most different systems' analysis which would lead us to expect pronounced differences in social capital in the two countries. Yet, from a sociological perspective, we may also expect some similarities, namely, that people in more advantaged social (class) positions in both countries would be more likely to find themselves in formal civic activities (and to benefit therefrom), and that there would not be much cross-country difference with regard to class effects. The questions we wish to address are therefore as follows: What are the shapes of civic engagement and neighbourhood trust in China and Britain? What are the common and the unique factors that explain the differences in the two respects? How big are the class differences relative to demographic/institutional ones?

\section{Data and Methods}

To address the questions outlined above, we use, in this study, the China General Social Survey (CGSS, 2005, hereafter called 'China') [44] and the Home Office Citizenship Survey for England and Wales (HOCS, 2005, hereafter called 'Britain' for ease of presentation although there is no intention that the findings will necessarily be applicable to Scotland) [45]. Both are large-scale national representative surveys. The CGSS is jointly conducted by the Survey Research Centre of the Hong Kong University of Science and Technology, and the Sociology Department of the People's University of China. The first CGSS survey was launched in 2003, followed annually or biannually. The CGSS covers 28 provinces, autonomous regions, and municipalities in mainland China with the exception of Qinghai, Tibet and Ningxia. The CGSS2005 has 10,372 respondents aged 18 years and over and resident in private households at time of interview. The HOCS is also a time-series data source conducted annually or biannually beginning in 2001. The HOCS2005 has 14,081 respondents aged 16 or over and resident in private households at time of survey. In the present paper, we confine the analysis to respondents aged 18 to 70 , resulting in a slightly reduced sample size for both surveys. Both datasets have cross-sectional weights (as provided by the data collectors) to account for selection biases, which are used in all analyses reported in the paper so that our findings can be generalized to the respective populations.

The most important reason for using the datasets is the availability of comparable questions on civic engagement and neighbourhood trust. In both data sources, the respondents are asked (CGSS2005 E18; CS2005 Fgroup) whether they partake in civic activities which are not sponsored by the state or organized by their employing organizations. Four common types 
of civic activity are selected for use in the analysis: sports/recreation, religion, children's/adult education, and public welfare (poverty relief, social justice, disaster aid and environment protection). The respondents are also asked (CGSS2005 E14b; CS2005 Strust) how many people in their neighbourhood could be trusted: many, some, a few, or none. As very few of the respondents say that they trust none of their neighbours (1.4\% in China and $1.6 \%$ in Britain), we have grouped the last two categories. These form our outcomes of interest (dependent variables) [46].

Both datasets have rich details on socio-demographic attributes. With regard to our main interest in the stratification factor, class, we use a modified Goldthorpe [47] class schema, differentiating the higher and the lower salariat (professionals, administrators and managers), routine non-manual, ownaccount, manual workers in industry and commerce, peasants [48] (for China) and never worked. Other variables included in the multivariate analysis are age, age squared, gender and marital status and, as mentioned above, China-specific factors on hukou and CCP membership [49]. As the central aim of the paper is to assess the class effects on the two domains of social capital in the two countries, it is essential that we assess whether class has stronger or weaker effects in Britain or China in each of the domains under discussion, and whether class effects are stronger or weaker than demographic/institutional ones in each country. For this purpose, we use the Wald test method [50].

\section{Analysis}

We now proceed with analysis. We start by looking at the sample characteristics and the overall profiles of civic engagement and neighbourhood trust in the two countries, and then move on to (gross and net) class effects on the two domains.

The data in Table 1 show that the two samples are basically similar in terms of age and gender distributions. Marital status is, however, much different, with around $87 \%$ of the Chinese sample but only $58 \%$ of the British sample being married [51]. In this regard, the Chinese people might be viewed as being much more 'traditional' than the British. Another salient difference concerns the distributions to class. As a developing country, China does not have as big a middle class as Britain. Only $10 \%$ of the Chinese are found in the salariat class, as compared with $35 \%$ in Britain. This is mainly due to a very large proportion of the Chinese ( $41 \%$ ) being peasants [52]. In terms of China-specific characteristics discussed earlier, we find $51 \%$ with rural hukou status and nearly $10 \%$ being CCP members.

Table 2 shows the overall profile of civic engagement and neighbourhood trust in the two countries. We list the proportions in each type of civic involvement in the upper, and those at each level of neighbourhood trust in the lower, panels. We also show whether the differences in the distributions in each category between the two countries are statistically significant, using China as the reference.

Table 1. Sample characteristics (percentages or means/standard deviations).

\begin{tabular}{lrc}
\hline & China & Britain \\
\hline Sex & & \\
$\quad$ Female & 53.2 & 50.4 \\
$\quad$ Male & 46.8 & 49.6 \\
Marital status & & \\
$\quad$ Non-married & 13.2 & 42.4 \\
$\quad$ Married & 86.8 & 57.6 \\
Class & & \\
$\quad$ Higher salariat & 4.8 & 10.8 \\
$\quad$ Lower salariat & 5.4 & 20.1 \\
$\quad$ Routine non-manual & 13.9 & 12.1 \\
$\quad$ Own account & 5.2 & 8.7 \\
$\quad$ Manual worker & 23.9 & 38.5 \\
$\quad$ Peasants & 40.9 & - \\
$\quad$ Never worked & 6.0 & 5.8 \\
Hukou origin & & \\
$\quad$ Urban & 48.6 & - \\
$\quad$ Rural & 51.4 & - \\
CCP member & 9.6 & - \\
Age (mean) & 42.8 & 42.6 \\
Age (SD) & $(13.0)$ & $(14.5)$ \\
(N) & 9,817 & 12,04 \\
\hline
\end{tabular}

Notes: 1. The urban/rural distinction and CCP membership status refer to China only; 2. For respondents resident in private households aged 18-70 at the time of interview; 3. Weighted analysis in this and all following tables. Sources: China General Social Survey (2005) [44] and Citizenship Survey (2005) [45]. 
Table 2. Proportions in civic engagement and neighbourhood trust in China and Britain.

\begin{tabular}{lrl}
\hline & China & Britain \\
\hline Participation in civic & & \\
organisations & & \\
$\quad$ Sports/recreation & 26 & $47^{* * *}$ \\
$\quad$ Religion & 6 & $17^{* * *}$ \\
$\quad$ Education & 24 & $32^{* *}$ \\
$\quad$ Public welfare & 23 & $33^{* * *}$ \\
Trust in neighbours & & \\
$\quad$ Many & 61 & $47^{* * *}$ \\
$\quad$ Some & 29 & $36^{* * *}$ \\
$\quad$ None/a few & 10 & $16^{* * *}$ \\
\hline
\end{tabular}

Note: Results of significance test for the difference in each category are shown with China as the reference category, $* p<0.05, * * p<0.01$ and $* * * \mathrm{p}<0.001$.

From the data in Table 2, we can see that the Chinese people are much less involved in civic activity but have much higher trust in their neighbours. In each of the four types of civic engagement, the Chinese sample has a significantly lower proportion than the British: around one half in sports/recreational and religious activities and two thirds in activities for children's/ adult education and for public welfare as compared with Britain. Yet a much higher proportion of the Chinese sample regards their neighbours as trustworthy: $61 \%$ of the Chinese as compared with $47 \%$ of the British say that many of their neighbours can be trusted [53].

The overall differences in the two domains are not hard to understand. China, as noted earlier, does not have a tradition of civic involvement. The Chinese culture encourages people to look up to the authorities for organizing socio-economic life and solving problems of social injustice. Yet, underlying these overall differences, there may be more powerful structural (class) differences. In the following analysis we try to disentangle such differences.

Table 3 shows the class differences in the four types of civic engagement. Apart from religion where the Chinese people are known to have a generally lower affiliation than the British, the distributions to the other aspects are as expected. Three notable features emerge from the table. First, the peasant class have a very low level of involvement in formal recre- ational, educational and public/welfare activities, much below any other group. Secondly, apart from this exceedingly low involvement as induced by the institutionally-enforced barrier, we also find marked class differences among the non-peasant sections in China, which amount to a similar extent to that found in Britain. Thus the differences between the higher salariat and the manual working class in sports/recreation in China run at 23 percentage points $(57 \%-$ $34 \%)$, comparable to the 24 point difference in the British sample in this regard $(61 \%-37 \%)$. The differences between the two classes are 19 and 14 points respectively in education, and 24 and 20 points respectively in public welfare. Thirdly, while there are fairly small class differences in religious involvement in China, such differences are still salient in Britain, with one in four of the higher salariat partaking in religious activities, twice as much as the manual working class.

Table 4 shows the data on neighbourhood trust. Here we find that those in the most disadvantaged positions in China, the peasants, are the most trustful group, with $71 \%$ saying that many people in their neighbourhood (village) can be trusted and only $6 \%$ believing that only a few or no one in their neighbourhood can be trusted. This is the most trustful class among all the Chinese social groups. Among the other classes in China, there is little difference in trust, with most groups having at least $50 \%$ believing that many of their neighbours can be trusted. The British profile is rather different, with those in more advantaged class positions being more trusting. Thus we find that $59 \%$ of the higher salariat but only $40 \%$ of the working class say that many of their neighbours can be trusted, with a difference of 19 percentage points in this regard.

While the data in Tables 3 and 4 show similar class effects in civic engagement between the two countries and greater class differentials in neighbourhood trust in Britain than in China, one might wonder whether such patterns are spurious. We noticed earlier that a much higher proportion of respondents in the Chinese sample were married and much research has shown that marriage is itself a form of social capital in multifaceted aspects $[2,7,20]$. So, perhaps the class differences as we have just observed are confounded and would reduce to insignificance once the demographic attributes such as age, gender and marital status as well as China-specific factors (hukou and CCP membership) are controlled for.

Table 3. Class differences in civic engagement in China and Britain.

\begin{tabular}{lcccccccc}
\hline & \multicolumn{2}{c}{ Sports/recreation } & \multicolumn{2}{c}{ Religion } & \multicolumn{2}{c}{ Education } & \multicolumn{2}{c}{ Welfare } \\
\cline { 2 - 9 } & China & Britain & China & Britain & China & Britain & China & Britain \\
\hline Higher salariat & 57 & 61 & 4 & 25 & 50 & 39 & 53 & 45 \\
Lower salariat & 56 & 57 & 6 & 23 & 48 & 41 & 48 & 45 \\
Routine non-manual & 43 & 51 & 8 & 19 & 39 & 36 & 36 & 35 \\
Own account & 20 & 46 & 8 & 18 & 27 & 31 & 23 & 29 \\
Manual worker & 34 & 37 & 6 & 12 & 31 & 25 & 29 & 25 \\
Peasants & 6 & - & 4 & - & 9 & - & 7 & - \\
Never worked & 42 & 32 & 10 & 16 & 30 & 26 & 25 & 20 \\
\hline
\end{tabular}


Table 4. Class differences in neighbourhood trust in China and Britain.

\begin{tabular}{lccrrrrr}
\hline & \multicolumn{3}{c}{ China } & \multicolumn{3}{c}{ Britain } \\
\cline { 2 - 7 } & Many & Some & Few & Many & Some & Few \\
\hline Higher salariat & 58 & 31 & 12 & 59 & 34 & 7 \\
Lower salariat & 54 & 34 & 12 & 57 & 32 & 11 \\
Routine non-manual & 50 & 37 & 13 & 48 & 39 & 13 \\
Own account & 60 & 30 & 10 & 49 & 32 & 19 \\
Manual worker & 54 & 33 & 13 & 40 & 38 & 22 \\
Peasants & 71 & 23 & 6 & - & - & - \\
Never worked & 54 & 30 & 16 & 31 & 44 & 25 \\
\hline
\end{tabular}

To address this question, we conduct multivariate analysis. Table 5 shows logit regression coefficients where participation in each type of civic activity, and trusting 'many' neighbours [54] are our outcome variables. Apart from within-country analysis, betweencountry comparisons are also made with China as the reference.

Looking at the demographic attributes, we find that, controlling for all other factors in the models, Chinese men are significantly less likely to be involved in religious but more involved in children's or adult educational activities than Chinese women. The first finding may indicate greater time constraint and the second a conventional perception and associated sense of responsibility [55] that men should take a greater role in educational matters, especially children's education by, for instance, actively partaking in PTA matters. Except for greater participation in sports/recreation, British men are less likely to attend religious, educational and welfare activities than British women. With regard to cross-country comparison, we find, with the exception of sports/recreation which may indicate a relative lack of facilities in China, that British men play a smaller role than Chinese men in both education and public welfare activities. It is interesting to note that whilst no significant gender difference manifests itself with regard to neighbourhood trust in China, British men are found as being significantly more trusting than British women, attesting to previous research on US and UK societies with regard to generalized and particularized trust ([3], p. 432; [7], p. 71; [20], p. 118; [26], p. 405; [27], p. 35; although [7] p. 74 find notably but non-significantly higher male than female trust in neighbours). In Britain, marriage seems to have a more salient impact on civic activity than is found in China, which is unsurprising as an overwhelming majority of the Chinese sample are married. Nevertheless, in both countries, the married tend to have more congenial neighbourly relations as indicated by higher levels of neighbourhood trust. Other things being equal, age effects are generally slight in both countries.

The class effects manifest themselves most systematically and saliently. Controlling for all other variables in the models, we find the Chinese peasants being least likely to be engaged in civic activities, which is a clear indication of their lack of resources and opportun- ities. To this, we also need to add the significant inactiveness for people with rural hukou origins: people with the rural hukou origin status and currently found as peasants are doubly handicapped and their likelihood to engage in sports, education and welfare activities is very much behind that of their higher salariat compatriots $\left(e^{(-1.71+-1.33)}=0.048, e^{(-1.60+-0.94)}\right.$ $=0.079$, and $\mathrm{e}^{(-1.73+-0.88)}=0.074$ in the odds). People in non-salariat positions, particularly manual workers, are also found to be significantly behind their higher salariat counterparts in sports, education and welfare activities, and that in both countries. CCP members have, other things being equal, a generally more active profile in sports/recreation, education and public/welfare activities as well as in trust, which is most probably due to their greater command of socio-economic-cultural resources [56]. In Britain, the class gradients are salient and systematic, including those in neighbourhood trust, with the manual workers being only around one third to one half as likely as the higher salariat to engage in civic activities or to trust their neighbours (ranging from $\mathrm{e}^{-0.99}=0.37$ to $\mathrm{e}^{-0.69}=0.50$ in the odds).

Having looked at the data in some detail, we come to an overall look. Here we are interested in three questions as outlined earlier: (1) are there significant cross-country class differences for people in the same class positions? (2) in which of the two countries do we find greater class differences at the overall level? and (3) do class differences manifest themselves at a higher or lower level than demographic/institutional ones within each country?

As for the first question, our data in Table 5 clearly show that, apart from religion and trust where the Chinese people do not show much difference as earlier noted, there are few significant cross-country class differences. Only in 3 out of 12 tests (bold figures in the class part) do we find significant differences, and two of them are related to the self-employed: namely, that the own-account workers in China are even less likely than their British counterpart to engage in sports/recreational activities, or children's/adult educational clubs. This suggests that people in the same class positions in the two countries behave in a fairly similar way in terms of civic engagement. In other words, the relative advantages and disadvantages associated with class manifest themselves in basically the same manner in the two countries. 
Table 5. Logit regression coefficients on civic engagement and trust in neighbours ('trusting many') in China and Britain.

\begin{tabular}{|c|c|c|c|c|c|c|c|c|c|c|}
\hline & \multicolumn{8}{|c|}{ Civic engagement } & \multirow{2}{*}{\multicolumn{2}{|c|}{ Neighbourhood trust }} \\
\hline & \multicolumn{2}{|c|}{ Sports/recreation } & \multicolumn{2}{|c|}{ Religion } & \multicolumn{2}{|c|}{$\begin{array}{c}\text { Children/adult } \\
\text { education }\end{array}$} & \multicolumn{2}{|c|}{ Public welfare } & & \\
\hline & China & Britain & China & Britain & China & Britain & China & Britain & China & Britain \\
\hline Male (female $=$ ref $)$ & 0.05 & $0.27 * * *$ & $-0.55^{* * *}$ & $-0.52 * * *$ & $0.14^{* *}$ & $-0.59 * * *$ & 0.08 & $-0.46^{* * *}$ & 0.04 & $0.20 * * *$ \\
\hline Age & $-0.10 * * *$ & $-0.03^{* *}$ & 0.04 & $-0.03^{*}$ & $0.03 *$ & $0.04 * * *$ & -0.02 & $0.02 *$ & 0.01 & 0.02 \\
\hline Age squared & $0.00 * * *$ & 0.00 & -0.00 & $0.00 *$ & $-0.00 * * *$ & $-0.00 * * *$ & -0.00 & -0.00 & -0.00 & 0.00 \\
\hline Married & $-0.35^{* * *}$ & 0.04 & -0.19 & $0.52 * * *$ & 0.00 & $0.54 * * *$ & -0.14 & 0.06 & $0.23 * *$ & $0.23 * * *$ \\
\hline \multicolumn{11}{|l|}{ Class $($ Higher salariat $=$ ref $)$} \\
\hline Lower salariat & -0.04 & -0.10 & 0.45 & $-0.22 * *$ & -0.15 & 0.02 & -0.17 & -0.11 & -0.10 & -0.02 \\
\hline Routine non-manual & $-0.47 * * *$ & $-0.33 * * *$ & $0.62 *$ & $-0.52 * * *$ & $-0.57 * * *$ & $-0.34 * * *$ & $-0.59 * * *$ & $-0.59 * * *$ & $-0.24 *$ & $-0.29 * * *$ \\
\hline Own account & $-1.24 * * *$ & $-0.56 * * *$ & $0.68 *$ & $-0.39 * * *$ & $-0.99 * * *$ & $-0.30 * * *$ & $-1.00 * * *$ & $-0.76 * * *$ & 0.04 & $-0.47 * * *$ \\
\hline Manual worker & $-0.66 * * *$ & $-0.98^{* * *}$ & 0.50 & $-0.98^{* * *}$ & $-0.78^{* * *}$ & $-0.69 * * *$ & $-0.75^{* * *}$ & $-0.99 * * *$ & -0.13 & $-0.69 * * *$ \\
\hline Peasants & $-1.71 * * *$ & & -0.33 & & $-1.60 * * *$ & & $-1.73 * * *$ & & 0.22 & \\
\hline Never worked & $-0.69 * * *$ & $-1.28 * * *$ & $0.78 * *$ & $-0.66 * * *$ & $-0.96 * * *$ & $-0.73 * * *$ & $-1.12 * * *$ & $-1.20 * * *$ & 0.01 & $-0.83 * * *$ \\
\hline Rural hukou (urban = ref) & $-1.33^{* * *}$ & & 0.12 & & $-0.94 * * *$ & & $-0.88 * * *$ & & $0.49 * * *$ & \\
\hline CCP member (other $=$ ref) & $0.51 * * *$ & & -0.29 & & $0.43 * * *$ & & $0.70 * * *$ & & $0.17^{*}$ & \\
\hline Constant & $2.95 * * *$ & $1.17^{* * *}$ & $-3.70 * * *$ & $-0.53 *$ & 0.34 & $-0.78 * * *$ & $0.83 * *$ & $-0.64 * *$ & -0.32 & $-0.88 * * *$ \\
\hline $\mathrm{N}$ & 9,624 & 11,781 & 9,624 & 11,781 & 9,624 & 11,781 & 9,624 & 11,781 & 9,534 & 11,77 \\
\hline
\end{tabular}

Notes: 1 . For within-country differences in each domain, each category is contrasted with the reference category. ${ }^{*} \mathrm{p}<0.05, * * \mathrm{p}<0.01, * * * \mathrm{p}<0.001 ; 2$. For between-country comparisons, significant differences in either direction are shown in bold under the column of Britain (all bold figures significant at the 0.05 level or higher). 
With regard to the second question, further analysis shows that there are no cross-country class differences at the overall level in terms of sports/recreational activities, children's/adult education and public welfare activities ( $p$ 0.817, 0.053, 0.993) but there are significantly greater class impacts in religion and trust in Britain than in China (at the 0.001 level) in both cases. This suggests that apart from religion, class operates in the same way in both countries in terms of civic engagement.

Finally in this section, further analysis with respect to the third question shows that class effects are significantly more pronounced than demographic (and including, in China, hukou and CCP membership) effects in each of the civic types and in neighbourhood trust, and that in both countries (all significant at the 0.05 level or above), attesting to the key role played by class in social capital development.

\section{Conclusions}

This analysis has focused on two domains of social capital in China and Britain: civic engagement and neighbourhood trust. Drawing on national representative surveys in the two countries containing similar questions on the two domains, our evidence shows stronger civic engagement in Britain but greater neighbourhood trust in China at the overall level. Yet underlying this are strong structural (class and, additionally in China, hukou) effects. In this section, we give some reflections on the findings.

With regard to the lower civic engagement in China than in Britain, there are of course many reasons. We have noted Fei's [39] famous discussion of China's tradition of clan-based social life under the centralised power system which, while fostering trust among family, friends, kin and neighbours, stifles civic spirit under which people spontaneously organize themselves to solve community problems, as was the case in the USA [2,57], and China also lacks the tradition of strong state support for civic associations as found in Britain $[3,37]$. The strict control by the Government since 1949 in almost every aspect of socio-economic life has also resulted in a rather unfavourable sociopolitical milieu for civic organizations to take root in China. It was during the reform period that NGOs, GONGOs (government-organized non-government organisations), or community groups such as literary groups, elderly groups, friendship groups, fellowstudent associations, sports/recreational clubs, religious and sundry hobby groups began to emerge and develop, which grew rapidly in the last one or two decades from 107,304 in 1991 to 386,917 in 2007 [58]. But civic organizations in general are finding themselves being sandwiched: they are being closely monitored by the Government and watched over by ordinary people with caution and even some suspicion [59].

The lower level of socio-economic development in China may also help to explain its lower civic engage- ment. As observed by many researchers $[2-4,7,20,26$, $30,33,34]$, the middle class has been the backbone of a vibrant civic life in the developed countries. As China's middle class is much smaller than that in Britain and as China has a very large peasant population, it may take decades for China to catch up. Yet our findings of a fairly similar role played by class in the two countries in civic engagement give the hope that as China's economy continues to grow and as its urbanisation programme strives forward, its civic life will begin to prosper too.

Our findings of the strong class effects on civic engagement also show the mounting challenges faced by the governments in the two countries in their attempts to build 'harmonious' or 'big' societies. Those in more privileged positions in China, just like their British counterparts, are more active in civic life whilst the manual working classes in both countries, particularly the peasants in China, face considerable shortages in socio-economic resources preventing them from taking an active part in civic activities. Although civic involvement has externalities, the main beneficiaries are the participants whose networks generate direct or indirect resources for themselves and their family. Privilege breeds privilege and many kinds of civic activity are arenas for developing bridging social ties serving both civic and instrumental purposes $[2,9,10]$.

Our analysis showed some apparently unusual features on religion and neighbourhood trust. As for religious engagement, the kind typically practised in rural China is folk religion such as ancestral tablets, memorial halls or Buddhist temples. In some urban and rural settings, Christianity has grown fairly rapidly in recent years, boasting more Christians in China than in Britain. Church activities are, however, not officially endorsed, may be shunned by the elites and are watched with suspicion by the authorities. Overall, formal religious activity is not a common practice. Religious involvement in Britain is much more formally organized where middle-class attendance is more prevalent than in China although a decline in both believing an belonging is also found in process $[26,60]$. The difference on trust is most probably due to the different mobility chances in the two countries. In Britain, owing to the high (absolute) rates of social mobility [61] and its attendant geographical mobility, the overall social homogeneity at the local level would be lower than that in China [62]. On the other hand, the presence of a long-existing housing market would mean that class clustering at the neighbourhood level would be higher than that in China. The greater social mixing may explain the class similarity in trust in China whilst the greater class clustering may explain the greater class differences in trust in Britain. Social mobility is a double-edged sword: it promotes economic development but disrupts social relations. As China's modernisation programme is bound to generate unprecedented levels of social and geographical mobility, 
how to maintain community cohesion is a challenge faced by the government and ordinary citizens.

Research on civic engagement and social trust tends to give the impression that the engaged and the trustful are heroes of a civil society. They are, in a certain sense. But their very ability to engage in civic life and to place trust in their fellow citizens resides in their greater command of socio-economic resources. The most disadvantaged, be they peasants or manual workers, are deprived of opportunities to engage in organized civic activities. It is these groups in whom the real hope of civic dynamics and social trust should be placed, for without their active engagement, no 'harmonious' or 'Big' society could be built. For that to happen, the rising socio-economic inequality must be curbed.

Finally, much research in the developed and the former socialist countries has shown the explanatory power of class in social mobility $[47,61]$ and educational attainment [63]. In this paper, we have shown similar class effects between Britain and China, and

\section{References}

1. Portes A. Social capital: Its origins and applications in modern sociology. Annual Review of Sociology. 1998;24:1-24.

2. Putnam R. Bowling alone: The collapse and revival of American community. New York, NY, USA: Simon \& Schuster; 2000.

3. Hall P. Social Capital in Britain. British Journal of Political Science. 1999;29(3):417-461.

4. Li Y, Savage M, Pickles A. Social Capital and Social Exclusion in England and Wales (1972-1999). British Journal of Sociology. 2003;54(4):497-526.

5. Grenier P, Wright K. Social capital in Britain: Exploring the Hall Paradox. Policy Studies. 2006;27(1): 27-53.

6. Sorensen E, Torfing J. Network Politics, Political Capital and Democracy. International Journal of Public Administration. 2003;26(6):609-634.

7. Sturgis $P$, Brunton-Smith I, Read S, Allum N. Does ethnic diversity erode trust? Putnam's 'hunkering-down' thesis reconsidered. British Journal of Political Science. 2010;41(1):57-82.

8. Castiglione D, Van Deth J, Wolleb G, editors. The Handbook of Social Capital. Oxford, UK: Oxford University Press; 2008.

9. Lin N. Social Capital. Cambridge, UK: Cambridge University Press; 2001.

10. Lin N, Erickson B, editors. Social Capital: An International Research Program. Oxford, UK: Oxford University Press; 2008.

11. Bourdieu P. Sociology in Question. London, UK: Sage; 1993.

12. Coleman JS. Foundations of Social Theory. Cambridge, MA, USA: Harvard University Press; 1990.

13. Putnam R. Commentary: 'Health by association': that in the social capital domain. The two countries possess as much difference as can be found almost in any other two countries in the world in terms of civic tradition, socio-economic development and political institutions. The similar class effects not only attest to the construct validity of class as a sociological concept but also the challenges faced by the governments in reducing the class inequalities.

\section{Acknowledgements}

I am grateful to the Economic and Social Research Council (ESRC) in Britain for funding the project 'Social mobility and social capital in China and Britain, a comparative study', (ES/I035168/1) which is linkfunded by the National Natural Science Foundation of China (NSFC) (71010090). Part of the analysis predated the project. I am very grateful to the three anonymous reviewers for their very helpful suggestions. I am alone responsible for any errors that may exist in the paper.

Some comments. International Journal of Epidemiology. 2004;33(4):667-671.

14. Halpern D. Social Capital. Cambridge, UK: Polity; 2005.

15. While most surveys use the classical question, the most recent one (the Great British Social Class survey conducted by the GfK in 2011) separates the elements. Two thirds of Britons (65.5\%) who agree that 'most people can be trusted' also agree to the statement that 'you cannot be too careful'.

16. Newton K. Social Capital and Democracy. American Behavioural Scientist. 1997;40(5):575-586.

17. Halpern D. Moral values, social trust and inequality-Can values explain crime? British Journal of Criminology. 2001;41(2):236-251.

18. Roth F. Does too much trust hamper economic growth? Kyklos. 2009;62(1):103-128.

19. Wilkinson R. Unhealthy Societies: The Afflictions of Inequality. London, UK: Routledge; 1996.

20. Li Y, Pickles A, Savage M. Social Capital and Social Trust in Britain. European Sociological Review. 2005;21(2):109-123.

21. Frietag M. Beyond Tocqueville: The origins of social capital in Switzerland. European Sociological Review. 2003;19(2):217-232.

22. Mayer N. Democracy in France: Do associations matter? In: Stolle D, Hooghe M, editors. Generating Social Capital: Civil Society and Institutions in Comparative Perspective. New York, NY, USA: Palgrave Macmillan; 2003. pp. 43-66.

23. Freitag M. Social Capital in dissimilar democracies-The development of generalised trust in Japan and Switzerland. Comparative Political Studies. 2003; 36(8):936-966.

24. Kerbo $H$. Social Stratification and Inequality, 5th ed. New York, NY, USA: McGraw Hill; 2003. 
25. Uslaner E. The Moral Foundations of Trust. Cambridge, UK: Cambridge University Press, 2002.

26. Li Y, Savage M, Warde A. Social mobility and social capital in contemporary Britain. British Journal of Sociology. 2008;59(3):391-411.

27. Welch M, Sikkink D, Loveland $M$. The Radius of Trust: Religion, Embeddedness and Trust in Strangers. Social Forces. 2007;86(1):23-46.

28. Pahl R, Pevalin D. Between family and friends: A longitudinal study of friendship choices. British Journal of Sociology. 2005;56(3):433-450.

29. McPherson M, Smith-Lovin L, Brashears M. Social isolation in America: Changes in core discussion networks over two decades. American Sociological Review. 2006;71(3):353-375.

30. Heath A, Lawrence J. Predictors of community cohesion: Multilevel modelling of the 2005 Citizenship Survey. 2008. Available from: http://www.communities. gov.uk/documents/communities/pdf/681539 (accessed on 22 March 2008). See also: Lawrence J. The Effect of Ethnic Diversity and Community Disadvantage on Social Cohesion: A Multi-Level Analysis of Social Capital and Interethnic Relations in UK Communities. European Sociological Review. 2009;1(1):1-20.

31. Other aspects of civic engagement and trust can be differentiated such as politically-oriented associations and trust in political institutions ([32,33,34]).

32. Paxton P. Is Social Capital Declining in the United States? A Multiple Indicator Assessment. American Journal of Sociology. 1999;105(1):88-127.

33. Li Y, Marsh D. New forms of political participation: Searching for Expert Citizens and Everyday Makers. British Journal of Political Sciences. 2008;38(2): 247-272.

34. Li Y. Measuring social capital: Formal and informal activism, its socio-demographic determinants and socio-political impacts. In: Bulmer M, Gibbs J, Hyman $L$, editors. Social measurement through social surveys: an applied approach. Aldershot, UK: Ashgate Publishing; 2010. pp. 173-194.

35. Fukayama F. Trust. New York, NY, USA: Free Press; 1995.

36. Paxton P. Association Memberships and Generalized Trust: A Model of Generalized Trust in ThirtyOne Countries. Social Forces. 2007;86(1):47-76.

37. Szreter S. The state of social capital: Bringing back in power, politics and history. Theory and Society. 2002;31(5):573-621.

38. Cameron D. We must mend our broken society. The Guardian; 11 August 2011.

39. Fei X. Xiangtu Zhongguo. Beijing, China: Sanlian Shudian; 1947. English translation by: Hamilton G, Zheng W. From the Soil: The Foundations of Chinese Society. Berkeley, CA, USA: University of California Press; 1992.

40. An analysis of the trends can help make this point clearer. The Social Mobility Inquiry survey conducted in 1972 shows that $40 \%$ of men aged $20-64$ in that year were union members and the proportion for those in the working class was at a much higher level: $52 \%$. In the Home Office Citizenship Survey of 2010 we find that, for men of the corresponding ages, the figures are only $10 \%$ and $9 \%$ respectively.

41. Hung $H$, Kucinskas J. Globalization and Global Inequality: Assessing the Impact of the Rise of China and India, 1980-2005. American Journal of Sociology. 2011;116(5):1478-1513.

42. UNDP. Regional Report on Human Development; 2010. Available from: http://hdr.undp.org/en (accessed on 10 September 2012).

43. Hu J. Take real steps in enhancing scientific social management. People's Daily; 19 February 2011.

44. China General Social Survey. Available from: http://www.cssod.org/search.php?key=CGSS (accessed on 7 March 2008).

45. Home Office Citizenship Survey. Available from: http://www.data-archive.ac.uk/findingData/hocsTitles.a sp (accessed on 12 September 2007).

46. The question wording to these outcome variables in the two surveys are rather long and we do not reproduce them here. Interested readers could follow the links in Notes 44 and 45.

47. Goldthorpe J. Social Mobility and Class Structure in Modern Britain. Oxford, UK: Clarendon Press; 1987.

48. Class is indexed by the respondent's current (and for those currently not in gainful employment, last main) job in both countries as is the standard practice in class analysis. Around a quarter of people with rural hukou origins in our Chinese sample were doing non-agricultural work and are coded according to the jobs they were doing. It is also noted here that some people residing in suburban areas and doing agricultural work are given urban hukou. Residence and hukou are not equivalent in China. Over two hundred million peasants are living and working in cities as 'migrant workers', who retain their origin hukou status. Manual workers in Classes V-VII in the Goldthorpe class are hard to differentiate in China and are thus grouped together for both countries. As only $0.39 \%$ and $0.48 \%$ of the working-age population in Britain were found in Classes IVc and VIIb respectively in the Goldthorpe class schema (farmers and small holders, and agricultural labourers), it is not possible to code a farming class in the British data for comparative analysis with China's peasant class.

49. We do not include education in the analysis. This is because class destination in China depends primarily upon hukou. Only a very small proportion of people with rural hukou origin status could have tertiary education. The overwhelming majority, even those with higher secondary education, would have to stay in the countryside. The institutional barriers thus mean that educational effects between the urban and the rural sectors are incomparable and to introduce them to the comparative analysis is likely to bring bias. (We conducted analysis including education and that for the urban and the rural hukou origins separ- 
ately. The overall class patterns are similar to those reported in the text. The results are available on request). We also conducted analyses including employment status in addition to all the other variables in the modelling exercises. Unemployment has little effect on civic engagement in Britain but negative effects in China (with the exception of religion). The unemployed in both countries are less trusting, more so in Britain than in China. However, including employment status does not change the main patterns on class. As the main focus in this paper is on class, we do not present the analysis on employment status (available on request).

50. The formula for the test is written as $t=(b 1-$ b2) $/\left(s 1^{2}+s 2^{2}\right)^{1 / 2}$. The tests are conducted using the seemingly unrelated estimation method (suest in Stata).

51. Further analysis, not shown in the table, reveals that over half of the Chinese sample aged 24 and 25 were married, reaching $70 \%-80 \%$ between ages $26-29$ and over $90 \%$ for people aged 30 or over but in none of the similarly coded age groups in the British sample do we find over $70 \%$ of the respondents being married.

52. Among the urban sample in China, the salariat was much larger, at $18 \%$, and the proportion of the working class (38\%) was almost the same as that in Britain (39\%).

53. Further analysis shows that apart from religion, the urban sample in China had similar civic engagement to the British: $45 \%, 38 \%$ and $36 \%$ in sports, education and public welfare. The rural sample had much lower involvement: $9 \%, 11 \%$ and $10 \%$ respectively.

54. We also conducted an ordinal logit model on neighbourhood trust. The patterns including the Wald test results are similar to those reported here (data available upon request).

55. This may reflect the influence of Confucianism which, for thousands of years, has taught us that men in general, and intellectuals in particular, should take it as their duty to 'nurture the mind, cultivate the body, support the family, provide good governance to the country and bring peace to the world' (zhengxin, xiushen, qijia, zhiguo, pingtianxia, from Confucius: The Great Learning).

56. We also carried out an analysis excluding hukou and CCP membership which shows basically similar patterns but with some slight changes in the cross-country comparisons (data available upon request).

57. Tocqueville A. Democracy in America. New York, NY, USA: W.W. Norton \& Company; 2007.

58. Chan K. Civil Society and Social Capital in China. Democracy. 2009;16(3):5-19.

59. NGOs in China have to register with the Government or become 'patronised' (affiliated to government units, state enterprises or public organisations such as universities) and are thereby directly or indirectly controlled. Although many NGOs have made significant contributions to poverty alleviation, children's education in rural and especially mountainous areas, environmental protection and public health, some of them are notoriously corrupt, turning away many volunteers and potential donors as witnessed in the very low levels of donations to the earthquake victims earlier this year (2003) as compared with the profuse enthusiasm and very generous donations a few years ago in a similar natural disaster. Given the already very weak basis of civic engagement in China, the corruption scandals add salt to the wound. This also shows the challenges faced by the nascent civic organisations in China.

60. Voas D, Crockett A. Religion in Britain: Neither Believing nor Belonging. Sociology. 2005;39(1):11-28.

61. Goldthorpe JH, Mills C. Trends in intergenerational class mobility in Modern Britain: Evidence from national surveys. National Institute Economic Review. 2008;205(1):83-100. See also: Li Y, Devine F. Is Social Mobility Really Declining? Intergenerational Class Mobility in Britain in the 1990s and the 2000s. Sociological Research Online; 2011. Available from: http://www.soc resonline.org.uk/16/3/4.html (accessed on 3 September 2011).

62. Further analysis using the HOCS2005 shows that $60 \%$ of higher salariat households in Britain live in wealthy and prosperous areas as compared with only $17 \%$ of those headed by routine manual workers. No data on neighbourhood deprivation are available in CGSS2005.

63. Breen R, Luijkx R, Müller W, Pollak R. Non-Persistent Inequality in Educational Attainment: Evidence from Eight European Countries. American Journal of Sociology. 2009;114(5):1475-1521. 


\title{
A Neo-Rawlsian Approach to Residential Integration
}

\author{
Kevin J. Brown
}

Department of Business, Economics, and Political Science, Asbury University, 1 Macklem Drive, Wilmore, KY 40390, USA; E-Mail: kevin.brown@asbury.edu; Tel.: +1 8598583511; Fax: +1 8598583921

Submitted: 15 July 2013 | In revised form: 22 August 2013 | Accepted: 23 August 2013 |

Published: 29 August 2013

\begin{abstract}
Over the past 40 years, the United States has engaged in various policies to integrate otherwise segregated black and white households within a shared space. However, little work has been done to fully articulate a moral argument for residential integration among black and white households. This paper offers what I refer to as the normative argument, which possesses two morally-impelled arguments for residential integration. Since the ethical appeal to integrate is often couched in the language of justice, I begin with a frameworkbased upon the work of the late philosopher John Rawls-for considering the moral aspects of residential integration. However, I go on to point out intractable problems related to the Rawlsian framework that would fail to flesh out all ethical considerations of the normative argument. From here, I provide a revised, or neo-Rawlsian, framework for understanding residential integration which addresses the aforementioned problems. This exercise is both important and necessary for the future of residential mixing, as better understanding the moral and ethical attributes of this discussion is, perhaps, the best means to lubricate the fundamental shift from 'spatial' to 'social' integration.
\end{abstract}

Keywords: common good; integration; John Rawls; liberalism; residential housing; segregation; social capital; social integration

\section{Introduction}

Today in the United States, the chasm of black-white race-relations remains evident throughout various sectors and institutions in society. One area where this is most clear is in housing arrangements: white and black households are not typically integrated within the same space. However, within the US, we can find several policies directed toward racial and socioeconomic de-concentration over the last 40 years as a means to mix communities with the intended outcome of increasing or enhancing life chances of low-income minorities.

For example, the Chicago Gautreaux Initiative or the multi-state Moving to Opportunity Program were efforts to literally move low-income minorities into more racially and economically heterogeneous neighborhoods (what has been referred to as a "TenantBased Approach") ([1], p. 4). The Gautreaux Program originated from a series of class action lawsuits that were filed against the Chicago Housing Authority ( $\mathrm{CHA})$ in the US and the Department of Housing and 
Urban Development (HUD) where it was alleged that the housing authorities deliberately segregated lowincome African-Americans through tenant and site selection. As a result of the lawsuit, a new program named after plaintiff Dorothy Gautreaux was created in 1976 that offered vouchers and rent subsidies allowing for eligible families to move to desegregated areas throughout the region. By the year 2000, the Gautreaux Program had placed thousands of families into new homes (often times within newer, lesspoverty stricken areas). Planners were inspired by preliminary results from the Gautreaux program, and this evidence informed expectations for Moving to Opportunity. Thus, the Moving to Opportunity (MTO) program was created in the early 1990s as a longitudinal effort that used the poverty rate of the receiving neighborhood rather than its racial composition as the dispersal criterion. Families living in poverty-stricken areas were eligible to receive counseling and apply for assistance to move to a low-poverty neighborhood. The results of these initiatives continue to be explored and researched to the present.

Other programs, such as HOPE VI funding or Fair Share Housing legislation, seek to renovate lowincome public housing to create residential mixedincome and mixed-race housing environments (what has been referred to as a "Unit Based Approach") ([1], p. 4). The HOPE VI program was launched in 1992 and facilitated by the US Department of Housing and Urban Development. HOPE VI grants continue to be awarded for community revitalization initiatives. Fair Share Housing legislation-such as the Mount Laurel, New Jersey rulings-require that every town provide a "fair share" of low- to moderate-income (LMI) housing. This ruling engendered public-private cooperation in addition to cooperation between the suburbs and the cities to rehabilitate urban housing as a way of meeting their fair share requirement.

These aforementioned initiatives differ in their focus on how they address segregation (de-segregation; integration) as well as their target group (race; class). Describing the underlying motivation for integration policy, Sociologist John Logan writes: 'neighborhood integration has remained a goal of public policy and popular opinion because it is seen as proof of the American ideal of equal opportunity' ([2], p. 1).

One of the major issues related to segregation data is not simply where households are segregated from, but where they are segregated to. Indeed, patterns of residential segregation are often associated with stark inequalities related to housing, education, health, labor opportunities, safety, and local resources and amenities. These fundamental features for stability in an advanced democracy are disproportionately secured by white households relative to black households in a racially segregated nation. Thus, it has been concluded that 'Segregation [...] is the key factor responsible for the creation and perpetuation of communities characterized by persistent and spatially concentrated poverty' ([3], p. 118). In addition to segregation demonstrating a deleterious effect on housing values for black segregated areas, it has been positively associated with increased unemployment, poorer educational results, and neighborhood crime ([4], see also $[5,6])$. Further, segregation has been correlated with lower socio-economic status and racial disparities in health [7]. Given this evidence, it is little wonder that social and economic outcomes for blacks are substantially worse, both in absolute terms and relative to whites, in racially segregated cities [8]. Authors Dreier and Moberg (2001) summarize the problems of segregation and what appears to be the intuitive solution: integration.

As politicians and policy analysts revisited the thorny problems of urban poverty in recent years, they seemed to be arriving at a rare consensus: poor people are hurt by their concentration in large, inner-city neighborhoods that further social isolation and racial segregation. In this view, it would be better to disperse poor people and minorities, putting them in closer proximity to jobs, decent suburban schools, and safe communities [9].

This, in essence, is at the heart of the integration idea. It is the belief that segregation is the cause of myriad social ills and integration is a key remedy to this problem.

Despite this evidence and its apparent relation to residential segregation, it is unclear that 'integration' is, indeed, the appropriate solution. Schwartz and Tajbakhsh (1997) advise that while housing policy that encourages racial mixing is a recent trend, the effectiveness of such policy remains questionable until a more robust understanding of social benefits, costs, and preconditions can be sufficiently answered. Until then, they write, advocacy of mixed-housing will be based 'largely on faith' ([10], p. 81).

Despite this skepticism, most who advocate for integration initiatives share a common assumption: the underlying belief that 'segregation is harmful.' Indeed, it has been said that 'few would dispute that racial segregation and concentrated poverty are ongoing challenges' ([11], p. 7). Thus, the assertion that segregation is not good for society holds nearly universal agreement among social scientists and a comprehensive review of the literature would only serve to verify this claim. Yet the core of the issue has less to do with whether segregation is not good and more to do with whether mixing is good. If segregation is the problem, is mixing the solution? Based upon the empirical evidence to date, there is little evidence to definitively support an affirmative answer to this question. In their 2010 book 'The Integration Debate'-Hartman and Squires describe the segregation/integration quagmire well: 'this book provides a harsh reminder of the grave costs of segregation. But it also identifies some of the perhaps unintended consequences that have been encountered in at least 
preliminary efforts to realize more integrated living patterns' ([11], p. 7).

With this in mind, we might remark that there will, perhaps, never be a unified voice as it relates to residential integration and mixing. However, this article aims to offer a new vantage point. The residential integration discussion has been presented and understood under a guise of economic efficacy and the maximization of utility in an aggregate social context. In other words, the goals of mixing programs have sought to improve the welfare and well-being of lowincome minority households in such a manner that the benefits exceed the costs of such programs. The intended outcomes related to integration programs are consistent with this framework, as they seek to de-concentrate citizens for reasons of security, better homes and schools, job opportunities, and a more equal expression of citizenship. If we were only to view these outcomes in a vacuum, we might rightly understand residential segregation as solely an economic problem-particularly as it relates to matters of distribution and, as Elizabeth Anderson describes it, participation in society [12].

However, discussions of residential integration on strictly economic terms without deference to other moral and ethical considerations can be problematic in itself. More specifically, if we understand integration strictly through the lens of the existing framework, are important ethical questions left to the side? This is not to suggest that the utility framework for integration is not a moral framework in itself. Indeed, such a framework has an explicit moral dimension-one that is referenced throughout related literature (particularly where intended integration outcomes are expressed in terms of justice). Improving the lives of segregated minorities through integration initiatives aligns with an array of democratic ideals that are replete with values such as rights, equality, fairness, and equal opportunity (values that are often expressed in economic terms but are ethically driven). In a technical sense, then, the issue has less to do with the presence of ethical reasoning, but rather, is more concerned with the nature of the ethical reasoning that may be absent by virtue of using a utility-based paradigm to evaluate integration.

By including a more capacious ethical paradigm in this discussion, we have grounds to state that 'mix'not necessarily 'mixing'-is good. This is important because mixing strategies have occurred as a result of segregation. They have not occurred, however, from the premise that mix is good. Engineered mixing as a blunt welfare instrument may indeed be a poor device for securing and protecting the welfare and well-being of low-income segregated members of society. However, to communicate the appeal for integration strictly in these terms is to miss and even exclude important normative features.

The balance of this paper is arranged as follows: in Section 2, I begin by stating two normative attributes that are primary in the residential integration discussion. Simply stated, these attributes comprise what I shall refer to as the normative argument. In Section 3, I attempt to provide a philosophical justification for this argument. Specifically, I draw upon the work of John Rawls as a means to support residential integration in a more explicitly moral and ethical manner. However, while Rawls may provide strong ethical support for the first tenet of the normative argument, his framework is a poor foundation for the second. Thus, in Section 4, I offer a neo-Rawlsian model that I submit to be a more appropriate framework for understanding and deliberating upon the moral and ethical features of residential integration. I summarize the implications of this model in my conclusions.

\section{The Normative Argument}

Evaluations of residential mixing have relied upon a general utilitarian ideology. Here, I utilize the term 'utilitarian' in its most general sense: the maximization of utility (the greatest 'good') in an aggregate social context (the greatest 'number'). Thus, to determine efficiency, the optimal arrangement is the one that provides maximum aggregate utility.

I submit, however, that the multifaceted nature of integration, community, and US race relations are not adequately captured in a utilitarian framework, given the singular aim of such a framework. This statement begs the question: what facet(s) of residential integration is the utility framework failing to capture? Here I offer two primary ethical elements relevant to residential integration that have escaped the utility framework as I have defined it. I shall hereafter refer to these elements as the normative argument for residential integration.

The first is the issue of societal fairness and social equity based upon the presence of enhanced risk and vulnerability occurring as a function of living in a racially segregated community. Simply put, we might state that it is unfair when sectors of society are more socially or economically vulnerable and 'bear a disproportionate share of environmental risks' ([13], p. 131). While the efficiency model may be of great importance insofar as providing the optimal social arrangement for utility maximization, it often fails to consider the distribution of this utility. Sen (1997) writes: 'the trouble with this approach is that maximizing the sum of individual utilities is supremely unconcerned with the interpersonal distribution of that sum. This should make it a particularly unsuitable approach to use for measuring or judging inequality' ([14], p. 16). To summarize, we can describe the first ethical issue of the normative argument as relating to considerations in social equity.

The second ethical element that the existing utility framework fails to address is the trajectory of integration's end. Velasquez (1982) suggests that the major drawback to a utility framework is its inability to 
deal with moral issues ([15], pp. 53-54). This is not to suggest that such a framework is amoral or devoid of ethical considerations. However, they are ethical considerations of a very specific kind. For example, most integration initiatives are born out of a desire for enhanced welfare and equal opportunity. While this is appropriately understood as a moral consideration, the rightness of this ethic is based upon the consequence of the activity in question, expressed in material terms (i.e., morally appropriate if integration equals more welfare). This consequentialist approach, commensurate with traditional economic cost-benefit discourse, seems to limit the full range of ethical considerations as it is still conceived under the greater paradigm of utilitarianism. Dismissing consequentialism is problematic, however, as an alternative motivation would also aim toward a specific end. Thus, it is important to distinguish between integration as a means to promote material ends and integration as a means to promote moral and ethical ends beyond economic welfare. To pursue the latter is to ask: 'is it right?' in contrast to 'Does it work?' [16] We might say that this argument addresses how we value integration. In other words, should we have an equitable arrangement, albeit a segregated one-is this an arrangement worth aspiring toward? Is this the most morally appropriate arrangement? To summarize, we can describe the second ethical issue of the normative argument as a pluralistic valuation of integration.

Specifically, one of the important features of the normative argument's second tenet involves the recognition that existing in the same space and integrating within that space are not the same. Karst (1985) makes the important distinction between physical exclusion and social exclusion, i.e., exclusion from 'belonging' ([17], p. 323). While one may be physically included in spatial terms, that does not necessarily mean they belong. We might refer to this distinction as the difference between spatial integration and social integration. While the latter requires the former, the former does not necessarily lead to the latter. Later in the paper, more attention will be given to this distinction.

On the whole, such moral reflection has been notably absent in the existing appraisal of mixedcommunity initiatives [18]. As discussed, some scholars have critiqued residential integration as constituting nothing more than a 'faith-based displacement activity' [19]. In response, we might ask: is there space for a normative element in our evaluative framework as it relates to residential social arrangements? Can residential integration endeavors be substantiated on ethical values or principle beyond what we may hear in common economic and material considerations? While the absence of this line of inquiry in the existing literature might leave us skeptical as to the relevance of ethics in the residential integration debate, valueladen ideals and language can often be found in social mix discussions. These ideals are best captured in the language of justice.

\section{Supporting the Normative Argument- Rawlsian Justice and Social Integration in Housing}

If our aim is to incorporate an ethical component in the integration discussion as identified in the normative argument, such an argument would likely find support and justification in the field of justice. To be sure, utilitarianism proper is not antithetical to justice, and further, is considered a form of justice. However, as mentioned, this particular brand of justice, as I have defined it, risks bracketing out the ethical components identified as being necessary in our understanding of housing arrangements. Therefore, to give full support to the normative argument and flesh out its contributions relative to the integration discussion, it is appropriate to begin with a conception of justice articulated against the backdrop of utilitarian ideology. The seminal expression of such justice is found in the work of John Rawls. Jon Mandle (2009) writes: 'although the term "justice" is used in a [sic] many different contexts, justice as fairness addresses a fairly narrow topic, although an indisputably important one. It is concerned with what we might call "basic social justice"' ([20], p. 11). Rawls' work is known for an array of important characteristics, but it is best understood as a response to utilitarian conceptions of justice, or what he calls the 'predominant systematic theory' in modern moral philosophy ([21], p. vii). He describes the brand of utilitarianism he is responding to: 'the main idea is that society is rightly ordered, and therefore just, when its major institutions are arranged so as to achieve the greatest net balance of satisfaction summed over all the individuals belonging to it' ([21], p. 22).

Rawls' theory of justice offers a promising ethical framework for exploring the inequality of impacts relative to segregated black and white households. His approach is favored as possessing a greater degree of 'egalitarian criteria' for a system of justice and helps to concentrate the 'variety of principles of equity, fairness and justice held and applied independently' by 'ordering and prioritizing or tradeoff' ([14], p. 501). Further, his theory of justice provides an alternative to otherwise consequentialist systems of determining what should or should not be done-a necessary step in the survey of fairness and justice in housing arrangements. It has been said that Rawlsian justice is employed where institutions 'undertake to avail themselves of the accidents of nature and social circumstances only when doing so is for the common benefit' ([22], p. 2021).

Rawls' theory of justice is based on the principle of social contract, or the idea of giving up certain rights and liberties so as to enhance social order. However, this social contract is not necessarily an historical reality, but rather, it is an imaginary device used to discover our moral principles [23]. The purpose of the contract is to elucidate what is just, and moreover, to arrange society around just ideals. 
How does one go about determining what is just? Rawls proposes that justice be constructed in a neutral state where the following question is considered: what principles would we live by if we knew we would have to live together in a society governed by these principles but did not necessarily know our place in society? Rawls proposes a hypothetical state where individuals are unaware of their natural abilities, place, and position in the social hierarchy of society. This hypothetical state is referred to as the 'original position'. He writes:

By contrast with social theory, the aim is to characterize this situation so that the principles that would be chosen, whatever they turn out to be, are acceptable from a moral point of view. The original position is defined in such a way that it is a status quo in which any agreements reached are fair. It is a state of affairs in which the parties are equally represented as moral persons and the outcome is not conditioned by arbitrary contingencies or the relative balance of social forces ([21], p. 120).

It is in this equilibrium, according to Rawls, that societal decisions should be made. Decision making without assuming one's particular standing in society, class position, or social status is referred to as the 'veil of ignorance' [21]. The outcomes of decision-making in this equilibrium should be an acceptable standard to all parties for a just distribution of social goods such as liberty, income, wealth, and opportunity [24]. In other words, if one had no influence relative to where they were born, what abilities they were born with, and what future fortunes they would have, they must articulate what kind of society they would choose to frame so as to ensure their standing in society and opportunities for advancement were equal, fair, and just, and not simply subject to the 'luck of the draw' in a social lottery [25].

While there is much to be said about Rawls' theory, we can conclude that Rawlsian justice would give support to the notion of integrated communities or social institutions that support integrated settings for low-income minority-segregated households who find themselves more vulnerable and at-risk in society as a function of their segregation. In other words, the Rawlsian exercise would support the first tenet of the normative argument by suggesting that we would not choose a housing arrangement marked by segregation and inequality. The fact that I may be born into a society where I do not know my skin color and yet must decide how I would arrange housing, leaves me open to living in a residentially segregated white or black neighborhood. If I were to live in the latter, I would be compromising my desire to maximize primary social goods, or the attributes that all people behind the veil of ignorance desire in the society they will inevitably inhabit. These include liberties and opportunities, income and wealth, and the social bases of self-respect.
It should be pointed out that such a thought process is based upon the belief that minority-segregated neighborhoods potentially leave members more vulnerable and at risk to market or environmental forces. To be clear, not all segregation is harmful, and some have even argued that segregated enclaves-or 'specialized neighborhoods'-are optimal in many ways ([19], p. 5; see also [26]). However, these considerations must be weighed with the abundance of evidence supporting the notion that residential segregation is socially and economically sub-optimal for low-income minorities [27].

In light of the realities of segregated living patterns, we might rightly call residential segregation unjust. Because an unequal distribution of primary goods is not to everyone's advantage in this particular arrangement, Rawls would suggest institutions should be designed in order to satisfy the principles of justice forged behind the veil of ignorance [28]. This, in turn, would result in redressing the bias in social contingencies as overtures toward equality. Therefore, we might properly understand efforts such as the Gautreaux dispersal program, Moving to Opportunity, HOPE VI funding, and legislation such as the Mount Laurel rulings against exclusionary zoning-all efforts to engineer integration through housing - as appropriate overtures necessary for the achievement of Rawlsian equality.

At best, the Rawlsian exercise provides strong ethical rationale and support for the first consideration of the normative argument which recognizes the adverse effects disproportionately shouldered by segregated black households as a violation of social equity and fairness. When made ignorant of their natural and social contingencies, rational and mutually disinterested persons in the original position would not choose to structure society in such a way so as to leave some members more at risk and vulnerable. However, as we turn our attention to the second consideration in the normative argument, the same degree of support is altogether absent.

\section{Why Rawlsian Justice Will Not Do Justice to the Integrated Housing Discussion}

Rawlsian justice, a justice understood as distinct from utilitarian sentiments, while seemingly providing a credible theory of justice to buttress the first consideration in the normative argument, on closer inspection reveals insurmountable problems - two of which I shall emphasize - that stand as an impediment to the full expression of the second consideration. While there is a wide body of criticism against Rawls' two theories of justice, this particular critique has less to do with his theory in general and more to do with the usage of Rawlsian theory as a framework for justice in the residential integration discussion. That is to say, Rawls' theory-as it stands-is insufficient to support both tenets of the normative argument.

First, a Rawlsian framework can condemn the pres- 
ence of risk and vulnerability experienced by segregated black households, but it cannot necessarily place an intrinsic value on social integration. In other words, Rawlsian justice can condemn the consequences of segregation as morally wrong but cannot praise integration, in itself, as morally right.

The second problem of Rawlsian justice concerns the origin of his framework as being drawn from the liberal appeal to individual rights. A society seeking moral guidance for distributive principles based upon the language of rights has already presupposed a certain conflict among members of that society. A 'right' for one citizen is often understood as a right against another (e.g. property rights: 'my propertynot yours'). In other words, our rights-important as they may seem-reinforce the belief that others exist as a threat to my rights, and not the fulfillment of them. Further, this conflict is sustained, and perhaps exacerbated, in the appeal to one's rights. This argument finds a strong expression in Marx, who referred to a 'rights-based society' as a 'conflict society' ([29], p. 44). Thus, Rawlsian dependence on one's rights would ideally provide each person the opportunity to secure basic liberties, but at the expense of enhancing a greater sense of community.

In the context of residential integration, this would denigrate one of the more fundamental ethical aspects of the integration endeavor: social integration among community members (in contrast to mere spatial integration). While the scope of this article does not allow for more detailed attention to these aforementioned problems, we can say that both intractable problems reveal that Rawlsian justice undermines the cultivation of community and the moral power of solidarity that is inherent in the normative argument and which is also necessary to achieve the aim of socially integrating mixed neighborhoods.

\subsection{Thickening the Thin: A Neo-Rawlsian Approach}

If one accepts these arguments and agrees that Rawlsian justice is devoid of a certain sense of community and solidarity-both relationally-based concepts -then it is worth exploring what the inclusion of relationship would look like for Rawls and the subsequent implications for the support of the normative argument in residential integration. I submit that such an inclusion does not require a major overhaul to Rawlsian theory, but rather, can be envisaged in a minor adjustment of an earlier Rawlsian assumption. To explore this, we revisit Rawls' depiction of rational man found in the hypothetical original position.

The independence and self-regard ('mutually disinterested persons' behind the veil of ignorance giving consideration to their welfare) that Rawls assumes of actors in the original position is the lynchpin of the aforementioned problems arising from the Rawlsian framework. More specifically, notions of relationship and communal cultivation are notably absent in this picture of the rational Rawlsian agent. For Rawls, the autonomous features of 'independence' and 'selfregard' are necessary for individuals to achieve their own ends. There are two primary arguments against such a conception. While this article does not aim to give full attention to both, I am not the first to address them as problems within the Rawlsian model (for example see [30]). First, we could dispute the idea of an 'unencumbered self' that Rawls assumes. Second, we may dispute whether the existing Primary Social Goods (liberty, opportunity, money and wealth) -endowed to agents behind the veil of ignoranceare adequate to advance communal conceptions of the good, or the 'common good'.

Agents in the original position are ignorant of their eventual station in life, in addition to a host of other attributes, desires, characteristics, etc.- that they may have. They are aware, however, that they desire primary social goods. Rawls refers to this desire as a 'thin conception of the good'. In other words, while members are not considered thickly constituted selves -they do at least possess these basic desires. It is at this point that we can make a small adjustment to the Rawlsian exercise by 'thickening' his otherwise thin conception of the person in the original position. The move from thin to thick is a move from the person understood as an individual with preferences to be satisfied to a person 'whose identity and fulfillment are inextricably bound up with relations and communities' ([31], p. 143; see [32]). If we accept the terms of this adjustment, this will have significant implications for the support of the normative argument and our ethical interpretation of social integration in housing.

Thus, the adjustment I make to Rawls is a simple one: the person in the Rawlsian position, in addition to the other primary goods they desire, would also desire meaningful relationships. I define 'meaningful relationships' as follows: the intrinsic desire for participation and membership in social networks consisting of the norms of reciprocity and trust whose object is the good of another. I understand this addition to be a general purpose means useful for tempering the existing primary goods in addition to carrying out the variety of ends people may choose (whether they be of a individualistic or communal nature). Although this is a small and simple change, it has significant implications. This article does not aim to deliberate as to each and every change the addition of this primary good may potentially create. Rather, my aim is to focus on the implications that have particular relevance for the normative argument in housing and the ethical paradigm of residential integration.

\subsection{Implications of the Rawlsian Adjustment}

In addition to the range of questions that assist to determine the final principles of justice for Rawls, a rational person, in the thickly-constituted sense, be- 
hind a veil of ignorance would desire three additional qualities of the societies they would inhabit:

a. Real, meaningful relationships with others;

b. Cultivation of identity through community and interaction;

c. Maximization of security; minimization of enmity.

Before elaborating on these additional qualities, it is important to note a distinction often made by social theorists upon examining social networks. When reflecting on human interaction and relationships, we might say the distinction relates to answering the question: 'relationship with whom?' Putnam (2000) writes: 'some forms of social capital are, by choice or necessity, inward looking and tend to reinforce exclusive identities and homogeneous groups' ([33], p. 22). This is referred to as 'bonding' capital in social capital parlance. Segregated neighborhoods, school fraternities, ethnic social clubs-or anything that demonstrates the 'reinforcement of homogeneity'-are all examples of bonding capital ([34], p. 10). Bonding social capital links groups that have much in common, and are often characterized by reciprocity and solidarity. This is different from bridging capital, characterized as being 'outward looking and encompass[ing] people across diverse social cleavages' ([33], p. 22). Racially integrated communities, ecumenical religious organizations, or diverse work environments are examples of bridging capital. Putnam notes that bridging capital is good for getting linked to external assets and information diffusion. Bridging networks also play a valuable role as it relates to cultivating self-identity and reciprocity among a wider range of diverse networks. Most social scientists whose work addresses social capital point to the importance of both bonding and bridging networks for a healthy society. It is important to point out, however, that the composition of bonding and bridging capital for social agents need not be equally pursued. For example, for low-income members of society, bonding networks will play a particularly important role (job networks, support systems, mobilized labor initiatives, etc.). While bridging capital is important and in many cases, necessary, the degree of bonding and bridging capital an agent possesses will vary in their social capital calculus. With this in mind, we may now explore the additional qualities a thickly-constituted self in the original position would desire.

First, they would desire real, meaningful relationships with other individuals. This desire is a direct reflection of the newly endowed attribute of meaningful relationships, and makes a baseline assumption that individuals are not simply sensory beings whose aim is to author and fulfill various desires. Rather, individuals are also relational and desire human engagement, social capital, affiliation, membership, and solidarity. These goods can be achieved through various social and political institutions such as family, clubs and sports, work and educational environments, shared public resources, and neighborhoods.
The desire for a real relationship has implications for both bonding and bridging capital. As Walzer (1983) writes: 'the primary good that we distribute to one another is membership in some human community' ([35], p. 31). He goes on to assert that men and women without membership are 'stateless persons' ([35], p. 31). Individuals possess the desire to engage in meaningful associations and to cultivate a sense of belonging through group identity. While meaningful associations can occur in a bonding or bridging framework, it is bonding capital that is most natural: 'bridging ties are harder to build than bonding ones' ([36], p. 280). Moreover, homogeneity often serves as the social lubricant for belonging and affiliation among individuals [33]. Putnam writes: 'for most of us, our deepest sense of belonging is to our most intimate social networks, especially family and friends'-i.e., our bonding networks ([33], p. 274). While real relationships may occur more naturally among similar individuals (i.e., homophily-'love of the same'), we should not dismiss the importance of bridging capital in achieving real relationships. Briggs (2007) writes: 'popular discussions of race in America often center on interpersonal relations [between white and black] -which relate so closely to the respect, security, and feelings of mutuality we all crave' ([37], p. 264).

Second, thickly-constituted persons in the original position would (a) understand that their identity is formed and shaped through community and relationships (not self-derived) and (b) as a result, actors in the original position would not desire strictly homogeneous relationships which would minimize the full scope of identity cultivation available to them. To the latter point, if community and interaction are identityshaping mechanisms, thickly-constituted persons in the original position would not desire a society that was segregated and strictly homogeneous, although they may equally place a limit on the degree of heterogeneity they encounter as well.

We might say that bridging capital would be attractive, particularly in a hypothetical state of ignorance, so as to ensure one's self-understanding and identity were not limited to one particular group. While bonding capital is a natural, and necessary, component of any society aspiring to community cohesion and social solidarity-there are disadvantages when bonding occurs bereft of bridging. Indeed, one may appropriately claim that ours is a society where bonding capital is disproportionately higher than bridging capital as it relates to black and white relationships. Emerson et al. (2001) write:

In the post-Civil Rights United States, the racialized society is one in which intermarriage rates are low, residential separation and socioeconomic inequality are the norm, our definitions of personal identity and our choices of intimate associations reveal racial distinctiveness, and where 'we are never unaware of the race of a person with whom we interact.' ([38], p. 7). 
Emerson's quote describes our present arrangement where the threat of limited identity looms amidst an otherwise diverse society. In a racialized society, should one be born white or should one be born black, the risk is to be limited to the norms, traditions, and identities that accompany that race. This has implications for path dependency and preference formation and therefore limits the full scope of human potential and self-understanding. It is here suggested that such an arrangement would be avoided by a thickly-constituted self in the original position.

Limited identity, however, is not the only risk in a society where bonding and bridging capital are disproportionate. Thus, thirdly, thickly-constituted actors in the original position would desire more security and less enmity. They would desire social arrangements that allow for human interaction and the advancement of given ends to flourish, unrestrained by the potential threat of forces that might jeopardize such goods. Not only would they desire the maximization of security, they would equally desire the minimization of enmity, meaning that they would want to minimize structures that incite or exacerbate hostility between parties.

Rawls notes that 'although a society is a cooperative venture for mutual advantage, it is typically marked by conflict as well as an identity of interests' ([21], p. 126). Rawls' liberal conception of the self and the existing primary goods he aims to secure and utilize to achieve his ends is not only consistent with, but may very well contribute to, a society 'marked by conflict'. It is such conflict, though, that thickly-constituted persons in the original position would want to avoid insofar as it is possible. Again, this has implications for the importance of bridging capital.

We might think of the argument as followsconsider Putnam's proposition:

Here is one way of framing the central issue facing America as we become ever more diverse ethnically. If we had a golden magic wand that would miraculously create more bridging social capital, we would surely want to use it. But suppose we had only an aluminum magic wand that could create more social capital, but only of a bonding sort. This secondbest magic wand would bring more blacks and more whites to church, but not to the same church, more Hispanics and Anglos to the soccer field, but not the same soccer field. Should we use it? ([33], p. 362).

The issue, writes Putnam, is that if we ignore this question, then 'our efforts to reinvigorate community in America may simply lead to a more divided society' ([33], p. 362). There are two relevant remarks to be made about a 'divided society'. First, it has less capacity to foster a healthy democracy in contrast to a more integrated populace. Gutmann (1998) observes that economically, ethnically, and religiously heterogeneous associations possess a greater capacity 'to cultivate the kind of public discourse and deliberation that is conducive to democratic citizenship' ([39], $\mathrm{p}$. 358). Similarly, Anderson (2010) points out, 'The ideal of democracy essentially involves relations of social equality' ([12], p. 102).

Second, a 'divided society' has greater capacity to foster antagonism between homogeneous groups. A strong presence of bonding capital bereft of bridging capital (closing gaps in social distance based on race, class, culture, etc.)-while creating strong in-group loyalty and membership-may equally produce strong out-group antagonism-i.e., animosity toward the 'other' [33]. Putnam warns of the potential for conflict among homogeneous groups when bonding, and not bridging, capital is the societal norm: 'a society that has only bonding social capital risks looking like Bosnia or Belfast' ([33], p. 279).

We may conclude, therefore, that a society bereft of the presence of bridging capital may serve to ensure that one is born into a society with enmity; born into conflict. We may equally say that such a society would not be 'secure.' For the reasons above Briggs concludes that 'social bridges resting on intergroup ties have important consequences for individuals and for society, for social equality as well as for democracy' ([37], p. 265).

\subsection{Spatial Implications of the Neo-Rawlsian Exercise}

If we were to accept that relationally-based persons (desiring 'meaningful relationships'), behind a veil of ignorance would desire the aforementioned attributes, there are very real spatial implications. Where the first feature (real relationships) would technically only require bonding networks for its realization in society, the desire for a full range of social expressions by which to build and shape one's identity would require what has been referred to as 'bridging capital'-or associations that 'bridge' across diverse groups of people creating heterogeneous social networks. To realize this desire in the basic structure, institutions should lubricate the grounds for contact among differing individuals on levels such as race, class, or culture. As mentioned, an appropriate arrangement for enhanced contact would likely involve housing. Neighborhoods offer a natural platform for social intercourse through increased contact, shared amenities and goods, and collective responsibility. Such diversity offers a practical means by which to widen my self-identity and understanding, in addition to establishing norms of trust and reciprocity along more diverse lines. Conversely, a segregated neighborhood may serve to limit my ability to aspire to a healthy balance of self-understanding and personality as I would be limited to social development within a limited, and potentially rigid, environment. There are social consequences for such an arrangement, as Stolle et al. (2008) write: '...social interactions among homogeneous individuals may actually make it much harder-or even impossible-for individuals to transfer 
their in-group trust to the outside world' ([40], p. 60). Not only would being born in a homogeneous community limit my own self-identity, understanding, and potential-but it would make it very difficult to socially navigate an increasingly diverse world.

Thus, the second implication of the neo-Rawlsian exercise would likely support residential integration. The support of integrated neighborhoods on racial terms will have natural implications for socio-economic and cultural integration as well. Thickly-constituted selves would desire the opportunity to identify with different races so as to have a fuller understanding of themselves and human beings in general. As Putnam writes: 'social distance depends...on social identity: our sense of who we are. Identity itself is socially constructed and can be socially de-constructed and reconstructed' ([41], p. 159). Navigating through identities, or what Putnam refers to as the 'intentional transformation of identities' requires a 'dynamic and evolving society' ([41], p. 159). Thus, exposure to different races in an integrated neighborhood setting provides a full palette of social expressions by which to identify myself with, which allows me to re-construct my own identity. Putnam offers a practical advantage to this social flexibility: '....adapting over time, dynamically, to immigration and diversity requires the reconstruction of social identities, not merely of the immigrants themselves (though assimilation is important), but also of the newly more diverse society as a whole (including the native born)' ([41], pp. 159$160)$. In a society of ever-changing ethnic and racial composition-flexibility is a necessary attribute since 'the most certain prediction that we can make about almost any modern society is that it will be more diverse a generation from now than it is today' ([41], p. 137).

Third, and finally, thickly-constituted persons behind a veil of ignorance would desire to maximize security and minimize enmity. The connection between space and conflict is easily visible and the examples are legion. Persons in the original position may offer the following question: 'if I was unaware of my race, religion, ethnicity, culture, gender, etc.-would I want to enter a world where I could be born into conflict with a distinct person or group?' For example, an African American born into southern US territory in the mid-1800s is born into conflict with white landowners. Equally so, being born into gang territory, political territory, or border territory among rival ethnicities or cultures is to inherit a conflict with a distinct 'other' upon entering the world. This is not to suggest that segregation always causes tension, but to point out that spatial tension is evident in residentially segregated areas as well.

As these examples make clear, the 'other' is often defined in spatial terms. However, this does not presume that space is the problem-only a mechanism of identification. Indeed, it would be wrong to assume that enmity is absent in integrated spaces.
Moreover, tension within an integrated space may actually lead to spatial segmentation, suggesting a mutual causality between tension and segregation (segregation can produce tension, but tensionsometimes originating from 'integrated' spaces-can produce segregation). Related to this, consider the remarks of Stolle et al. (2008):

A growing body of evidence suggests that localities, neighborhoods, regions or states and even countries with more ethnic, racial and socio-economic diversity experience substantially more problems with the creation of various kinds of social capital, cooperation, trust and support necessary for collective action critical to social welfare programs ([40], p. 57).

There are two points to reflect upon here. First, if there is enmity within space (i.e., integrated space), then it does not necessarily follow that segregation is the solution. This may only make tensions worse by establishing a defined 'we' in conflict with a defined 'them' and exacerbating out-group hostility. Second, as mentioned, we should not presume that space is the problem. Rather, it may be a symptom of the problem, which is better understood as the absence of healthy contact thus creating more fear and a lack of rationality. We can remark, however, that space and spatial integration is a part of the solution-although not the direct solution. If thickly-constituted agents in the original position desire the maximization of security and the minimization of enmity-then we may say that they desire an integrated society constituted by shared norms and collective mindfulness and responsibility. The achievement of integration of this sort requires, as a baseline, shared space and close proximity. This is a necessary overture toward harmonious community relationships so as to introduce new social dynamics necessary for healthy integration to occur. We may conclude, therefore, that this feature also supports the cultivation of bridging networks and would equally support residential integration as a means of achieving this strand of social capital.

\section{Conclusions}

To solely explore the economic implications of segregation/integration is to risk missing a larger moral and ethical dimension. As mentioned, this is not to suggest that an economic dimension is devoid of moral considerations. Rather, this paper has argued for a more capacious moral argument as it relates to our social arrangements (normative argument). These elements include (a) considerations in fairness and social equity as well as (b) considerations as to the essence of integration.

Further, this paper has endeavored to give philosophical support to the normative argument by utilizing a Rawlsian framework. This framework, it has been argued, is sufficient to support the first feature of the normative argument (social equity), but insuffi- 
cient to support its second feature (essentialist argument for integration). To maintain the integrity of the first argument while giving additional support for the second, a neo-Rawlsian framework was suggested, where agents behind a veil of ignorance were 'thickly' constituted with a desire for meaningful relationships (in addition to their desire for other primary social goods).

Some will likely question the nature of this exercise, as Rawls' original 'thinly' constituted agent behind a veil of ignorance would only desire primary social goods such as liberty, wealth, and opportunity that would allow them to choose their social networks. Moreover, it is likely that some would argue this exercise infringes upon, or de-emphasizes, choice as an important feature of a liberal democracy. For example, Imbroscio (2004) presents a case for the liberty of 'choice' in the context of place with the underlying notion that choosing where one wants to live is a fundamental freedom and remains a positive human right for all human beings [42]. Specifically, Imbroscio supports what has been referred to as 'community integrity' ([43], p. 595). Integrity, in contrast to the goal of integration, upholds the right to travel or stay put as a tenet of the US constitution and as the 'fabric of American life' ([44], p. 578). This notion, which would likely garner support from the original Rawlsian exercise, promotes spatial equality above any attempts to engineer integration: 'real freedom of residential choice should be conceived of as dyadic, expanding both the exit/entry opportunities for the urban poor as well as possibilities to stay put; it should, consequently, be constituted by policy efforts to facilitate mobility as well as efforts to make inner cities more livable' ([45], p. 123). In other words, instead of supporting integrated environments, respecting individual rights would require the primacy of spatial equality and choice for all social agents.

While much can be said in relation to choice, a few cursory responses are necessary. First, as this paper has pointed out, engineered mixing (spatial integration) is distinct from organic mixing (social integration). In other words, 'mix' may be good, but it doesn't follow that 'mixing' is good. Even if one accepts the terms of the neo-Rawlsian exercise, this still requires thoughtful consideration as to how integrated arrangements are arrived upon. Steps can be taken to fertilize the grounds for spatial mixing patterns, but this is altogether different from a forced arrangement. Thus, choice should always be a feature of healthy social engagement-but this does not prohibit us from reflecting upon our choices and how they are arrived upon.

Second, and related, the primacy of choice is the primacy of preference. However, where do those preferences originate from? Economists are primarily concerned with the consequences of our preferences, but not necessarily their origin (preference formation). Our preferences, desires, and choices are, however, conceived and developed within a certain environment. Living within a segregated arrangement is likely to breed preferences that reinforce segregation (referred to earlier as path dependency).

Finally, the expression of one's preference still does not make that particular preference immune from moral evaluation. For example, the preference for participation in a hate group (e.g., the $K K K$ ) is hardly a morally superior arrangement-even though it could be rightfully described as an expression of 'choice'.

These points support the usefulness of the neoRawlsian exercise, as thickly constituted agents reflect the value and importance of relationships for human beings, but still allow for deliberation behind a veil of ignorance. This does not de-emphasize choice or human freedom in society (attributes supported by the Rawlsian framework). However, it does recognize that-in an abstract 'original position'-bonding and bridging networks would be an attractive attribute of the social landscape we might later inhabit, and this has implications for how we might consider integration.

To summarize the two aforementioned features and their spatial implications-space is a necessary component for real relationships, a more comprehensive setting for identity formation, and for the maximization of security and the minimization of enmity. Moreover, among other things, the spatial implications of the aforementioned features allow for a more concise statement that thickly-constituted agents in the original positions would likely agree upon: they would desire a society that is socially integrated. This term, introduced earlier, makes the important distinction that proximity does not equal acceptance or that shared space does not equal inclusion. In other words, spatial integration does not equate with social integration. Thus, where spatial integration may refer to close proximity and shared space-social integration refers to close proximity, shared space, and inclusion, or the idea of social assimilation where trust, cooperation, and collective responsibility define the norms of such membership.

Spatial segregation may be a problem or even the problem-but it does not follow that integration, in general, is the solution. The answer lies in the kind of integration we want (social; not simply spatial). Social integration is much more morally thick and ethically charged understanding of integration. Could it be that our failure to discuss integration in these terms (ethical terms) has reinforced the problem of segregation and our attempts to integrate? Could it be that communicating the problem of segregation solely on the terms of utility and economic efficacy has stripped the idea of social integration of its ethical flavor and, in doing so, has redefined the norms of integration leaving us to ask the wrong questions? If the impetus to integrate originated from the premise that 'mix' is good (i.e., ethically right and morally appropriate), might this change how we think about, conduct, and measure mixing overtures? 
This article has argued that a fundamental shift in our social ethos is necessary to lubricate a pathway where social, not simply spatial, integration can occur. This begins, it is suggested, with framing the argument in ethical, in addition to economic, terms. Integration as an ethically right and socially just feature offers moral rationale as to why residential mixing would be an appropriate social desire worthy of pursuit. However, when the argument is communicated solely in the language of the economic paradigm, we change the norms of the argument and important ethical considerations and features are lost in the translation. Efficiency is an important consideration, but not at the expense of larger moral considerations.

\section{References and Notes}

1. Goetz E. Housing Dispersal Programs. Journal of Planning Literature. 2003;18(3):3-16.

2. Logan J. Ethnic Diversity Grows, Neighborhood Integration Lags Behind. Albany, NY, USA: Lewis Mumford Center; 2001. pp. 1-32.

3. Massy DS, Denton NA. American Apartheid: Segregation and the Making of the Underclass. Cambridge, MA, USA: Harvard UP; 1993.

4. Flippen $C$. Unequal Returns to Housing Investments? A Study of Real Housing Appreciation among Black, White, and Hispanic Households. Social Forces. 2004;82(4):1523-1551.

5. Vartanian TP, Buck PW, Gleason P. Intergenerational Neighborhood-Type Mobility: Examining Differences between Blacks and Whites. Housing Studies. 2007;22(5):833-856.

6. Collins WJ, Margo RA. Residential Segregation and Socioeconomic Outcomes: When Did Ghettos Go Bad? Economics Letters. 2000;69(2):239-243.

7. Williams DR, Collins C. Racial Residential Segregation: A Fundamental Cause of Racial Disparities in Health. Public Health Reports. 2001;116(5):404-416.

8. Cutler DM, Glaeser EL. Are Ghettos Good or Bad? The Quarterly Journal of Economics. 1997;112 (3):827-872.

9. Dreier P, Moberg D. Moving From the 'Hood: The Mixed Success of Integrating Suburbia. The American Prospect. 2001. Available from http://www. prospect.org/cs/articles?article=moving_from_the_ho od (accessed on 1 June 2010).

10. Schwartz A, Tajbakhsh K. Mixed-Income Housing: Unanswered Questions. Cityscape: A Journal of Policy Development and Research. 1997;3(2):71-92.

11. Hartman CW, Squires GD. Integration Exhaustion, Race Fatigue, and the American Dream. In: Hartman CW, Squires GD, editors. The Integration Debate: Competing Futures for American Cities. New York, NY, USA: Routledge; 2010.

12. Anderson $\mathrm{E}$. The Imperative of Integration. Princeton, NJ, USA: Princeton UP; 2010.

13. Wolff J, De-Shalit A. Disadvantage. Oxford, UK:
Therefore, given the relational nature of humans and the communities they inhabit in a society, a more appropriate approach to the larger residential integration discussion would be to invite ethical deliberation into the discussion. An ethical dimension is important -we may even say necessary - to achieve the social integration (where mix is both a means to an end and an end in itself) that engineered or 'imposed' efforts can only aspire to. Citizens who find themselves morally impelled by the ethical argument to mix-in addition to conditions that fertilize the grounds for integration to occur-may best cultivate the necessary means that allow for an organic progression of residential, and more importantly, social integration.

Oxford UP; 2010.

14. Sen A. On Economic Inequality. Oxford, UK: Clarendon; 1997.

15. Velasquez MG. Business Ethics: Concepts and Cases. Englewood Cliffs, NJ, USA: Prentice Hall; 1982.

16. To assert that utilitarianism is concerned with consequences and morality and justice is not would be inaccurate, as achieving justice, for example, has a particular end in mind-though it may not necessarily be a material end (e.g., achieving a sense of belonging).

17. Karst KL. Paths to Belonging: The Constitution and Cultural Identity. North Carolina Law Review. 1985;64(1):302-379.

18. A notable exception would be Elizabeth Anderson's 2010 work 'The Imperative of Integration' [12]. Here, Anderson suggests that 'integration of racial, ethnic, and other groups that mark significant lines of social inequality is a vital ideal for the democratic society, necessary for its basic institutions to function successfully' ([12], p. x). Anderson concerns herself with socially integrated living arrangements, but the normative thrust of her argument relates to inequality between black and white households. See [12].

19. Cheshire P. Policies for Mixed Communities: Faith-Based Displacement Activity? International Regional Science Review. 2009;32(3):1-32. Available from: http://eprints.Ise.ac.uk/30783/1/Policies_for_mi xed_communities_(LSERO_version).pdf (accessed on 15 August 2013).

20. Mandle J. Rawls' A Theory of Justice: An Introduction. Cambridge, UK: Cambridge UP; 2009.

21. Rawls J. A Theory of Justice. New Delhi, India: Universal Law; 1971.

22. Beaumont J. Faith Action on Urban Social Issues. Urban Studies. 2008;45(10):2019-2034.

23. Velasquez MG, Rostankowski C. Ethics, Theory and Practice. Englewood Cliffs, NJ, USA: Prentice-Hall; 1985.

24. Curtis M. The Great Political Theories. Volume 2. New York, NY, USA: Avon; 1981.

25. Philosopher Jonathan Wolff offers a contemporary understanding of the original position and the accompanying veil of ignorance: 'suppose you have just 
woken up in a hospital bed. First you realize that you are suffering from an extensive memory loss. Looking down you see that you are swaddled from head to toe in bandages. You don't remember your name, sex, or race, nor can you discover these by self-inspection (the tag on your bandaged wrist only has a number). Facts about your family, occupation, class, strengths, skills, and so on are all lost to you. You do recall some general theories you once learnt in economics and sociology classes, but you cannot remember anything from your history lessons. In fact, you could not even say what century it was. Then into the ward walks a man in a white coat. "Good morning", he says, "I am Professor John Rawls. Tomorrow your memory will return, your bandages will be removed, and you will be free to leave. So we don't have much time. What we need you to do is to tell us how you would like society to be designed, bearing in mind that, from tomorrow, you will be living in the society you have chosen. We want you to design society purely in your own interests. Although you do not know what your actual interests are, I can tell you that you want as many primary goods as possible-liberties, opportunities, wealth, and income-and you should not consider the fortunes of anyone else. I will come back this evening to see what you have decided." Under these conditions, what would it be rational to choose?' (p. 159) See: Wolff J. An Introduction to Political Philosophy. Oxford, UK: Oxford UP; 2006.

26. Specifically, Cheshire writes, "Indeed, it can be argued specialisation is the central contribution of cities to progress and welfare" ([19], p. 5).

27. While the literature is extensive regarding the associated disadvantages of segregated, low-income neighborhoods - there is a distinction between a high correlation among segregated, deprived neighborhoods and constrained life chances and the assertion that neighborhoods cause such constraints. For example, as it relates to poverty, we might ask: is an impoverished neighborhood a reflection of poverty, or does it actually cause poverty?

28. Rawls offers two theories of justice he believes rational and mutually disinterested agents in the original position would agree upon. The first principle is that each person is to have an equal right to the most extensive total system of basic liberties compatible with a similar system of liberty for all. The second principle is that social and economic inequalities are to be arranged so that they are both (a) to the greatest benefit of the least advantaged, consistent with the just savings principle, and (b) attached to offices and positions open to all under conditions of fair equality of opportunity. See: ([21], p. 302).

29. Wolff J. Why Read Marx Today? New York, NY, USA: Oxford UP; 2002.

30. Kymlicka W. Liberal Individualism and Liberal
Neutrality. Ethics. 1989;99(4):883-905.

31. Fergusson D. Community. Liberalism and Christian Ethics. Cambridge, UK: Cambridge UP; 1998. This quote should not suggest that a shift from 'thin' to 'thick' is a clear shift from individual preferences to relations in a community. Rather, it is to recognize that agents behind a veil of ignorance-in addition to desiring the existing primary social goods (liberty, wealth, opportunity)-are relationally constituted agents and, as such, would utilize their primary goods and pursue their ends in a way that would reflect this. In other words, our individual and communal attributes are not zero-sum. Rather, as Etzioni (1996) has suggested, they exist within a symbiotic relationship where the two forces enrich one another 'rather than merely work well together' ([32], p. 34).

32. Amitai Etzioni. The New Golden Rule: Community and Morality in a Democratic Society. New York, NY, USA: Basic; 1996.

33. Putnam RD. Bowling Alone: The Collapse and Revival of American Community. New York, NY, USA: Simon \& Schuster; 2000.

34. T. Schuller, Baron S, Field J. Social Capital: A Review and Critique. In: Baron S, Field J, Schuller T, editors. Social Capital. Oxford, UK: Oxford University Press; 2000.

35. Walzer M. Spheres of Justice: A Defense of Pluralism and Equality. New York, NY, USA: Basic; 1983.

36. Putnam RD, Feldstein LM, Cohen D. Better Together: Restoring the American Community. New York, NY, USA: Simon \& Schuster; 2003.

37. De Souza Briggs X. 'Some of My Best Friends Are...': Interracial Friendships, Class, and Segregation in America. City and Community. 2007;6(4):263-290.

38. Emerson MO, Yancey G, Chai KJ. Does Race Matter in Residential Segregation? Exploring the Preferences of White Americans. American Sociological Review. 2001;66(6):922-935.

39. Amy Gutmann in [33].

40. Stolle D, Soroka S, Johnston R. When Does Diversity Erode Trust? Neighborhood Diversity, Interpersonal Trust and the Mediating Effect of Social Interactions. Political Studies. 2008;56(1):57-75.

41. Putnam RD. E Pluribus Unum: Diversity and Community in the Twenty-first Century The 2006 Johan Skytte Prize Lecture. Scandinavian Political Studies. 2007;30(2):137-174.

42. Imbroscio DL. Can We Grant a Right to Place? Politics and Society. 2004;32(4):575-609.

43. Gordon Clark in [42].

44. Paul Dimond in [42].

45. This, Imbroscio contends, achieves one of the original policy goals in housing from the 1949 housing act: 'to provide housing for Americans in a suitable living environment' ([42], p. 123). 
librello \&s

\begin{abstract}
About Librello
Librello is a publishing house established in Basel, Switzerland. All content published by Librello is open access, available upon publication for any reader. We strongly believe that open access improves the exchange of scientific knowledge, and consists in a more ethic way of publishing the results of research supported by public funds.

Librello is an innovative publishing enterprise. Our novel model works on a membership basis to decouple the payment from the publication. On one side, we can afford a stringent peer-review with no economic pressure, and the authors also profit from our business model by being able to submit multiple manuscripts by a single annual fee.
\end{abstract}

Librello Publishing House

4000 Basel

Switzerland

http://librelloph.com 